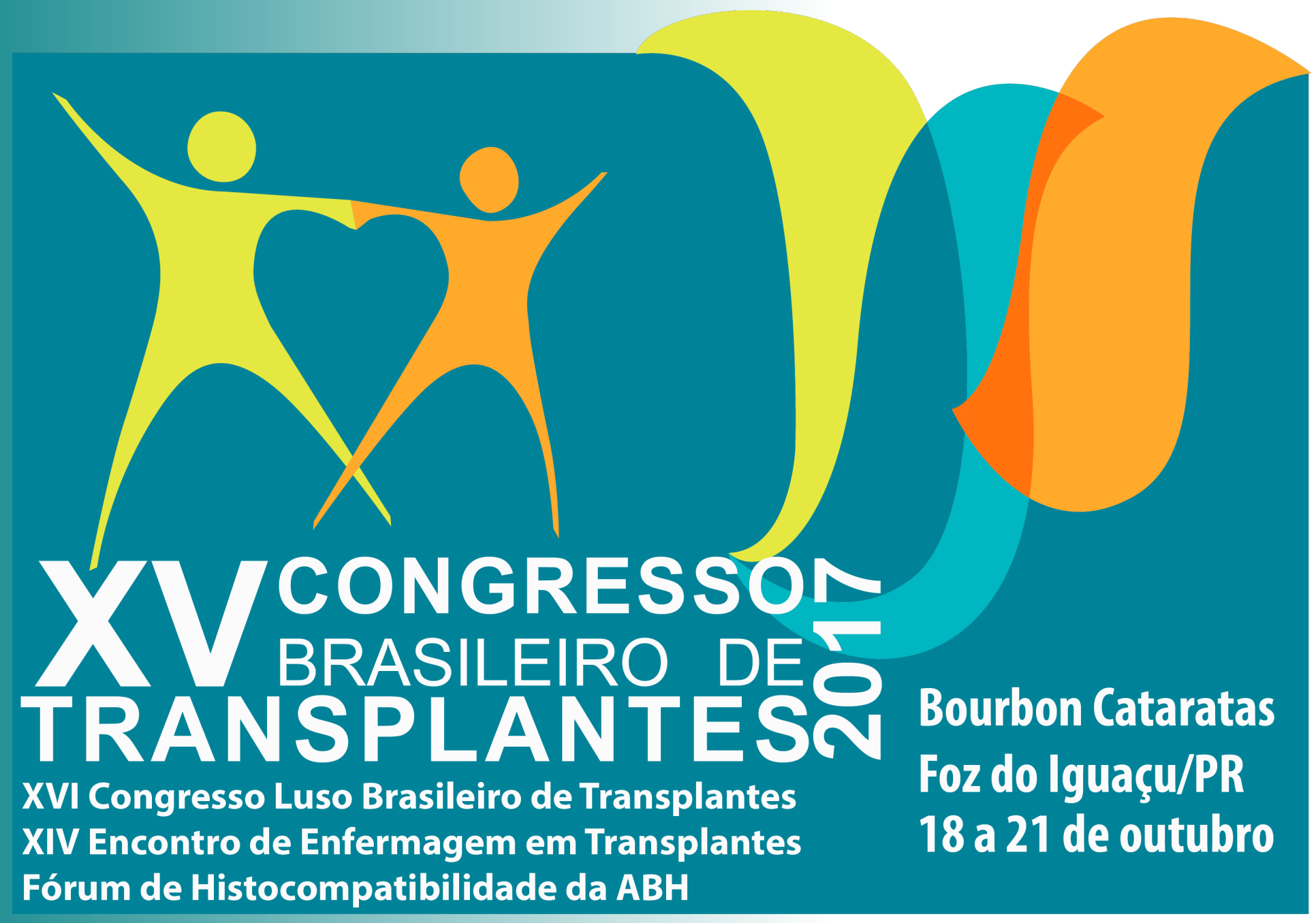




\section{ANAIS do Congresso}

Apresentaçóes Orais e

\section{Pôsteres}

Neste número:

- Rim

- Rim-Pâncreas

- Pediatria

- Multidisciplimar 
C001-01

EFICÁCIA E SEGURANÇA DA INDUÇÃO COM BAIXA DOSE DE GLOBULINA ANTI-O PAPEL DO COORDENADOR DE COLHEITA E TRANSPLANTE NA MAXIMIZAÇÃO DO DADOR DE PULMÃO

Fernando Rodrigues; Paula Pico; Maria João Xavier

GCCT Hospital S. Jose - Centro Hospitalar Lisboa Central

A Unidade de Transplante (UT) Pulmonar de um Centro Hospitalar, articulando com um Gabinete Coordenador de Colheita e Transplantacao (GCCT), e a unica UT a realizar este tipo de transplante em Portugal. Deste modo, todos os potenciais dadores de pulmao, nos hospitais da rede de referenciacao dos 5 GCCT's nacionais, devem ser referenciados a este GCCT para avaliacao. O GCCT conjuntamente com a UT Pulmonar assumem, assim, a responsabilidade de procurar dar resposta aos doentes em lista de espera para transplante pulmonar. Fruto da alteracao que vem sofrendo o perfil do dador em Portugal, com idade media cada vez mais avancada e com co morbilidades, torna-se um desafio otimizar todos os potenciais dadores para a doacao de pulmao. Este trabalho pretende apresentar as estrategias adotadas pela UT pulmonar e pelo GCCT, na tentativa de ultrapassar este problema, bem como os resultados alcançados apos implementacao das medidas.

Palavras-chave: coordenacao, dador, colheita, pulmao
CO01-03

INÍCIO DO PROCESSO DE ADAPTAÇÃO TRANSCULTURAL E VALIDAÇÃO DO MÉTODO INTERMED SELF-ASSESSMENT DE AVALIAÇÃO BIOPSICOSSOCIAL EM PACIENTES PRÉ E PÓS-TRANSPLANTE PARA USO NO BRASIL

Carolline Rangel'; Elen Almeida Romão'

1 - Hospital das Clínicas da Faculdade de Medicina de Ribeirão Preto da Universidade de São Paulo

O Interdisciplinary Medicine Self-Assessment (INTERMED SELF-ASSESSMENT) é um instrumento desenvolvido por um grupo de pesquisadores europeus que classifica a complexidade biopsicossocial de pacientes em diversos níveis de assistência, qualifica o cuidado e melhora a comunicação interprofissional, permitindo avaliar a complexidade do paciente através da investigação de quatro domínios: biológico, psicológico, social e sistema de saúde. No contexto dos pacientes pré e pós transplante renal, instrumentos que avaliem os candidatos a transplante e seu momento pós cirúrgico podem auxiliar a promoção do cuidado integrado com foco no paciente, realizar ajuste necessário entre a prestação de serviços de saúde e saúde mental e complementar a entrevista médica. O objetivo do presente estudo é realizar a tradução, a adaptação transcultural e a validação do INTERMED SELF-ASSESSMENT em pacientes pré e pós transplante renal para uso no Brasil. A metodologia utilizada é a recomendada pela literatura para a adaptação de instrumentos, e compreende duas etapas: tradução e ajuste cultural e validação para uso em outro ambiente que não o original. A coleta de dados é realizada na Unidade de Transplante Renal (UTR) do HC-FMRP-USP e no ambulatório com pacientes em preparo para inscrição em lista de transplante renal, através de convite aos pacientes para participação voluntária na pesquisa. A análise de dados segue as recomendações da literatura para adaptação transcultural de instrumentos. Até o momento, os avanços do estudo consistiram na a) levantamento bibliográfico, apontando necessidade de novos instrumentos que auxiliem na avaliação de pacientes candidatos e receptores de transplante; b) autorização por parte dos idealizadores do instrumento; c) início do processo de tradução, composto por seis fases, com vistas a obter a versão final deste instrumento para o português brasileiro e posterior uso para melhor manejo dos pacientes pré e pós-transplante.

Palavras-chave : INTERMED, AVALIAÇÃO BIOPSICOSSOCIAL, TRANSPLANTE RENAL, MULTIPROFISSIONAL

CO01-05

AVALIAÇÃO DO PERFIL DAS REAÇÕES ADVERSAS PARA MELHORIA DA QUALIDADE DAS INFORMAÇÕES EM BIOVIGILÂNCIA

Lara Alonso Da Silva; Isabel Menezes Carmo; Luciana Valéria Ferrari Machado Porto; Leonardo Oliveira Leitão

\section{AGÊNCIA NACIONAL DE VIGILÂNCIA SANITÁRIA}

Os profissionais envolvidos com transplantes devem assegurar que a transmissão de doenças associadas à utilização de células, tecidos e órgãos - CTO sejam reduzidas e controladas, já que, embora possam trazer benefícios, não estão isentas de riscos. Assim, criou-se um formulário de Biovigilância para o relato de reações adversas. $\mathrm{O}$ objetivo do estudo é avaliar o perfil das notificações de reações adversas informadas e propor recomendações de melhoria da qualidade das informações. Realizou-se um estudo descritivo da avaliação das fichas de notificação extraídas do banco de dados da Biovigilância. Entre junho de 2015 a dezembro de 2017 foram notificadas 224 reações adversas. Categorizou-se as variáveis quanto o perfil do indivíduo afetado, temporalidade e local de ocorrência. E classificadas quanto ao tipo de reação adversa, a gravidade e imputabilidade com o uso de CTO. Verificou-se que $95 \%$ das reações adversas ocorreram em receptores. $40 \%$ estavam relacionadas ao transplantes de órgãos, $32 \%$ ao uso de células e $27 \%$ com tecidos. Os tipos de reações mais reportadas foram as infecções $(85 ; 38 \%)$ e as complicações peri-operatórias (33; $15 \%)$, e as menos freqüentes as rejeições $(13 ; 6 \%)$ e as neoplasias $(6 ; 3 \%)$. Quanto à gravidade, 77 foram caracterizadas como leves, 68 moderadas, 27 graves e 52 óbitos. Identificou-se que as reações adversas estavam, em sua maioria, relacionadas a transplantes de órgãos. Já os óbitos, mais associados aos transplantes de células. Conclui-se que há uma subnotificação importante, tendo em vista que, segundo o Ministério da Saúde, em 2016, foram realizados 24.958 transplantes, 1.291 a mais que no ano anterior. Considerando esse quantitativo, torna-se importante sensibilizar as instituições para notificarem as reações adversas. Nesse contexto da Biovigilância como uma ferramenta do gerenciamento de risco, a partir da notificação da reação adversa, pretende-se garantir a segurança do paciente e melhorar qualidade dos transplantes.

Palavras-chave : transmissão de doenças; qualidade, Biovigilância, riscos

Palavras-chave : análise espacial, doação, saúde, transplantação 


\section{C001-06}

\section{ANÁLISE DE TENDÊNCIA DE DOAÇÃO DE ENXERTOS DE PELE}

Stephanie Castilho Grando'; Marcelo José Dos Santos'; Edvaldo Leal De Moraes²; Ágata Nunes Brito'

1 - Escola de Enfermagem da Universidade de São Paulo; 2 - Organização de Procura de Órgãos da Faculdade de Medicina da Universidade de São Paulo

Introdução - No Brasil, ocorrem aproximadamente 1.000.000 de acidentes com queimaduras por ano. $O$ enxerto de pele homóloga excisada de um doador falecido, pode representar a diferença entre a vida e a morte de grandes queimados. No entanto, o percentual de doação de enxerto de pele é baixo quando comparado à doação de órgãos. Objetivo - Identificar a tendência da taxa de doação de enxertos de pele de doadores em situação de morte encefálica em uma Organização de Procura de Órgãos (OPO) do Município de São Paulo no período entre 2001 e 2017. Método - Estudo retrospectivo, quantitativo, cujos dados foram obtidos a partir da análise de $3633(100 \%)$ registros de entrevistas familiares para doação de órgãos e tecidos realizados em uma OPO do Município de São Paulo nos anos de 2001 a 2017. Os dados foram coletados após aprovação pelo Comitê de Ética em Pesquisa. Para análise foi aplicado um modelo de regressão logística e identificada a chance de doação ao longo dos anos, considerando-se a razão de chances (RC) diferente de 1. Por fim, buscou-se medir a precisão da razão de chances por meio do intervalo de confiança (IC). Resultados - Do total de entrevistas documentadas e analisadas, constatou-se a autorização de extração de enxertos de pele em $863(23,8 \%)$ casos. O valor $-p<0.001$ e a RC de 1,067 com IC $-1,050-1,085$. Considerações finais - Há tendência de aumento significativo de doação de enxertos de pele ao longo dos anos. No entanto, a taxa de doação ainda é baixa. O desconhecimento da possibilidade da doação de enxertos de pele para implante, sua finalidade e necessidade, bem como a associação do tecido a um órgão sensorial, pode contribuir para a ideia de dor e mutilação do corpo que a solicitação da extração de pele pode causar

Palavras-chave : Obtenção de tecidos e órgãos, Pele, Transplante
CO01-08

DISPARIDADE GEOGRÁFICA NO ACESSO A DOAÇÃO E TRANSPLANTE RENAL NO BRASIL (2007-2017)

Priscila Ribeiro Campos Paura; Aluísio Gomes Da Silva-Júnior

\section{1 - PROGRAMA DE PÓS-GRADUAÇÃO EM BIOÉTICA, ÉTICA APLICADA E SAÚDE} COLETIVA

O Brasil possui o maior programa público de transplante do mundo com melhoria em seus indicadores de doação e transplante de rim com doador falecido na última década. Entretanto este progresso não ocorreu de forma homogênea nas 5 regiões brasileiras, pois o acesso ao transplante é desigual no país. Método: Trata-se de uma análise observacional dos dados das tabelas “№ anual de transplantes - conforme tipo de doador", "Dados por Estado" e "Dados por região brasileira" do Registro Brasileiro de Transplantes de 2017. Variáveis analisadas: $n$ o de notificações de potenciais doadores em morte encefálica (NOTIF), $n^{\circ}$ de doações efetivas (D.Ef) e $n^{\circ}$ de transplantes renais com doador falecido (TXDF) de 2007 a 2017. Os dados foram padronizados por milhão de população (pmp), correlacionando as regiões brasileiras com a média nacional. Resultados: Houve aumento no NOTIF, D.Ef e TxDF no Brasil de $72,6 \%(29,9-$ $51,6), 264 \%(6,3-16,6), 145 \%(9,5-23,3)$ e nas 5 regiões: Sul de $135 \%(35,6-83,8)$, $192 \%(11,7-34,1), 138 \%(18,2-43,3)$; Sudeste de $42 \%(37,9-53,8), 139 \%(7,5-17,9)$, $138 \%$ (11,7-27,8); Centro-Oeste de 55\% (35,2-54,7), 234\% (3,5-11,7), 209\% (3,5$10,8)$; Nordeste de $108 \%(19,5-40,5), 177 \%(3,9-10,8), 167 \%(5,7-15,2)$; e Norte de $156 \%(7,9-20,2), 680 \%(0,5-3,9), 450 \%(0,8-4,4)$, respectivamente. Observase que a região Sul concentrou os melhores resultados absolutos em relação às variáveis observadas. A região norte foi a que mais cresceu proporcionalmente, no entanto apresenta os piores resultados. Ainda que os progressos sejam percebidos, fica evidente a acentuada disparidade geográfica entre as regiões. Os achados apontam para a necessidade de se implantar diferentes mecanismos compensatórios, objetivando minimizar as desigualdades e assim alcançar a universalidade no acesso ao transplante renal no Brasil e sua efetiva regionalização.

Palavras-chave : Transplante de rim, Acesso aos serviços de saúde
CO01-07

COMPARAÇÃO DO PROCESSO DE DOAÇÃO-TRANSPLANTE ENTRE OS HOSPITAIS LA FE DE VALENCIA - ESPANHA E O HOSPITAL ESTADUAL ALBERTO TORRES DO RIO DE JANEIRO - BRASIL, OPORTUNIDADES DE MELHORA.

Sandro De Gouvêa Montezano'; Juan Bautista Galán Torres ${ }^{2}$

1 - PROGRAMA ESTADUAL DE TRANSPLANTES/HOSPITAL ESTADUAL ALBERTO TORRES; 2 - HOSPITAL UNIVERSITÁRIO E POLITÉCNICO LA FE

Fundamento: A avaliação sistemática do processo de doação de transplante conforme proposto pela Organização Nacional de Transplantes da Espanha - ONT e que utiliza um Programa de Garantia de Qualidade, proporciona um conhecimento real do potencial doação, identificando limitações e garantindo melhores resultados.

Material e métodos: Comparação sistematizada dos dados estatísticos de todos os óbitos e mortes encefálicas (ME) ocorridos nas UTI (Unidade de Terapia Intensiva) do Hospital La Fe e dos óbitos e mortes encefálicas notificadas do Hospital Estadual Alberto Torres (HEAT) em 2017.

Resultados: No La Fe 427 óbitos ocorreram em UTI, 24,6\% de todos os óbitos do hospital, 120 desses óbitos (28,1\%) ocorreram por causa neurológica, 45 (37,5\%) receberam diagnóstico de ME e 21 (46,7\%) foram doadores efetivos de órgãos, não houve perdas devido falhas de detecção. No HEAT houve 1025 (61,9\%) óbitos na UTI, dos quais 341 (33,3\%) foram por diagnóstico neurológico, 91 $(26,7 \%)$ foram identificados como ME, a conversão foi de $37(40,7 \%)$ doadores efetivos, as perdas por falhas de detecção são desconhecidas, não é utilizado nenhuma ferramenta para avaliar os óbitos.

Conclusões: O Hospital La Fe, em comparação com o Hospital Estadual Alberto Torres em 2017 foi $6 \%$ mais efetivo em seus processos de trabalho nos doadores com ME. Com um Programa de Garantia de Qualidade poderíamos conhecer o número real de potenciais doadores e identificar as causas de sua não efetividade. $O$ atraso no diagnóstico da $\mathrm{ME}$ e as dificuldades logísticas são causas de perdas de potencial doador por parada cardíaca no HEAT, seria necessário diminuir o tempo.

Palavras-chave : PROCESSO DE DOAÇÃO-TRANSPLANTES, PROGRAMA DE GARANTIA DE QUALIDADE, HOSPITAL LA FE, HOSPITAL ESTADUAL ALBERTO TORRES

\section{CO01-09}

PERFIL CLÍNICO DOS DOADORES EFETIVOS NOTIFICADOS À ORGANIZAÇÃO DE PROCURA DE ÓRGÃOS E TECIDOS DA UNIVERSIDADE ESTADUAL DE CAMPINAS EM 2016 E 2017.

Catherine Reigada; Elaine Ataíde; Simone Perales; Luiz Antonio Sardinha; Maria Valeria Athayde; Rafaela Pedrosa; Helder José Zambelli; Klenio De Oliveira Bonfim; Ilka Boin

\section{UNICAMP}

Introdução e importância: o número insuficiente de órgãos para transplante é um problema de saúde pública. Nas últimas décadas houve um aumento significativo do número de notificações de potenciais doadores e também do número de captações de órgãos, entretanto, ainda há incontestável carência de enxertos, sobretudo para o transplante de fígado, rins e coração. Objetivo: realizar o perfil clínico dos doadores de órgãos sólidos de nossa OPO regional durante 2 anos e avaliar a porcentagem de órgãos sólidos que foram transplantados. Método: estudo de carácter descritivo e retrospectivo com análise de prontuário dos doadores efetivos em morte encefálica (ME) no ano de 2016 e 2017, notificados à Organização de Procura de Órgãos da Universidade Estadual de Campinas. As variáveis avaliadas foram: sexo, idade, causa de $\mathrm{ME}$, comorbidades, uso de droga vasoativa, distúrbios hidroeletrolíticos, presença de infecção (hemocultura positiva não sugestiva de contaminação) e disfunção renal (nível de creatinina sérica superior a 1,5 mg/dl). Resultados: A maior parte dos doadores foram homens $(57,6 \%)$ de raça branca $(65,9 \%)$, com média de idade de 44 anos. A principal causa de morte encefálica foi acidente vascular encefálico hemorrágico (41\%), seguido de trauma crânioencefálico (29\%). A comorbidade mais comumente encontrada foi hipertensão arterial sistêmica $(33,6 \%)$. No tocante à manutenção hemodinâmica dos doadores, praticamente todos estavam em uso de alguma droga vasoativa, mais comumente noradrenalina $(85,5 \%)$. Houve alto índice de hipernatremia $(81,4 \%)$ e hiperglicemia $(89,7 \%)$. $9 \%$ dos doadores apresentaram hemocultura positiva. $26,6 \%$ dos doadores estavam com disfunção renal. A maior taxa de aproveitamento dos órgãos doados foi de rins (91,7\%), seguido de fígado $(62,8 \%)$ e coração (22,7\%). Conclusão: É de suma importância para o aumento do número de transplantes que se crie estratégias de melhora da condição clínica dos potenciais doadores; uma dessas estratégias é a educação contínua sobre o manejo do paciente com morte encefálica.

Palavras-chave : doador, perfil, OPO 
CO01-10

\section{ANÁLISE DAS DOAÇõES DE TECIDOS CARDÍACOS NO ESTADO DO PARANÁ,} BRASIL

Rafael Rodrigo Da Silva Pimentel'; Rosane Almeida De Freitas²; Izabela Melo Garcia'; Cátia Millene Dell'agnolo ${ }^{3}$; Maria José Quina Galdino²; Maria Do Carmo Fernandez Lourenço Haddad ${ }^{1}$

1 - Universidade Estadual de Londrina - UEL; 2 - Universidade Estadual de Maringá - UEM; 3 - Hospital Universitário Regional de Maringá - HUM

INTRODUÇÃO: O transplante de valvas cárdicas é o tratamento mais indicado nos casos de insuficiência das valvas aórtica e pulmonar. OBJETIVO: Analisar as doações de tecidos cardíacos realizados no estado do Paraná, Brasil. METÓDO Estudo transversal de abordagem quantitativa, realizado com dados de 2.041 notificações de óbitos por morte encefálica entre os anos de 2011 e 2015 , fornecidos pela Central Estadual de Transplantes do Paraná. Os dados foram analisados por meio de estatística descritiva no software Statistical Package for the Social Sciences, versão 20.0 e aplicados testes de significância, QuiQuadrado de Pearson e Mann-Whitney, adotando-se nível de significância de $p<0,05$. RESULTADOS: Das notificações de morte encefálica estudas, foram efetivadas $297(14,6 \%)$ doações de valvas cardíacas. Destes doadores a idade média variou entre 28 a 45 anos, sendo a maioria do sexo masculino 180 $(60,6 \%)$. Quanto ao ano que obteve o maior número de doações, destacouse 2015 com 73 (24,5\%). Já com relação ao nível de atenção $254(85,5 \%)$ dos hospitais pertencia a alta complexidade e de gestão dupla 127 (42,7\%). A Macrorregional que obteve o maior número de doações efetivadas foi a leste, localizada em Curitiba com 142 (47,8\%). CONCLUSÕES: Os dados deste estudo evidenciam um aumento nas doações de valvas cardíacas no estado que podem ser decorrentes da estruturação da doação de tecidos e das capacitações dos profissionais envolvidos neste processo. O levantamento das informações deste estudo fornecem subsídios para que os gestores elaborem estratégias que auxiliem no aumento das doações de tecidos cárdicos e proporcionem uma melhor qualidade de vida para aqueles que aguardam este tecido.

Palavras-chave : Obtenção de órgãos e tecidos, Valvas Cardíacas, Gestão em Saúde
CO01-12

IMPLEMENTAÇÃO DE UM SISTEMA DE CERTIFIACAÇÃO DA QUALIDADE DOS PROCESSOS DE DOAÇÃO E COLHEITA DE ORGÃOS, TECIDOS E CÉLULAS EXPERIÊNCIA DE UM HOSPITAL DADOR

Ana P. Fernandes; Carla Rocha; Fátima Pinheiro; Patrícia Marques; António Gomes; João Vieira

1 - Hospital Professor Doutor Fernando Fonseca, EPE Núcleo de Coordenação Hospitalar de Doação Serviço da Qualidade

A escassez de órgãos e tecidos para transplante em relação às necessidades, torna crítica a minimização de falhas em toda a cadeia do processo de doação/ transplante.

O Hospital Professor Doutor Fernando Fonseca (HFF) tem atividade de doação e colheita com mais de 10 anos. Nos últimos 8 anos, a criação de uma equipa pluridisciplinar de profissionais, com formação específica e uma estruturação de tarefas definidas e organizadas traduziu-se num maior mero de colheitas de forma sustentada.

Em 2015 foi iniciado o projeto de certificação dos processos de doação e colheita de órgãos, tecidos e células no HFF com a aplicação do Normativo NP EN ISO 9001.

Os autores descrevem a experiência do desenvolvimento, implementação, execução e avaliação deste processo de certificação da qualidade:

- Identificação dos subprocessos e atividades necessários;

- Definição das melhores práticas;

- Definição das responsabilidades e recursos necessários;

- Analise das competências necessárias;

- Documentação e divulgação das práticas definidas;

- Criação das condições para que o processo seja continuamente efetivo

CO01-13

UTILIZAÇÃO DE SANGUE DO CORDÃO UMBILICAL - ORGANIZAÇÃO DE RECURSOS NUM HOSPITAL COM PROGRAMA DE DOAÇÃO

Ana P. Fernandes; Anabela Barradas; Isabel Prieto; Graça Nascimento; Ana P. Gomes1; Sandra Rebelo

1 - Hospital Professor Doutor Fernando Fonseca, EPE Núcleo de Coordenação Hospitalar de Doação

O soro autólogo (SA) é utilizado há mais de duas décadas em oftalmologia no tratamento doenças oculares e sistémicas como substituto das lágrimas. Contem vários dos seus componentes contribuindo para a proliferação, diferenciação e maturação do epitélio de superfície ocular e situações graves de xeroftalmia.

Mais recentemente verificou-se que o soro obtido a partir do sangue do cordão umbilical (SCU) é rico em muitos fatores de crescimento, neurotróficos e outros componentes da lágrima, tornando-se uma alternativa no tratamento de condições de secura ocular grave. Permite colheitas em maior quantidade sem necessidade de múltiplas punções dos doentes sobretudo quando coexistem anemia, discrasias hemorrágicas, maus acessos venosos ou doenças autoimunes ou infeciosas.

No nosso Hospital, a possibilidade de obtenção de SCU para uso oftalmológico seguindo os mesmos requisitos de qualidade para as amostras de SCU utilizadas na criopreservação, aliada à existência prévia de uma atividade de processamento de SA e de colheita de córneas, tornaram-se uma mais valia, assegurando a qualidade do soro obtido a partir de SCU.

O projeto aqui apresentado, mostra como a conjugação de recursos humanos e técnicos de atividades previamente estabelecidas em diferentes serviços Imunohemoterapia, Bloco de Partos, Oftalmologia e Coordenação Hospitalar de Doação, pode dar uma resposta valiosa e de qualidade a numerosos doentes sem outras alternativas terapêuticas eficazes. 


\section{CB03-001}

IMPACTO DA ATUAÇÃO DE UM PROJETO BRASILEIRO DE DOAÇÃO DE ÓRGÃOS E TECIDOS PARA TRANSPLANTE: UMA ANALISE DOS INDICADORES DE EFICIÊNCIA

Roberta Cristina Cardoso Dos Santos; Dayana Aparecida Martins Correa Calado; Clayton Gonçalves Almeida; Marli Marcos; André Ramos Carneiro; Felipe Alves Moreira; José Maria Do Nascimento; Maria Valeria Athayde; Guilherme Ono; Renata Fabiana Leite; Luis Gustavo Torres Dias Cruz; Heloisa Barbosa Paglione; José Eduardo Afonso Junior

\section{Hospital Israelita Albert Einstein}

Introdução: O Brasil possui cerca de 32 mil pessoas ativas em lista de espera para transplante. Entre as razões pelas quais ainda é insuficiente o número de doadores falecidos está a complexidade do processo de doação, fazendose necessária a melhora da qualidade deste processo. Por essa razão em 2014 o Projeto iniciou suas atividades em 10 Hospitais públicos no Estado de São Paulo-BR, 1 em Goiás-BR e 1 no Rio de Janeiro-BR. Criavam-se protocolos assistenciais, indicadores e ferramentas de qualidade. O profissional conduzia a educação permanente dos colaboradores, bem como a busca ativa, avaliação, notificação, manutenção de potenciais doadores e acolhimento familiar. Tinha como princípio a criação de uma cultura de doação de órgãos, através da avaliação do diagnóstico situacional e desenho de um planejamento estratégico afim de operacionalizar o processo, desenvolvendo uma Comissão Intrahospitalar de Transplantes conforme determina a legislação brasileira. bjetivo: Analisar os indicadores de eficiência no processo de doação de órgãos em 12 Hospitais assistidos pelo Projeto. Material e Método: Trata-se de um estudo de coorte, retrospectivo dividido em 2 fases: Fase 1 estendeu-se de janeiro de 2010 a dezembro de 2013, quando não havia a presença do projeto nos hospitais. A fase 2 entre janeiro de 2014 e dezembro de 2017, caracteriza-se pela atuação do projeto. Foi elaborado um instrumento de coleta de dados padronizado avaliando causa do óbito, critérios para diagnóstico de ME e desfecho dos casos. Resultados: Na fase 1, houve 1.518 notificações de Mortes Encefálicas e 381 doadores efetivos. Já na fase 2 foram notificadas $2.066 \mathrm{ME}$ e 580 doadores. Discussão e Conclusões: Houve um aumento de $36 \%$ das notificações e $52 \%$ dos doadores efetivos em 4 anos nos hospitais.

Palavras-chave: doação de órgãos gestão

\section{СB03-002}

IMPACTO DE UM PROGRAMA DE IDENTIFICAÇÃO PRECOCE DE POTENCIAIS DOADORES

Marizete Peixoto Medeiros; João Luis Erbs Pessoa; Oswaldo Donnini

Sistema Estadual de Transplantes do Estado de São Paulo

Introdução: Aumentar o número de doadores de órgãos se torna imprescindível frente ao aumento constante do número de receptores. Pesquisas apontam que a não identificação do potencial doador, indivíduo em coma aperceptivo (status neurológico Escala de Glasgow 3), é um dos principais problemas para o não aumento da doação de órgãos.

Objetivo: Analisar o impacto de um programa de identificação precoce de potenciais doadores.

Método: Pesquisa de abordagem quantitativa com delineamento transversal e prospectivo. A população do estudo foi composta de todos os pacientes sinalizados pela Central de Regulação de Ofertas de Serviços de Saúde (CROSS) a Central de Transplantes do Estado de São Paulo, identificados com Glasgow = ou $<5$. Todos os pacientes sinalizados à Central de Transplantes foram avaliados pelos profissionais das Organizações de Procura de Órgãos (OPO), com o intuito de identificar pacientes com critérios clínicos para abertura do protocolo de morte encefálica (ME). A amostra foi composta de 783 casos sinalizados entre agosto de 2017 a abril de 2018.

Resultados: Dos 783 casos sinalizados pelo sistema CROSS de pacientes classificados como Glasgow $=$ ou $<5$. Em relação ao tempo, a informação chegou a OPO em menos de duas horas em $67 \%$ dos casos. Do total de casos sinalizados $13 \%$ foram notificados posteriormente a Central de Transplantes como doador elegível em ME. O acompanhamento foi descontinuado em $87 \%$ dos casos sinalizados, tendo como principais causas o óbito e a melhora do quadro neurológico. $\mathrm{O}$ número de doadores efetivos viabilizados através do projeto excluindo os descontinuados foi de $41 \%$.

Conclusão: A possibilidade de identificação precoce de potenciais doadores se mostrou eficaz para o aumento do número de doadores efetivos, com efetivação de $41 \%$ do total de potencias doadores do projeto.

Palavras-chave: Doação de órgãos, morte encefálica
CB03-003

PANORAMA DA DOAÇÃO E CAPTAÇÃO DE MÚLTIPLOS ÓRGÃOS EM UMA ORGANIZAÇÃO DE PROCURA DE ÓRGÃOS (OPO) NO ESTADO DO CEARÁ

Antonia Thamara Ferreira Dos Santos ${ }^{3}$; Bruna Bandeira Oliveira Marinho'; Amana Da Silva Figueiredo'; Gustavo Martins Dos Santos'; Jose Wagner De Souza Brito'; Lidia Samantha Alves De Brito'; Vitória De Cássia Felix Rebouças'; Eliana Régia Barbosa De Almeida²; Mônica Maria Paiva Lima²

1 - OPO Cariri - Ceara;

2 - Central Estadual de Transplante do Ceara;

\section{3 - URCA}

O programa de transplantes no Brasil se destaca pelo crescimento no número de transplantes nos últimos anos e pelo investimento público na doação e transplante no país. O panorama atual apresentado na área, é de uma tendência crescente dos transplantes, o que reflete positivamente na saúde pública, pois esse aumento representa a sobrevida de pessoas. Objetivou-se analisar o crescimento das doações de uma região do Nordeste brasileiro. Trata-se de um estudo documental, realizado na Organização de Procura de Órgãos (OPO), localizada em uma região do Estado do Ceará, Nordeste, Brasil. Foram analisados os prontuários dos anos de 2012 a 2017. A coleta de dados aconteceu por meio de um formulário. Na pesquisa foram preservados os aspectos éticos e legais, e tem o parecer favorável de número 1.397.157. No ano de 2012, no Cariri, houve 9 doadores efetivos; 18 em 2013; 27 doadores em 2014; 34 doadores em 2015; 89 doadores efetivos em 2016 e 60 doadores efetivos em 2017. Nos anos de 2012 a 2017 foram abertos pela OPO-Cariri 365 protocolos de morte encefálica, dos quais $184(50,4, \%)$ tornaram-se doadores efetivos. A partir desses doadores de múltiplos órgãos e dos pacientes doadores de córnea, onde a grande maioria não tiveram morte encefálica, houve 318 órgãos e tecidos doados, uma vez que apenas um único doador pode tornar-se doador de múltiplos órgãos. Os órgãos mais captados na região são córneas, rins e fígado. O número de órgãos e tecidos doados são:192 córneas (60,5\%); 59 rins (18,6\%) e 58 fígados (18,4\%); 7 corações $(2,2 \%)$, e 1 pâncreas $(0,3 \%)$. Conclui que a partir dos resultados apresentados, os índices relacionados a doação de órgãos na região apresentam ascensão, os números têm demonstrado crescimento satisfatório, demostrando assim, um trabalho contínuo e sustentável da equipe de busca e captação de órgãos da região.

Palavras-chave: Doação, Transplantes, OPO 
CB03-004

DOAÇÃO DE ÓRGÃOS NA REGIÃO NORTE DO BRASIL: ANÁLISE DE UMA DÉCADA

Alessandro Prudente1; Andresa Tumelero1; Edclea Gonçalves1; Emanuel Esposito1; Henrique Rebello2; Alberto Tolentini2; Leny Pasos3; Elizete Keitel4; Clotilde Garcia4; Fabian Pires4; Valter Garcia4

1 - Hospital de Base de Porto Velho; 2 - Hospital Regional do Baixo Amazonas; 3 - Central de Transplantes do Amazonas; 4 - Santa Casa de Porto Alegre

A região norte com sete estados, tem população de 17,938 milhões é a mais desassistida em relação à doação e ao transplante. Em 2008: doadores falecidos somente no Pará e transplante renal em apenas três estados. Para reverter essa situação uma série de medidas foram implementadas: tutorias, treinamento e cursos. Objetivo: Analisar o início da procura de doadores nos estados da região norte. Comparar a evolução das taxa de potenciais doadores, efetivação da doação e doadores efetivos nessa região com taxas das outras regiões e do Brasil. As taxas analisadas, de 2008 a março de 2018, foram obtidas no RBT. Utilizado teste T de Student para comparação dos valores. Os sete estados notificaram potenciais doadores e seis efetivaram a doação. Em quatro os rins foram removidos e implantados localmente, em dois equipes de outros estados removeram os órgãos. $O$ crescimento na região norte foi significativamente superior aos das demais regiões (tabela) nas taxas de potenciais doadores $(p=0,007)$, efetivação da doação $(p=0,010)$ e doadores efetivos $(p=0,0030)$.

\begin{tabular}{|l|c|c|c|c|c|c|c|c|c|}
\cline { 2 - 10 } \multicolumn{1}{c|}{} & \multicolumn{3}{c|}{$\begin{array}{c}\text { Potenciais Doadores } \\
\text { (pmp) }\end{array}$} & \multicolumn{3}{c|}{$\begin{array}{c}\text { Taxa de efetivação } \\
\text { (\%) }\end{array}$} & \multicolumn{3}{c|}{$\begin{array}{c}\text { Doadores efetivos } \\
\text { (pmp) }\end{array}$} \\
\cline { 2 - 10 } & 2008 & $03 / 18$ & Variação & 2008 & $03 / 18$ & Variação & 2008 & $03 / 18$ & Variação \\
\hline Norte & 7,0 & 30,1 & $330 \%$ & 8,6 & 16,3 & $90 \%$ & 0,5 & 4,9 & $718 \%$ \\
\hline Nordeste & 24,8 & 42,6 & $72 \%$ & 17,7 & 23,5 & $33 \%$ & 4,4 & 10,0 & $127 \%$ \\
\hline Centro-Oeste & 37,0 & 57,4 & $55 \%$ & 9,7 & 24,2 & $150 \%$ & 3,6 & 13,9 & $286 \%$ \\
\hline Sudeste & 42,3 & 52,8 & $25 \%$ & 22,5 & 30,5 & $36 \%$ & 9,5 & 16,1 & $69 \%$ \\
\hline Sul & 34,5 & 82,6 & $139 \%$ & 32,2 & 40,7 & $26 \%$ & 11,1 & 33,5 & $203 \%$ \\
\hline Brasil & 32,5 & 50,4 & $55 \%$ & 22,2 & 32,1 & $45 \%$ & 7,2 & 16,2 & $125 \%$ \\
\hline
\end{tabular}

Os sete estados notificam doadores, seis efetivam a doação e quatro realizam transplante. Houve crescimento maior nos parâmetros analisados que o do Brasil e demais regiões. Apesar do aumento, as taxas ainda estão muito abaixo das do Brasil e demais regiões. Medidas adicionais devem ser intensificadas para alcançar as taxas de doação do Brasil nos próximos oito anos.

Palavras-chave: doação, procura de órgãos, transplante

\section{СB03-005}

PLANO DE AÇÃO BASEAdO NA FERRAMENTA DE QUALIDADE CICLO PDCA AUMENTA A TAXA DE APROVEITAMENTO DE ÓRGÃOS TORÁCICOS

Dayana Aparecida Martins Correa Calado; José Maria Do Nascimento; Felipe Alves Moreira; Roberta Cardoso; Maria Valeria Athayde; Renata Fabiana Leite; André Ramos Carneiro; Marli Marcos; Clayton Gonçalves Almeida; Heloisa Barbosa Paglione; Guilherme Ono1; José Eduardo Afonso Junior

\section{Hospital Israelita Albert Einstein}

Introdução: O Brasil realizou em 2017380 transplantes cardíacos e 112 transplantes de pulmão provenientes de doadores falecidos. No mesmo ano $36 \%$ dos potenciais doadores apresentaram parada cardíaca durante o processo, uma perda consideravelmente elevada. Algumas medidas podem auxiliar na manutenção destes potenciais doadores aumentando a oferta destes órgãos.

Objetivo: Avaliar o efeito da aplicação de um plano de ação baseado na ferramenta de qualidade Ciclo PDCA afim de otimizar a manutenção destes potenciais dadores e assim evoluir com aumento no seu aproveitamento.

Material e Método: Estudo de coorte com base em analise retrospectiva de indicadores em dez Hospitais públicos localizados no Estado de São Paulo-BR. $\mathrm{O}$ estudo se dividiu em duas fases: A fase 1 estendeu-se de janeiro de 2014 a dezembro de 2015, quando as medidas de manutenção do potencial doador eram instituídas a critério de cada hospital, sem orientações específicas quanto ao seu manejo. Na fase 2 entre janeiro de 2016 e dezembro de 2017, caracterizando-se pela aplicação de um plano de ação baseado na ferramenta de qualidade Ciclo PDCA otimizando a manutenção destes potenciais doadores. Resultados: Na fase 1 foram captados 35 corações e 13 pulmões. Já na fase 2 foram captados 41 corações e 31 pulmões. Totalizando um aumento na taxa de aproveitamento de $17 \%$ dos corações e $138 \%$ dos pulmões captados.

Discussão e Conclusões: Houve um aumento na taxa de aproveitamento de órgãos torácicos para transplante de 50\%, sendo que em 2017 100\% dos órgãos captados foram efetivamente transplantados.

Palavras-chave : manutenção do potencial doador doação de órgãos

\section{CB03-006}

ISOLAMENTO ENTRE DOADORES E RECEPTORES DE ÓRGÃOS: UMA PROPOSIÇÃO LABORAL PARA QUE FAMÍLIAS DOADORAS E RECEPTORAS POSSAM CONSTRUIR VÍNCULOS- CASO DESEJEM.

\section{Luiz Antonio Silva; Sandro Gouveia Montezano}

\section{Hospital Estadual Alberto Torres}

O objetivo deste estudo proposto é baseado na reflexão e revisão no Sistema Nacional dos Transplantes (SNT), a partir do trabalho e demandas que recaem sobre o Psicólogo e das possibilidades de seu trabalho. $O$ isolamento entre doadores e receptores post mortem é um padrão nacional, raramente rompido, a fim de manter a confidencialidade da doação e interferências ou aproximações que podem não ser saudáveis para ambas as partes quando não mediadas.

O estudo proposto se desenvolve em torno da construção de uma proposição laboral para a atuação do Psicólogo e equipe(médico e enfermeiro) nessa frente, em um setor de informação familiar para que famílias doadoras e receptoras possam construir - caso desejem (opção que seria obtida já nas entrevistas de doação) - vínculos de aproximação e acompanhamento.

É conhecida a angústia e as expectativas de esperança e alento que acompanham as famílias doadoras após a decisão de doar, da mesma forma que o comum desconhecimento que as acompanha. A partir disso, uma das propostas deste estudo é a construção de um instrumento de avaliação altruística para profissionais atuantes em equipes de transplantes de órgãos, a fim de ser aplicada nas etapas iniciais de sua abordagem para conduzir a atuação em Psicologia do trabalho para seu fortalecimento e estruturação como grupo e fonte de resultados - o amor entre as pessoas. A doação depende de sentidos pessoais de vida e morte, além de fatores sociais, culturais e religiosos. Representa a fragmentação do indivíduo. Quando voluntária e orientada, apresenta sentimentos positivos de ajuda, numa devolutiva do altruísmo. A partir disso, a proposta da central de informação familiar posiciona o Psicólogo nesse papel fundamental pós-doação, que pode vir a ser um importante estímulo para a decisão de doar (substituir a morte pela possibilidade do acompanhamento real da vida) e âncora de superação do processo de luto.

Palavras chave: Sistema nacional de Transplantes; Psicologia Social; Ética; Moral e Doação de Órgãos e Religião. 
CB03-007

\section{INVALIDAÇÃO DE CÓRNEAS COLHIDAS EM CORAÇÃO PARADO: PREVALÊNCIA} DE MARCADORES INFECCIOSOS

António Gomes; Anabela Barradas; Alberto Batista1; Sandra Rebelo; Cíntia Santos; Sílvia Silva; Ana P. Fernandes

Hospital Professor Doutor Fernando Fonseca, EPE Núcleo de Coordenação Hospitalar de Doação Serviço de Sangue e Medicina Transfusioal

Introdução: Na doação de órgãos/tecidos, a otimização de recursos está no equilíbrio entre a identificação de possíveis/potenciais dadores e a preditibilidade de critérios de exclusão.

O objetivo foi avaliar a casuística de invalidação de córneas colhidas em dadores de coração parado (CP), todos eles sujeitos a avaliação e validação prévia pelos Coordenadores Hospitalares de Doação (CHD).

Metodologia: foram revistos retrospetivamente todos os dadores de córneas de CP efetivados entre Abril de 2012 e Maio de 2018 e avaliados os fatores de eliminação das córneas. Particular atenção foi dada às causas associadas a serologias/ácidos nucleicos (TAN's) positivos.

Resultados: dos 123 dadores de córneas efetivados no período considerado, em $41(33,9 \%)$ estas foram rejeitadas por diversos motivos, dos quais se destacam $32(78,0 \%)$ excluídas por serologias/ TAN's positivos. Destes últimos, 15 $(46,9 \%)$ apresentaram VDRL/TPHA positivo. Apesar de existir variabilidade de prevalência de testes positivos para os vírus ao longo dos anos, a prevalência de serologias confirmadas para sífilis manteve-se estável no período avaliado, não se associou a outras positividades e é muito superior à encontrada nos dadores voluntários de sangue a nível nacional e no nosso hospital $(12,19 \%, 0,19 \%$ e $0,0012 \%$ respetivamente).

Não foram identificadas diferenças relativas a idade, género, comorbilidades ou causa de morte entre os dadores das córneas aceites e rejeitadas.

Conclusões: A prevalência de marcadores de doenças infecciosas em dadores devidamente selecionados pelos CHD representa um motivo de descarte de córneas colhidas muito significativo. De entre elas, a sífilis comporta-se como uma infeção de caráter endémico com uma prevalência muito elevada mesmo quando não existem à priori, fatores de risco na avaliação dos dadores.

\section{CB03-008 \\ MUDANÇA NA LEGISLAÇÃO BRASILEIRA: QUAL O IMPACTO NA DOAÇÃO DE ÓRGÃOS NO ESTADO DO CEARÁ?}

Eliana Régia Barbosa De Almeida1; Mônica Maria Paiva Lima1; Lilian Alves Amorim Beltrão1; Rosângela Gaspar Cavalcante1; Pedro Elder Silva Lima1

Central Estadual de Transplantes - Ceará

Em 15/12/2017 foi publicada resolução do conselho federal de medicina - CFM no 2173, atualizando os critérios para definir a morte encefálica. As principais atualizações foram: a) Quadro clínico do paciente apresentará os pré-requisitos: presença de lesão encefálica de causa conhecida e irreversível; ausência de fatores tratáveis que confundiriam o diagnóstico; temperatura corporal superior a 35C; saturação arterial > 94\%; pressão arterial sistólica maior ou igual a $100 \mathrm{mmHg}$; ou pressão arterial média maior ou igual a $65 \mathrm{mmHg}$ para adultos e tratamento e observação em hospital por mínimo de seis horas. b) 0 teste de apneia será realizado uma única vez por um dos médicos responsáveis pelo exame clínico e deverá comprovar ausência de movimentos respiratórios na presença de hipercapnia ( $\mathrm{PaCO} 2$ superior a $55 \mathrm{mmHg}$ ). c) Realização de dois exames clínicos, por médicos diferentes, - capacitado a realizar esses procedimentos para determinação de morte encefálica. Considerar-se-ão capacitados médicos com no mínimo um ano de experiência no atendimento de pacientes em coma, que tenham acompanhado ou realizado pelo menos dez determinações de ME ou curso de capacitação para determinação em ME. Objetiva avaliar o impacto dessa resolução nos indicadores do processo de doação no Estado do Ceará. É um estudo observacional comparativo dos indicadores de doação (notificação de potencias doadores, doadores elegíveis; doadores efetivos e de doadores com órgãos transplantados) de dois períodos: pré-publicação (01/08/2017 a 30/11/2017) e pós publicação (01/01/2018 a 30/04/2018). A taxa de notificação aumentou de 176 para 198 potencias doadores. A taxa de notificação de potencias doadores cresceu $12,5 \%$. 0 número de doadores elegíveis foi de 149 no primeiro e 157 no segundo período. Doadores efetivos aumentaram de 76 para 84 doadores, crescimento de 10,5\%. O número de doadores com órgãos transplantados subiu de 71 para 81, aumentando $14 \%$. A nova resolução impactou positivamente nos indicadores de doação no Ceará.
CB03-009

PERFIL DE DOADORES EFETIVOS NO ESTADO DO CEARÁ NO ANO DE 2017

Eliana Régia Barbosa De Almeida; Mônica Maria Paiva Lima; Pedro Elder Silva Lima; Rosângela Gaspar Lima; Tatiane Maia De Melo

Central Estadual de Transplantes - CE

O trauma é a principal causa de morte entre os doadores de órgãos no Estado do Ceará. O traumatismo cranioencefálico (TCE) é o principal determinante de mortalidade dentro deste grupo. O TCE está associado à violência do trânsito e a agressões, principalmente com armas de fogo. O objetivo deste trabalho é identificar o perfil dos doadores de órgãos no Estado do Ceará quanto as causas mortis e tipos de TCE, no ano de 2017. Foi realizada uma abordagem quantitativa, a partir dos relatórios gerados pela Central Estadual de Transplantes do Estado do Ceará, analisando-se os dados referentes às doações efetivas, considerando: sexo, causa mortis e tipos de TCE, no período de janeiro a dezembro de 2017. Entre os 209 doadores efetivos $65,55 \%$ são do sexo masculino e $54,07 \%$ estão entre 18 e 49 anos de idade, em plena faixa de idade economicamente ativa. Traumatismo cranioencefálico (TCE) foi a causa mortis de $52,15 \%$ dos doadores efetivos enquanto que $32,54 \%$ dos doadores sofreram acidente vascular cerebral hemorrágico ( $\mathrm{AVCH}$ ) e 9,09\% acidente vascular cerebral isquêmico (AVCI). Os acidentes envolvendo automóveis e motocicletas correspondem a $50,46 \%$ dos doadores, $24,77 \%$ estão associados com atos de violência entre os doadores com TCE, $22,94 \%$ decorrentes de quedas e $1,83 \%$ de causas não informadas. Concluímos que a maioria dos doadores efetivos são do sexo masculino e tem como causa mortis TCE, e dentro deste grupo a causa principal é a violência, tanto a do trânsito com as resultantes de agressões físicas e por projéteis de arma de fogo. Essa violência impacta na economia do estado, considerando-se que a maior frequência está na idade economicamente ativa. Medidas de contenção e redução desses indicadores devem ser realizadas através de políticas púbicas de combate à violência.

Palavras-chave : Doadores, Doadores Efetivos, Doação

\section{CB03-010} PERCEPÇÃO DE UMA COMUNIDADE INDÍGENA DE ETNIA KAINGANG SOBRE O
DIAGNÓSTICO DE MORTE ENCEFÁLICA

Janiel Glinke; Regina Martins Reggiori'; Simoni Engler'; Gabriela Zanatta ${ }^{1}$; Regina Dimas Albarello'; Edvaldo Leal De Moraes $^{2}$

1 - Associação Hospitalar Beneficente Santo Antônio; 2 - HOSPITAL DAS CLÍNICAS DA FACULDADE DE MEDICINA DA UNIVERSIDADE DE SÃO PAULO

Resumo - O conhecimento da percepção de familiares da comunidade indígena sobre o processo doação de órgãos para transplante, permite, contribuir para a implementação e otimização de ações que promovam a melhoria da qualidade do processo de doação de órgãos para transplante. O objetivo deste estudo foi relatar a experiência da equipe da CIHDOTT de um hospital de médio porte, no interior do Rio Grande do Sul-RS, a buscar compreender a percepção de uma família indígena da etnia Kaingang acerca do diagnóstico de morte encefálica. A morte encefálica (ME), mesmo sendo aceita como a morte do indivíduo pela comunidade científica mundial, ainda é pouco compreendida pela população uma vez que, classicamente, a morte era definida como a cessação irreversível das funções cardíaca e respiratória, o que gera resistência não somente na população, mas, também, entre os profissionais de saúde. Para a manifestação do consentimento, é importante que os familiares tenham os esclarecimentos necessários sobre o processo de doação. No entanto, observa-se que muitas famílias parecem ter dificuldades para compreender as orientações dadas e que são necessárias para a tomada de decisão. No Brasil, um país de dimensões continentais, e grandes diferenças sociais, culturais e religiosas, as dificuldades relacionadas ao processo de doação tornam-se ainda maiores. Nas comunidades indígenas a dificuldade para compreender todo esse processo é ainda mais relevante. A família não percebe o doador como morto e crê na possibilidade de reversão do quadro. A indecisão da família e acreditando que a falecida não era doadora em vida foi o motivo principal da recusa apontado. A equipe interdisciplinar de saúde deve oferecer apoio aos familiares, independente da manifestação ser favorável ou contrária à doação.

Palavras-chave : Transplante de órgãos, Obtenção de Tecidos e órgãos, Morte Encefálica, Família, Enfermagem 
CB03-011

PERFIL DOS DOADORES CARDÍACOS NA REGIÃO DO CARIRI CEARENSE: 2012 A 2018

Mônica Maria Paiva Lima2; Bruna Bandeira Oliveira Marinho1; Amana Da Silva Figueiredo1; Gustavo Martins Dos Santos1; José Wagner De Souza Brito1; Lidia Samantha Alves De Brito1; Vitória De Cássia Felix Rebouças1; Eliana Régia Barbosa De Almeida2; Antonia Thamara Ferreira Dos Santos3

1 - OPO Cariri - Ceará; 2 - Central Estadual de Transplantes do Cear; 3 - URCA

O programa de transplantes no Brasil se destaca pelo crescimento nas últimas décadas, o país tem se tornado referência no transplante cardíaco, porém há dificuldades para esse tipo de procedimento, em especial a escassez de doadores. O transplante cardíaco tornou-se o tratamento de escolha para a insuficiência cardíaca refratária. E no Brasil há um grande potencial para o aumento dos doadores efetivos e na utilização de dispositivos que podem impactar positivamente nos resultados do transplante cardíaco. Objetivou-se identificar o perfil dos doadores de coração de uma região do Nordeste brasileiro. Trata-se de um estudo documental, realizado na Organização de Procura de Órgãos (OPO), localizada em uma região do Estado do Ceará, Nordeste, Brasil. Foram analisados os prontuários dos anos de 2012 ao segundo trimestre de 2018. A coleta de dados aconteceu por meio de um formulário. Na pesquisa foram preservados os aspectos éticos e legais, e tem o parecer favorável de número 1.397.157. No ano de 2012 e 2013 não houve doação de coração, em 2014 e 2015 ocorreu uma doação, 2016 três doações, 2017 duas doações e até o segundo trimestre de 2018 já havia ocorrido 4 doações de coração. Quanto ao perfil dos doadores: Faixa etária: $18,2 \%$ apresentavam idade entre 0-14 anos; $36,3 \%$ de $15-30$ anos; $45,5 \%$ de $31-60$. Gênero: $90,9 \%$ eram do sexo masculino, e 9,1\% feminino. Etnia: $72,7 \%$ eram pardos; $18,2 \%$ brancos; e 9,1\% negros. Estado civil: $72,7 \%$ solteiros; $18,2 \%$ casados, $9,1 \%$ viúvos. Causa da morte encefálica: 81,8\% por Traumatismo Crânio Encefálico (TCE); 18,2\% sofreram Acidente Vascular Cerebral (AVC) - Hemorrágico. Antecedentes pessoais: 25\% diabetes; $25 \%$ tabagismo; $12,5 \%$ etilismo; $12,5 \%$ hipertensão; e $25 \%$ outras drogas. Tipagem sanguínea: $81,8 \%$ O+; 9,1\% A+; O- 9,1\%. Considerando os resultados apresentados, os índices relacionado apresentam ascensão, e é possível evidenciar o perfil dos doadores de coração.

Palavras-chave : Doadores Cardíacos, Doação 
CO02-001

AWAKE ECMO AS BRIDGE TO LUNG TRANSPLANT: EXPERIENCE OF PORTUGUESE CENTRE

Nidia Caires ${ }^{1}$; Sara Silva ${ }^{1}$; Ricardo Coelho'; Sara Alfarroba'; Ana Santos'; Telma Lopes'; Rita Gerardo'; Alexandra Borba'; Nicole Murinello'; Luisa Semedo'; Joao Reis'; Pedro Coelho'; Paulo Calvinho ${ }^{2}$; Joao Cardoso'; Jose Fragata ${ }^{2}$

1 - Pneumology Service, Hospital Santa Marta, Centro Hospitalar Lisboa Central; 2 - Cardiothoracic Surgery Service, Hospital Santa Marta, Centro Hospitalar Lisboa Central

Introduction: Extracorporeal membrane oxygenation (ECMO) has been used for bridging to lung transplant (LTX) in patients receiving invasive mechanical ventilation (IMV). In order to avoid prolonged IMV's complications, the use of venovenous ECMO (VV-ECMO) in spontaneously breathing patients have emerged as an option for respiratory support in those who are severely deteriorating while waiting for LTX.

Methods: Of 197 LTx performed since 2001, we did a retrospective analysis of six patients who underwent LTx on awake VV-ECMO support.

Results: Of six patients, four were female with mean age $48.5 \pm 14.9$ years. In most cases patients were transplanted for interstitial lung fibrosis $(n=5)$. One patient was connected to ECMO fully awake, three were intubated about 24hours (median) to introduce and start ECMO support and two initiate ECMO after a few days of IMV. The mean time on ECMO support before LTX was 23.7 days (between 5 and 97 days) and no one needed IMV before LTX. All patients survived successfully and underwent LTX on VV-ECMO support. During transplant, four were converted to venoarterial ECMO and then back to venovenous at the end of the procedure. After LTx all patients remained invasive ventilated for median 28.5 days and the mean duration of ECMO support after LTx was $3.3 \pm 2.3$ days. Average Intensive Care Unit length of stay after LTx was $50.7 \pm 40.5$ days. Among this population, three presented with primary graft dysfunction and one with hemorrhagic complication. Four patients died after LTx due to multiple organ dysfunction syndrome, septic shock and refractory acute rejection.

Conclusion: VV-ECMO is an important strategy in bridging patients to LTx and in this group survival to perform LTx was $100 \%$. Further research is needed to help to identify the most optimal candidates, the timing and duration of this approach to improve outcome after transplantation.

Palavras-chave: Lung Transplant, Venovenous Extracorporeal Membrane Oxygenation

\section{CO02-002}

EFEITOS DO BASILIXIMABE E DA TERAPIA TRÍPLICE EM CÉLULAS DO EPITÉLIO DAS VIAS AÉREAS DE RATOS

Aristides Tadeu Correia ${ }^{1}$; Elizabete Silva Santos ${ }^{2}$; Francine Maria Almeida ${ }^{2}$; Paulo Manuel Pêgo-Fernandes'; Rogerio Pazetti ${ }^{2}$

1 - Laboratorio de Pesquisa em Cirurgia Toracica LIM61, Programa de Pos Graduaçao em Cirurgia Toracica e Cardiovascular, Instituto do Coraçao, Hospital das Clinicas HCFMUSP, Faculdade de Medicina, Universidade de Sao Paulo, Sao Paulo, SP, BR.; 2 - Laboratorio de Pesquisa em Cirurgia Toracica LIM61, Faculdade de Medicina, Universidade de Sao Paulo, Sao Paulo, SP, BR.

Introdução: Estudos prévios mostraram que as drogas imunossupressoras comumente utilizadas no transplante de pulmão prejudicaram a depuração mucociliar das vias aéreas de ratos. O basiliximabe tem sido utilizado como terapia de indução antes do transplante pulmonar em diversos centros ao redor do mundo e com poucos relatos de efeitos colaterais. Assim, devido à sua alta especificidade e poucos efeitos indesejados, acreditamos que o basiliximabe, diferentemente das outras drogas imunossupressoras, não apresente eventos adversos nas células do epitélio das vias aéreas de ratos. Métodos: Oitenta ratos Wistar machos foram divididos em 4 grupos: Controle (água); Basiliximabe; Terapia Tríplice (tacrolimus, micofenolato e prednisona), e Basiliximabe+Terapia tríplice. Todos os grupos foram divididos em dois subgrupos de acordo com o tempo de tratamento. $O$ basiliximabe foi administrado em duas doses (1‥ e 4ㅇ․ dia do estudo). As drogas da terapia tríplice foram administradas por gavagem diariamente por 7 e 15 dias, com início no dia da 2 a dose de basiliximabe. Após este período, foi avaliada a concentração da proteína mucina do gene Muc5ac por Dot Blot e a morte celular pela quantificação de células marcadas com Bcl-2 e Caspase 3. Resultados: Não houve diferença significativa entre os grupos quanto à quantidade da proteína mucina do gene Muc5ac. Quanto à porcentagem de células positivas para $\mathrm{Bcl}-2$, foi encontrada diferença entre os grupos Controle (média 11,28 $\pm 3,6 \%$ ) e Basiliximabe (média 6,80 $\pm 3,1 \%$ ) $p=0,05$. Quanto a porcentagem de células positivas para Caspase 3 , foi encontrada diferença entre os grupos Controle (média 14,75 $\pm 4,8 \%$ ) e Basiliximabe+Terapia Tríplice (média 23,48 $\pm 8,2 \%$ ) $p=0,014$. Conclusão: $O$ basiliximabe e a terapia tríplice apresentaram eventos adversos nas células do epitélio das vias aéreas, especificamente em relação à morte celular. Apoio financeiro: Fundação de Amparo à Pesquisa do Estado de São Paulo - Processo 2012/09839-0.

Palavras-chave: Transplante de pulmão, Imunossupressores, Basiliximabe
$\mathrm{CO02-003}$

CREATINE SUPPLEMENTATION ATTENUATES THE EFFECTS OF ISCHEMIA AND REPERFUSION INJURY IN THE COLLATERAL LUNG AFTER TRANSPLANTATION

Francine Maria Almeida'; Angela Silva Battochio'; João Pithon Napoli²; Katiusa Abreu Almeida'; Grace Susana Balbin ${ }^{2}$; Manoel Oliveira-Junior ${ }^{3}$; Henrique Takachi Moriya4; Paulo Pego-Fernandes2; Rodolfo Paula Vieira5; Rogerio Pazetti 1 - Programa de Pos-Graduacao em Cirurgia Toracica e Cardiovascular, Instituto do Coracao (InCor), Faculdade de Medicina, Universidade de Sao Paulo; 2-Laboratorio de Pesquisa em Cirurgia Toracica, Departamento de Cardiopneumologia, Hospital das Clinicas HCFMUSP, Faculdade de Medicina, Universidade de Sao Paulo; 3 Universidade Nove de Julho - UNINOVE; 4 - Laboratorio de Engenharia Biomedica - LEB, Universidade de Sao Paulo; 5 - Instituto Brasileiro de Ensino e Pesquisa em Imunologia Pulmonar e do Exercício (IBEPIPE) and Universidade Brasil

Background: Ischemia and reperfusion injury (IRI) triggers an intense inflammatory process characterized mainly by the presence of activated neutrophils and macrophages, which release innumerable inflammatory mediators, perpetuating the inflammation. Our initial hypothesis was that creatine supplementation $(\mathrm{Cr})$ could attenuate IRI by increasing phosphocreatine (PCr) levels in cells. Objective: To evaluate the role of $\mathrm{Cr}$ supplementation in the attenuation of IRI in collateral lungs of rats that underwent to left lung transplantation (LTX). Methods: Sixty Sprague Dawley male rats were distributed into four groups: A90, control / water +90 minutes of ischemia; $\mathrm{Cr} 90$, creatine +90 minutes of ischemia; $\mathrm{A} 180$, control / water + 180 minutes of ischemia; $\mathrm{Cr} 180$, creatine +180 minutes of ischemia. Donor animals received creatine $(0.5 \mathrm{~g} / \mathrm{kg} /$ day) daily for five days prior to $\mathrm{LTx}$. Control group received only the vehicle. After 90 or 180 minutes of cold ischemia left lung was implanted and reperfused during 120 minutes. After reperfusion and isolation, we evaluated the right lung by the exhaled nitric oxide (exNO), the inflammatory cells in bronchoalveolar lavage fluid (BALF) and lung parenchyma. Results: There was a decrease in exNO in $\mathrm{Cr} 90$ and $\mathrm{Cr} 180$ groups ( $\mathrm{p}=0.010$ and $p=0.041$, respectively). The total number of leucocytes and neutrophils in BALF was lower in both creatine groups $(p<0.05)$, and there was a decrease in macrophages in $\mathrm{Cr} 180$ group ( $p=0.019)$. In lung parenchyma analysis, reduced number of mononuclear cells was found in $\mathrm{Cr} 90$ and $\mathrm{Cr} 180$ groups $(\mathrm{p}<0,017)$, but only $\mathrm{Cr} 90$ group showed a decrease in polymorphonuclear cells $(p=0,001)$. Conclusion: Creatine supplementation attenuates the effects of ischemia and reperfusion injury in collateral lungs after left lung transplantation.

Palavras-chave: Ischemia and reperfusion injury, Lung transplantation, Creatine supplementation, Inflammatory cells, Collateral lung

\section{CO02-004}

MANOBRA DE RECRUTAMENTO ALVEOLAR NO PÓS-OPERATÓRIO IMEDIATO DE TXP BILATERAL

Paulo Pego-Fernandes; Maria Ignez Zanetti Feltrin; Vera Regina Coimbra; Mariana Goldemberg1; Marcos Samano1 INSTITUTO DO CORAÇÃO HCFMUSP

Introdução: A manobra de recrutamento alveolar (MRA) é uma estratégia para aumentar as áreas de troca gasosa, recrutando unidades colapsadas. Em TxP há poucos relatos sobre sua aplicação na admissão do paciente na UTI após o procedimento cirúrgico. Objetivo: Avaliar a aplicabilidade da MRA na chegada à UTI e verificar a ocorrência de eventos adversos. Secundariamente, avaliar oxigenação e mecânica ventilatória, nas três primeiras horas do pós-operatório imediato. Metodologia: Ensaio clínico, prospectivo, pacientes submetidos TxP bilateral. A MRA foi realizada após retirada de secreção brônquica, logo após a admitição do paciente na UTI. A MRA foi executada com PEEP $=20 \mathrm{cmH} 2 \mathrm{O}$ e $\Delta P=15 \mathrm{cmH} 2 \mathrm{O}$, por 1 minuto, por 3 repetições. Após, realizou-se titulação da PEEP de forma decremental até atingir PEEP ideal. Após a MRA, dados de oxigenação, mecânica ventilatória, necessidade de nova MRA e análise de eventos adversos foram coletados. Análise estatística utilizou-se teste t-Student pareado e teste de Pearson para correlações. Nível de significância de $p<0,05$. Resultados: Incluídos 17 pacientes, 10 mulheres, tempo isquemia 710min (670812), tempo de ventilação mecânica 10h (6,3-16hs), tempo de UTI 7 dias (3-19). Não houve significância estatística entre a 1a e a 3a. hora do estudo quanto à complacência pulmonar ( 29 vs $31 p=0,35)$, resistência de vias aéreas ( 13 vs $13 p=1,0), \Delta P(14$ vs $13,7 p=0,47)$, PEEP (10 vs $12 p=0,78)$ e PaO2/FiO2 (281 vs $295 p=0,510)$. Não houve necessidade de realização de novas MRA e nenhum evento adverso foi registrado. Conclusão: A MRA mostrou-se segura e aplicável em pacientes de TxP bilateral. Não houve necessidade de ajustes ventilatórios, mantendo ventilação protetora e adequada oxigenação, até o momento da extubação. Nenhuma intercorrência clinica foi associada à MRA.

Palavras-chave : Ventilação mecânica, transplante pulmonar, manobra de recrutamento alveola 
CO02-005

MEDIDAS DE ULTRASSONOGRAFIA DO MUSCULO RETO FEMORAL E SUA ASSOCIAÇÃO COM FORÇA E DISTANCIA PERCORRIDA EM PACIENTES EM LISTA DE ESPERA DE TRANSPLANTE PULMONAR

Maria Ignez Zanetti Feltrin'; Paulo Pego-Fernandes'; Marcia Sangean1; Fabio Rodrigues'; Emanoel Ribeiro De Melo ${ }^{2}$

1 - INSTITUTO DO CORAÇÃO HCFMUSP; 2 - Divisão de Diagnóstico por Imagem do Instituto do Coração HCFMUSP

Introdução: Pacientes com pneumopatia avançadas, em lista de espera ao transplante pulmonar (TxP), apresentam sintomas limitantes como dispneia e hipoxemia, adotando posturas estáticas, principalmente a sedestação, por tempo prolongado. Desta forma, associada à disfunção pulmonar, há também progressivo descondicionamento físico, com baixa tolerância aos esforços. Em consequência, estabelecem-se alterações musculares evidenciadas nestes pacientes por perda de massa muscular, com comprometimento da força e/ou endurance. Estudos recentes, utilizando ultrassonografia, mostram perda da massa muscular, área e espessura do músculo reto femoral, em pacientes com doença pulmonar obstrutiva crônica, moderado a grave, e àqueles com doença pulmonar intersticial, justificando seu uso para avaliação muscular. Objetivo: Verificar o grau de associação das medidas de massa do músculo reto femoral, por ultrassonografia, com a força muscular e tolerância ao exercício.

Metodologia: Estudo transversal em pneumopatas graves, idade $\geq 18$ anos. Realizado avaliação da força muscular por meio de contração voluntária máxima de flexão e extensão de joelho (dinamometria), no hemicorpo dominante; da massa muscular (ultrassonografia) do músculo reto femoral para medidas de espessura e área seccional; distancia percorrida no teste de caminhada de seis minutos (TC6M). A análise estatística utilizou a correlação de Pearson. O nível de significância estatística considerado foi p<0,05.

Resultados: Foram incluídos no estudo 15 pacientes, sendo 11 mulheres (73\%), com pneumopatia avançada, com diagnósticos prevalentes de Fibrose Cística (n = 5; VEF1 = 32,4\%) e Fibrose Pulmonar ( $n=4 ; C V F=22,5 \%)$. Não foi encontrada associação significante entre distância percorrida e força muscular para extensão de joelho $(p=0,29 ; r=0,29)$ e para flexão de joelho $(p=0,47 ; r=0,20)$. Também não houve correlação significante entre distância percorrida e massa muscular (área ou espessura) nas posições sentado com o músculo relaxado $(p=0,73 ; r=-0,09$ e $p=0,15 ; r=0,10$, respectivamente), sentado com o músculo contraído ( $p=0,47 ; r=-0,20$ e $p=0,72 ; r=0,10$, respectivamente) e deitado com o músculo relaxado ( $p=0,42 ; r=-0,23$ e $p=0,46 ; r=0,21$, respectivamente). Houve significante associação entre força no movimento de extensão de joelho e a área do músculo reto femoral na posição sentada com o músculo contraído $(p=0,02 ; r=-0,61)$. Demais associações sem significancia.

Conclusão: Há maior associação entre área muscular e força, dependendo do estado do tônus muscular e da posição corporal. Em pacientes em lista de espera ao transplante pulmonar, a maior força associou-se à menor área seccional do músculo reto femoral, na posição sentada com o músculo contraído.

Palavras-chave : Transplante de pulmão, Ultrassom, Sistema Muscular
CO02-006

POST-TRANSPLANT LYMPHOPROLIFERATIVE DISORDER AFTER LUNG TRANSPLANTATION: THE PORTUGUESE EXPERIENCE

Sara Campos Silva'; Nídia Caires'; Vânia Caldeira'; Ricardo Coelho'; Ana Sofia Santos'; Sara Alfarroba'; Telma Lopes'; Nicole Murinello'; Rita Gerardo'; Alexandra Borba'; Luísa Semedo'; Eugénia Pinto ${ }^{2}$; Aida Botelho ${ }^{4}$; João Eurico Reis $^{3}$; Rita Barata ${ }^{3}$; Paulo Calvinho ${ }^{3}$; João Cardoso'; José Fragata ${ }^{3}$

1 - Serviço de Pneumologia, Hospital de Santa Marta, Centro Hospitalar Lisboa Central; 2 - Serviço de Anatomia Patológica, Hospital de São José, Centro Hospitalar Lisboa Central; 3 - Serviço de Cirurgia Cardio-torácica, Hospital de Santa Marta, Centro Hospitalar Lisboa Central; 4 - Serviço de Hematologia, Hospital Santo António dos Capuchos, Centro Hospitalar Lisboa Central

We present a review of four cases of PTLD, which represent an incidence of 2,5\% in the total of 162 lung transplants (LT) between 2009-2017 in our LT center.

We had 2 males who underwent unilateral LT for IFP and COPD with mean age of 59 years and 2 women who underwent bilateral LT for bronchiectasis non-cystic fibrosis with mean age of 22 years.

All had received induction immunosuppression with ATG. The maintenance regimen at PTLD diagnosis was prednisone $(n=4)$, tacrolimus $(n=4)$, sirolimus $(n=1)$, mycophenolic acid $(n=1)$ and azathioprine $(n=1)$. Only one had had previously episodes of acute rejection that required temporary increases in immunosuppression. Two patients were previously immune to CMV and one had positive viral charge for EBV at the time of PTLD diagnosis. The time between LT and PTLD was 49 and 41 months (older patients) and 9 and 8 months (younger patients).

There were two monomorphic PTLD, one polymorphic and one undefined. The affected sites were: 1 case of mantle cell lymphoma (MCL) with involvement of the bone marrow; 1 case of gastrointestinal (GI) involvement; and 2 cases of lung involvement in which one of them it appears in the native lung. Half patients were in stage I and another half in stage IV (Ann Arbor staging).

The clinical presentation was nonspecific, mainly presenting with fatigue (100\%), weight loss (50\%) and GI symptoms (50\%).

After PTLD diagnosis, immunosuppression was reduced in all. The patient with $\mathrm{MCL}$ did chemotherapy (R-CHOP) and died 4 months after the diagnosis. The others have been treated with rituximab and had a good response keeping under surveillance.

PTLD is an uncommon complication after LT. Treatments are most effective in the early stages, being fundamental an early diagnosis.

Palavras-chave : Lung transplantation, post-transplant lymphoproliferative disorder 


\section{CO03-001}

TRATAMENTO DA RECIDIVA GESF APÓS TRANSPLANTE RENAL PEDIÁTRICO

Clotilde Garcia'; Viviane Bittencourt'; Izadora Tonetto'; Roberta Rohde'; Ilka Atencia Amin'; Karen Velasquez Fuenmayor'; Sandra Mendez Correa'; Vandrea De Souza ${ }^{2}$

1 - SERVIÇO DE NEFROLOGIA PEDIÁTRICA - SANTA CASA DE PORTO ALEGRE; 2 - PROGRAMA DE PÓS GRADUAÇÃO EM CIENCIAS DA SAUDE- UNIVERSIDADE DE CAXIAS DO SUL

INTRODUÇÃO: Glomeruloesclerose segmentar e focal (GESF) primária é frequente na população pediátrica, apresentando elevado risco de recidiva pós transplante, devido a presença de fatores de permeabilidade circulantes (FC). Tratamento da recidiva de GESF consta de plasmaferese para remover os FC e mais recentemente Rituximabe, menos invasivo e atuando nas células $B$ e na manutenção do citoesqueleto do podócito. OBJETIVO: O objetivo desta análise é avaliar os resultados do tratamento de recidiva de GESF num período de 18 anos em centro único de transplante renal pediátrico. PACIENTES E MÉTODOS: Dados de 27 pacientes transplantados renais pediátricos no período de 2000 a 2018, que apresentaram recidiva de GESF no primeiro transplante, foram avaliados. RESULTADOS: A população avaliada apresentou idade mediana (IIQ) de $9,6[7,2-13,6]$ anos, sendo $52 \%$ do sexo masculino $(n=14)$ e $74 \%$ caucasianos. A imunossupressão de indução foi com IL2 ou timoglobulina e manutenção com inibidor de calcineurina (ciclosporina ou tacrolimo), prednisona e ácido micofenólico. $O$ tratamento inicial da recidiva foi plasmaferese (PF), no máximo 10 sessões, em $30 \%$ ( $n=8$ ) e Rituximabe como monoterapia ( 2 a 4 doses) (RTX) em $70 \%(n=19)$ dos casos. A taxa de resposta completa ou parcial foi de $68 \%$ no grupo RTX e $50 \%$ no grupo $\operatorname{PF}(p=0,63)$. Os não responsivos ao RTX $(n=6)$ receberam terapia adicional com $\mathrm{PF}$, com resposta em $83 \%$ dos casos $(5 / 6)$. A resposta final no grupo RTX foi de $95 \%$ e no grupo PF de $50 \%(p=0,02)$. Houve perda do enxerto em $55 \%$ dos casos, $62 \%$ do grupo PF, $53 \%$ do grupo RTX $(p=0,96)$. CONCLUSÃO: Os dados apresentados sugerem o tratamento inicial com Rituximabe como monoterapia e a plasmaferese, mais invasiva, como segunda linha de tratamento. Para confirmação desses achados são necessários novos estudos, com maior tamanho amostral.

$\| \mathrm{Q}=$ intervalo interquartil,

Palavras-chave : GESF, FSGS, transplante renal pediatrico, TRANSPLANTE RENAL

\section{CO03-002}

\section{PEDIATRIC KIDNEY TRANSPLANTATION - EXPERIENCE OF A CENTER OVER} FOUR DECADES

Carolina Cordinhã'; Luís Rodrigues²; Carmen Carmo'; Clara Gomes'; Fernando Macário $^{2}$; A. Jorge Correia'; Rui Alves ${ }^{2}$; Arnaldo Figueiredo ${ }^{3}$

1 - Unidade de Nefrologia Pediátrica, Hospital Pediátrico - Centro Hospitalar e Universitário de Coimbra; 2 - Serviço de Nefrologia - Centro Hospitalar e Universitário de Coimbra; 3 - Serviço de Urologia e Transplantação Renal Centro Hospitalar e Universitário de Coimbra

Introduction: Chronic kidney disease in the pediatric population is associated with numerous comorbidities and increased risk of mortality. Kidney transplantation (KT) is considered to be the option of choice in children with end stage renal disease. Aim: To characterize a single center experience in pediatric KT in the last 35 years. Material and Methods: Retrospective analysis of epidemiological and clinical data from KT patients younger than 18 years, from January 1981 to November 2016. Demography, end stage renal disease etiology, previous renal replacement therapy, type of donor, immunosuppression regimens, graft survival and death were collected. For analysis cases were divided in decades (1981-89/1990-99/2000-09/201016). Results: One hundred and four children (KT mean age $13.7 \pm 3.32$ years, $57.7 \%$ male) underwent 111 renal transplants ( $13.5 \%$ living donor). Congenital anomalies of the kidney and urinary tract $(34.2 \%)$ and glomerular disease $(27 \%)$ were the major causes of renal disease. Peritoneal dialysis was the predominant initial dialytic modality in 69 children (62.2\%). Mean dialysis time 18 months, nine patients (8.1\%) having had preemptive KT. Median follow-up was 181 months (1-379). Uncensored graft survivals rates at 5, 10, 15 and 20 years were $79.7 \%, 74.3 \%, 59.5 \%$ and $52.8 \%$. Graft survival improved significantly over the decades $(p=0.03)$. Higher estimated glomerular filtration rate measured at one year, induction immunosuppressive therapy use (thymoglobulin/basiliximab) and lower incidence of acute rejection rates were associated with superior graft survival $(p<0.05)$. There was a trend towards better graft survival in tacrolimustreated patients, but this difference was not statistically significant $(p=0.064)$. Conclusions: Uronephropathies were the most frequent cause of renal failure and peritoneal dialysis the main renal replacement therapy prior to KT. Results were in agreement with the published literature. Graft survival improved significantly over the study period, and we hypothesize if this was related with surgical advances and the use of more effective immunosuppressive drugs.

Palavras-chave: Pediatric Kidney transplantation; graft survival;

immunosuppression
CO03-003

REGISTRO COLABORATIVO BRASILEIRO DE TRANSPLANTE RENAL PEDIÁTRICO (COBRAZPED-RTX): RELATÓRIO DE 2004 À 2018

Vandrea De Souza'; Clotilde Garcia ${ }^{2}$; Paulo Koch ${ }^{3}$; Jose Medina Pestana ${ }^{3}$; Suelen Martins ${ }^{3}$; Viviane Barros ${ }^{4}$; Roberta Rohde ${ }^{4}$; Izadora Pires ${ }^{4}$; Maria Fernanda Camargo $0^{5}$; Luciana Feltran ${ }^{5}$; Ronaldo Esmeraldo ${ }^{6}$; Rebeca Carvalho ${ }^{6}$; Benita Schvartsman; ${ }^{7}$ Andreia Watanabe7; Mariana Cunha ${ }^{8}$; Romilda Santos $^{8}$; Liliane Prates ${ }^{9}$; Vera Belangero ${ }^{9}$; Lilian Palma ${ }^{9}$; Henrique Mochida Takase $^{10}$; Paula Dalsoglio Garcia ${ }^{10}$; Vanda Benini ${ }^{11}$; Simone Laranjo ${ }^{11}$; Mario Abbud Filho ${ }^{12}$; Ida Fernandes-Charpiot12; Horácio Ramalho ${ }^{13}$; Ana Carmem Quaresma Mendonça14; Mariana Vasconcelos14; Claudia Andrade ${ }^{15}$; Mariana Penido $^{16}$; Carolina Ferreira Leite ${ }^{16}$; Enzo Ricardo Russo ${ }^{17}$; Inalda Facincani ${ }^{17}$; Mario Wagner ${ }^{18}$

1 - Programa de Pós graduação em Ciências da Saúde - Universidade de Caxias do Sul; 2 - CoBrazPed-ABTO; 3 - Hospital do Rim. Universidade Federal de São Paulo; 4 - Hospital da Criança Santo Antonio-Santa Casa. Universidade Ciencias da Saude Porto Alegre; 5 - Hospital Samaritano São Paulo; 6 - Hospital Geral de Fortaleza; 7 - Instituto da Criança, Hospital das Clínicas, Faculdade de Medicina -Universidade de São Paulo; 8 - Hospital Pequeno Príncipe, Curitiba; 9 - Universidade Estadual de Campinas; 10 - Hospital das Clínicas -Faculdade de Medicina de Botucatu - UNESP; 11 - Santa Casa de São Paulo; 12 - Hospital de Base - São José do Rio Preto; 13 - Instituto Urologia Nefrologia São José Do Rio Preto; 14 - Hospital das Clinicas. UFMG, Belo Horizonte; 15 - Hospital Ana Neri. Salvador; 16 - Santa Casa de Belo Horizonte; 17 - Hospital das Clínicas Faculdade de Medicina de Ribeirão Preto - USP; 18 - Programa de Pós graduação em Saúde da Criança e do Adolescente- Universidade Federal do Rio Grande do Sul- Porto Alegre

INTRODUÇÃO: O registro colaborativo Brasileiro de transplante renal pediátrico iniciou em 2004 como uma iniciativa multicêntrica com objetivo de analisar, relatar e divulgar os resultados do transplante renal pediátrico no Brasil. METODOLOGIA: Dados de todos os transplantes renais pediátricos realizados de janeiro de 2004 à maio de 2018, nos 13 centros participantes, foram analisados. Dados demográficos, etiologia da doença renal crônica e sobrevida do enxerto e do paciente foram avaliadas.

RESULTADOS: Nos treze centros participantes foram realizados 2744 transplantes renais pediátricos. A idade mediana no transplante foi de 12,2 anos, sendo a maioria dos receptores do sexo masculino (56\%). As principais doenças de base foram malformações do trato urinário $(40,5 \%)$ e glomerulopatia (28\%). 1981 (72\%) dos enxertos eram provenientes de doadores falecidos (DF). A imunossupressão inicial consistiu principalmente de tacrolimo, micofenolato, corticosteroide e terapia de indução com anti-IL-2R. A sobrevida do enxerto em um ano (censurada por morte) foi de $94 \%$ no grupo doadores vivos (DV) e de $91 \%$ no grupo DF (Log rank test $p<0,01$ ). A sobrevida do paciente em um e em 5 anos foi de $97 \%$ e $95 \%$ para o grupo DV e $96 \%$ e $93 \%$ para o grupo DF (Log rank test $p=0,02)$. A taxa de perda do enxerto foi de $19 \%(n=517)$, mais frequentemente causada por trombose vascular $(n=102)$, nefropatia crônica do enxerto $(n=90)$, morte com enxerto funcionante $(n=75)$, recorrência da doença de base $(n=41)$, e rejeição aguda $(n=32)$. Receptores DF tiveram $1,6(1,0-2,2)$ vezes maior chance de morte e $1,5(1,2-1,8)$ vezes maior chance de perda do enxerto comparado aos receptores DV. A taxa de mortalidade foi de $5,4 \%(n=148)$, principalmente por infecção $(n=69)$ e doença cardiovascular $(n=31)$.

CONCLUSÃO: Os resultados desse registro colaborativo de transplante renal pediátrico são comparáveis a outros registros internacionais.

Palavras-chave : transplante renal pediátrico, registro 
CO03-004

DESFECHOS DO TRANSPLANTE RENAL DE URGENCIA EM PACIENTES PRIORIZADOS POR FALENCIA DE ACESSO VASCULAR

Tainá Veras De Sandes Freitas ${ }^{1,2}$; Juliana Gomes Ramalho De Oliveira ${ }^{3}$; Gilberto Loiola De Alencar Dantas ${ }^{2}$; Lucas Lobo Mesquita ${ }^{2}$; Marcel Rodrigo De Oliveira ${ }^{1}$; Celi Melo Girão ${ }^{1}$; Ronaldo De Matos Esmeraldo ${ }^{1}$

1 - Hospital Geral de Fortaleza; 2 - Universidade Federal do Ceará; 3 Universidade de Fortaleza - UNIFOR

Introdução: Há pouca informação disponível sobre o perfil clínico e os desfechos pós-transplante renal (TxR) de pacientes transplantados sob prioridade por falência de acesso vascular no Brasil. Metodologia: Estudo de coorte retrospectiva incluindo 74 pacientes transplantados sob prioridade por falencia de acesso vascular entre Jan/10-Mar/16. Como grupo controle, foram pareados pelo te po de TxR 74 paciente transplantados sob alocação regular. Resultados: Entre os priorizados, predominaram mulheres (58 vs. $34 \%, p=0,005$ ), com maior PRAI ( 22 vs. $12 \%, p=0,029)$, PRAll (12 vs. $7 \%, p=0,005)$, MM-HLA ( 4,8 vs $3,8, p<0,001)$, maior percentual de Re-TxR ( 27 vs. $4 \%, p<0,001)$, maior tempo entre o início da diálise e a inscrição para o TxR ( 55 vs. 29 meses, $p=0,002)$. Não houve diferença quanto a idade (40 anos), IMC ( $23 \mathrm{Kg} / \mathrm{m} 2)$, raça ( $73 \%$ pardos), etiologia da doença renal (39\% indeterminada), antecedente de diabetes (15\%), tempo em lista ( 8,5 meses), e perfil do doador $(0,7 \%$ doadores de critério expandido). Não houve diferença na incidência de DGF (47\%), rejeição aguda (7\%), reinternação no 10 mês (18\%), TFG em 1 ano $(63 \mathrm{~mL} / \mathrm{min})$ e sobrevida do paciente em 1 ano (97\%). No entanto, os priorizados apresentaram maior tempo de internação após o TxR ( 29 vs. 16 dias, $p=0,001)$ e pior sobrevida do enxerto censorada para o óbito em 1 ano ( 88 vs. 99\%, $p=0,002$ ). 44\% das perdas neste grupo ocorrem por trombose. Priorização (HR 8,101, p=0,050) e Re-Tx (HR $3,868, p=0,018$ ) foram fatores de risco independentes para perda. Conclusão: pacientes transplantados sob prioridade são predominantemente mulheres jovens, não diabéticas, com alto risco imunológico, que permanecem longo período entre o início da diálise e a inscrição para o TxR, e evoluem com elevado percentual de perda do enxerto por trombose. Estes resultados apontam para a necessidade de políticas locais para referenciamento precoce para o TxR após o inicio da diálise.

Palavras-chave : Priorização, Transplante de urgencia

\section{CO03-005}

ESTUDO PROSPECTIVO, ALEATORIZADO E CONTROLADO DE SUPLEMENTAÇÃO COM COLECALCIFEROL EM RECÉM TRANSPLANTADOS RENAIS - RESULTADOS PRELIMINARES AOS 42 MESES

Cristina Jorge'; Teresa Adragão'; Patrícia Matias1; Margarida Bruges1; Rita Birne1; Rita Calça1; Regina Oliveira1; Ana Casqueiro1; Jorge Azinheira2 Mã João Andrade3; Sara Querido1; Célia Nascimento1; André Weigert1; Domingos Machado1

1 - CHLO, Hospital de Santa Cruz, Unidade de Transplantação Renal; 2 - CHLO, Hospital S Francisco Xavier, Serviço de Patologia Clínica; 3 - CHLO, Hospital de Santa Cruz, Serviço de Cardiologia

Os benefícios da suplementação com vitamina $D$ (vitD) nutricional nos receptores de transplante renal (RTR) não estão bem definidos. Verificámos prospectivamente os efeitos da suplementação com colecalciferol (4000 UI/dia) num grupo de recém (r) RTR (GD, n=33), comparando-os com um grupo de rRTR sem suplementação ( $\mathrm{GC}, \mathrm{n}=33$ ).

Os 2 grupos foram semelhantes no género (masculino: $54,5 \%$ vs $51,5 \%$ ), idade ( 50 anos), tempo de diálise ( 52 vs 50 meses $(m)$ ), tempo de isquemia fria, grau de sensibilização ( $4 \%$ vs $9 \%$ ) e principais comorbilidades. A mediana do seguimento foi $43 \mathrm{~m}$ no GD e $27 \mathrm{~m}$ no GC ( $p=n s$ ).

Os níveis basais de calcidiol foram semelhantes em ambos os grupos (18,6 vs. $17,1 \mathrm{ng} / \mathrm{ml})$ bem como restantes valores laboratoriais, excepto a calcemia $(10,1$ no $\mathrm{GD}$ vs $10,2 \mathrm{mg} / \mathrm{dl}$ no $\mathrm{GC}$ ). Encontrámos aumento significativo e consistente nos níveis de calcidiol $(\mathrm{ng} / \mathrm{ml})$ aos $6 \mathrm{~m}(38,4$ vs 19,6$), 12 \mathrm{~m}(42,2$ vs 18,3$), 24 \mathrm{~m}$ $(43,3$ vs 18,5$), 36 \mathrm{~m}(48,6$ vs 17,8$)$ e aos $42 \mathrm{~m}(49,9$ vs 18,8$)$ sem aumento da calcemia mas com redução significativa da PTHi (pg/ml) aos $6 \mathrm{~m}$ (88 vs. 123), $12 \mathrm{~m}$ ( 82 vs 107), $24 \mathrm{~m}$ ( 81 vs 101$), 36 \mathrm{~m}$ (76 vs 150 ) e aos $42 \mathrm{~m}$ (70 vs 140 ), no GD em relação ao GC. Também não houve diferenças na evolução da fracção de excreção de $\mathrm{Ca}, \mathrm{P}$, ou $\mathrm{Mg}$.

Sem diferenças na relação proteina/creatinina urinária, pressão de pulso, índice de massa ventricular esquerda ou hospitalizações. O tratamento com antihipertensores, vitD ativa ou cinacalcet foi semelhante nos 2 grupos. Não houve diferenças na sobrevida do enxerto (1 perda em cada grupo) ou do paciente (1 falecido no GC).

A suplementação de $4000 \mathrm{UI} /$ dia de colecalciferol mostrou-se segura e permitiu subir os níveis de calcidiol no GD e reduzir a PTHi aos 6,12, 24, 36 e aos 42 meses, em comparação com o GC.

Palavras-chave : vitamina D, PTH, resultados
C003-006

TREATMENT OF PERSISTENT HYPERPARATHYROIDISM AFTER RENAL TRANSPLANT: SINGLE CENTER EXPERIENCE.

Gabriel Giollo Rivelli; Marcelo Lopes De Lima; Marilda Mazzali

1 - Programa de Transplante Renal - Universidade Estadual de CampinasUNICAMP

Background: Hyperparathyroidism is a frequent complication in chronic kidney disease and may persist after transplant in 20 to $50 \%$ of cases, manifest by hypercalcemia and hypophosphatemia. Persistent disease is associated with an increase in the incidence of cardiovascular events, fracture and death. Therapeutic options currently available are parathyroidectomy (PTX) and therapy with calcimimetic agent cinacalcet.

Methods: Single-center retrospective study including adult renal transplant recipients who developed hipercalcemia due to persistent hyperparathyroidism. Criteria for treatment: Elevated PTH with serum calcium $>11 \mathrm{mg} / \mathrm{dL}$ at any time after transplantation or serum calcium persistently higher than $10.2 \mathrm{mg} / \mathrm{dl}$ one year after transplantation. Patients treated with cinacalcet $(n=46)$ were compared to patients treated with parathyroidectomy $(n=30)$. The follow up period was 1 year. Demographic and laboratory data were analyzed. In the cinacalcet group, episodes of rejection and medication tolerance were also analyzed.

Results: PTX controlled the calcemia faster and reached significantly lower levels in the long term; PTX showed significantly higher levels of serum phosphate and returned PTH to normal levels. Cinacalcet, despite of controlling calcium and phosphorus in the long term, did not correct PTH. The proportion of patients that remained with PTH above normal range was $95 \%$ in the cinacalcet group and $22 \%$ in the PTX group. Patients treated with cinacalcet had better renal function. The drug was well tolerated and no rejection episode was detected.

Conclusions: The surgical treatment was superior to cinacalcet to correct the metabolic disorders of hyperparathyroidism; however, it was associated with worse renal function in the long term. Cinacalcet proved to be a safe and well tolerated drug.

Palavras-chave : hiperparatireoidismo, transplante renal, paratireoidectomia, cinacalcete

\section{CO03-007}

PREDICTIVE ROLE OF THE INDANA CV SCORE SYSTEM IN KIDNEY TRANSPLANT RECIPIENTS

José Alberto Rodrigues Pedroso; Maria Paola Salerno; Elisabetta Rossi; Evaldo Favi; Gionata Spagnoletti; Rosângela Munhoz Montenegro; Jacopo Romagnoli; Franco Citterio

Università Cattolica del Sacro Cuore, Roma, Italia

Purpose. Cardiovascular morbidity and mortality are a major cause of complication and death in renal transplantation. It is unclear whether cardiovascular scoring systems validated in the general population, could be predictive of Major Acute Cardiovascular Events (MACE) also in the renal transplant recipients $(\mathrm{KTX})$. Aim of this study was to evaluate the prognostic value of the Framingham and the INDANA score systems to predict MACE in KTx. Methods. Our study population included 359 consecutive KTx who underwent kidney transplantation between 1997 and 2007 at a single renal transplant unit. During the follow up period all the acute major cardiovascular events were recorded, and stroke, myocardial infarction, angina pectoris and cardiac death were considered MACE. The occurrence of MACE was related with well established cardiovascular risk factors as age, sex, arterial blood pressure, diabetes, renal function, CV history, BMI, dyslipidemia measured at 6 months, 5 and 10 years after transplantation. At these times the INDANA and Framingham scores were also calculated.

Results. Median follow up of the 359 pts included in the study was 135 months, mean age was $45+/-11$ years, median waiting time for transplant was 34 months (range 2.2 - 274.7).

During the follow-up, 22 patients (6.1\%) encountered MACE. Two MACE (0.55\%) occurred within 6 months post-tx; 10 occurred (3.1\%) between 6 months and 5 years and $10(6.5 \%)$ between 5 years and 10 years post-tx. The INDANA score at all the time period analyzed was significantly different in patients with or without MACE $(p<0.0001)$ while no significant difference was observed by means of the Framinghan score $(p<0.11)$.

Conclusions. Our study indicates that the INDANA scoring system can better predict the risk of MACE occurrence in KTx respect to the Framinghan scoring system. We hypothesize that the inclusion of renal function in the INDANA score may explain the better predictive capability of MACE in renal transplant recipients. The INDANA score could be used to plan selectively CV screening test in KTx.

Palavras-chave: cardiovascular events, risk factors, kidney transplant, prognostic scores, screening 


\section{C003-008}

SUPLEMENTAÇÃO COM COLECALCIFEROL EM RECÉM TRANSPLANTADOS RENAIS - IMPACTO NAS POPULAÇÕES LINFOCITÁRIAS?

Cristina Jorge'; Teresa Adragão'; Patrícia Matias'; Margarida Bruges; Rita Birne'; Rita Calça'; Regina Oliveira'; Ana Casqueiro'; Ma Jorge Arroz²; Ma Jorge Azinheira²; Sara Querido'; Célia Nascimento'; André Weigert'; Domingos Machado'

1 - CHLO, Hospital de Santa Cruz, Unidade de Transplantação Renal; 2 - CHLO, Hospital S Francisco Xavier, Serviço de Patologia Clínica

$A$ vitD influencia o sistema imunitário e parece ter efeito nos linfócitos $B$, mas o impacto da sua suplementação nos receptores de transplante renal (RTR) não está bem definido.

Verificámos prospectivamente os efeitos da suplementação com colecalciferol (4000 UI/dia) num grupo de recém ( $r$ ) RTR (GD, $n=33$ ), comparando-os com um grupo de rRTR sem suplementação ( $G C, n=33)$.

Os 2 grupos foram semelhantes no género (masculino: $54,5 \%$ vs $51,5 \%$ ), idade (50 anos), tempo de diálise ( 52 vs 50 meses $(m)$ ), tempo de isquemia fria, grau de sensibilização (4\% vs $9 \%$ ), presença de Ac anti_HLA I e II e principais comorbilidades. A terapêutica de indução (que incluiu ATG em 51\% do GD e 36\% do GC) e de manutenção (TAC + MMF + Pred em 97\% no GD e em 94\% no GC) foi semelhante nos 2 grupos. A mediana do seguimento foi $43 \mathrm{~m}$ no GD e $27 \mathrm{~m}$ no GC ( $p=n s)$.

Os níveis basais de calcidiol foram semelhantes em ambos os grupos (18,6 vs. $17,1 \mathrm{ng} / \mathrm{ml}$ ) bem como restantes valores laboratoriais, excepto a calcemia $(10,1$ no GD vs $10,2 \mathrm{mg} / \mathrm{dl}$ no GC). Os 2 grupos eram semelhantes também no no basal de linfócitos totais, linf-CD3, linf-CD4, linf-CD8, linf-CD19 e linf-CD16.

Encontrámos aumento significativo e consistente nos níveis de calcidiol $(\mathrm{ng} / \mathrm{ml})$ aos $12 \mathrm{~m}(42,2$ vs 18,3$), 24 \mathrm{~m}(43,3$ vs 18,5$), 36 \mathrm{~m}(48,6$ vs 17,8$)$ e aos $42 \mathrm{~m}(49,9$ vs $18,8)$ e nos valores dos linf-CD19 (céls/mm3) aos $30 \mathrm{~m}$ (197 vs 63), $36 \mathrm{~m}$ (184 vs 53 ) e aos $42 \mathrm{~m}$ (173 vs 65) no GD em comparação com o GC.

Sem diferenças nos episódios de rejeição ou hospitalizações entre os 2 grupos. A suplementação de $4000 \mathrm{UI} /$ dia de colecalciferol associou-se a elevação dos linf-CD19 a partir dos 30m no grupo suplementado. Estes dados devem ser confirmados com maior amostra e mais tempo de seguimento.

Palavras-chave: vitamina D, linfócitos, imunidade

\section{CO03-009}

DIABETES MELLITUS PÓS-TRANSPLANTE RENAL - AVALIAÇÃO DE FACTORES DE RISCO

Diana Cascais De Sá'; Lídia Santos'; Luís Rodrigues'; Catarina Romãozinho'; Maria Guedes Marques'; Fernando Macário'; Margarida Bastos'; Carla Baptista'; Rui Alves'; Arnaldo Figueiredo'

\section{1 - Centro Hospitalar e Universitário de Coimbra}

A diabetes mellitus pós-transplante (DMPT) é uma complicação da transplantação renal com efeitos deletérios na sobrevida do enxerto e do doente, aumentado a morbi-mortalidade deste último. É importante identificar factores de riscos para DMPT por forma a evitar o seu aparecimento, sendo o objectivo deste trabalho a identificação dos mesmos.

Foi realizada uma análise retrospetiva de 659 transplantes renais em adultos realizados entre Janeiro de 2013 e Dezembro de 2017. Destes, foram excluídos os doentes com diagnóstico prévio estabelecido de diabetes mellitus. Identificaram-se 61 doentes $(9,3 \%)$ com diagnóstico de DMPT, tendo estes sido comparados com doentes controlo livres de DMPT, nomeadamente o par ou o doente transplantado imediatamente a seguir. A DMPT foi definida por uma glicémia em jejum $\geq 126 \mathrm{mg} / \mathrm{dL}$, confirmada por um segundo doseamento em dia diferente.

$\mathrm{Na}$ análise comparativa entre os dois grupos, verificaram-se diferenças significativas em relação à utilização de beta-bloqueantes, glicémia ao 50 dia pós-transplante, idade do recetor e índice de massa corporal (IMC). Recorrendo a métodos de regressão logística multi-variada encontramos três variáveis com impacto no desenvolvimento de DMPT: utilização de beta-bloqueantes (odds ratio [OR] 0.420,95\% intervalo de confiança [IC] 0.181-0.979, $p=0.044)$, glicémia ao 5o dia pós-transplante (OR 1.044, 95\% IC 1.010-1.079, $p=0.010$ ) e IMC (OR $1.130,95 \%$ IC 1.009-1.264, $\mathrm{p}=0.034$ ). Não foram encontradas diferenças para outros potenciais factores de risco.

Em conclusão, poderá justificar-se explorar o potencial benefício associado à utilização de beta-bloqueantes. Uma glicémia elevada ao 5o dia e um IMC mais alto à data da transplantação devem promover maior atenção para o risco de desenvolvimento desta complicação. Devemos manter-nos alerta para o risco acrescido desta patologia com potencias consequências nefastas no recetor e envidar esforços na sua prevenção.

Palavras-chave : diabetes, DMPT, complicações
CO03-010

ESCORE DE GOWDAK NA AVALIAÇÃO DE DOENÇA ARTERIAL CORONÁRIA EM PACIENTES PRÉ-TRANSPLANTE RENAL

Paula Vitória Pereira Motoyama1; Felipe Medeiros Arruda1; Manuel Sampaio Teixeira Filho1; Carolina Cavalcante Cintra1; Ana Roberta Silveira Castro1; Rafael Cardoso Linhares Guedes1; Claudia Maria Costa De Oliveira2; Sonia Leite Da Silva3; Isabela Thomaz Takakura3

1 - Universidade de Fortaleza; 2 - Universidade Federal do Ceará; 3 Universidade Federal do Ceará / Universidade de Fortaleza

INTRODUÇÃO: Os pacientes candidatos ao transplante renal são de alto risco para doença arterial coronária. Foi validado escore por Gowdak em 2013, que usa cálculo de probabilidade de doença arterial coronária em pacientes prétransplante renal, utilizando os fatores de risco: diabetes, doença cardiovascular prévia e idade acima de 50 anos. OBJETIVO: Avaliar o perfil de pacientes transplantados renais quanto à probabilidade pré-transplante de possuírem doença arterial coronária (DAC) grave, de acordo com escore de Gowdak. MÉTODOS: Foram avaliados retrospectivamente, 175 pacientes transplantados renais nos anos de 2015 e 2016, sendo $58,8 \%$ do sexo masculino, com idade média de 43,5 anos. Desses, 73 pacientes foram considerados de alto risco para DAC de acordo com o escore de Gowdak, com média de idade de 55,8 anos, $46,6 \%$ possuíam diabetes, $17,8 \%$ possuíam doença cardiovascular e $37 \%$ tinham escore com probabilidade maior que $40 \%$ para DAC. $13,7 \%$ desses pacientes de alto risco para DAC foram submetidos à angiografia coronária. RESULTADOS: Comparando angiografia dos pacientes de alto risco com escore de Gowdak com probabilidade $\geq 40 \%$ para DAC (grupo 1) com angiografia dos pacientes de alto risco com escore com probabilidade $<40 \%$ para DAC (grupo 2 ), foi vista diferença estatística entre os grupos $(P<0,001)$, pois grupo 2 não apresentou nenhuma lesão obstrutiva coronária acima de $70 \%$, enquanto o grupo 1 apresentou várias lesões coronárias obstrutivas acima de 70\%. Mortalidade pós-operatória dos pacientes de alto risco foi 5,5\% e nenhuma morte cardiovascular ocorreu. CONCLUSÃO: Os pacientes pré-transplante renal com escore de Gowdak com alta probabilidade para DAC possuem doença arterial coronária mais grave do que os pacientes com escore abaixo de $40 \%$, de acordo com os resultados da angiografia. Porém, apesar desses achados, mesmo os pacientes com alta probabilidade para DAC não submetidos à angiografia coronária no pré-transplante, não apresentaram eventos cardiovasculares no pós-operatório hospitalar.

Palavras-chave : doença arterial coronária; transplante renal; risco cirúrgico; escore de Gowdak

\section{CO03-011}

TRANSPLANTE RENAL ASSOCIADO A REDUÇÃO DE FIBROSE MIOCÁRDICA: ESTUDO DE RESSONÂNCIA MAGNÉTICA

Mariana Moraes Contti; Luis Gustavo Modelli De Andrade; Hong Si Nga; Mariana Farina Valiatti; Guilherme Palhares Aversa Santos; Maurício Fregonesi Barbosa; Alejandra Del Carmen Villanueva Mauricio

\section{1 - Hospital das Clínicas da Faculdade de Medicina de Botucatu}

Introdução: Pacientes com doença renal crônica estágio 5 têm risco aumentado para doenças cardiovasculares, e a fibrose miocárdica é um fator fortemente envolvido. Após o transplante renal ocorre redução desse risco. Considerado marcador de fibrose miocárdica para pacientes em hemodiálise, o T1 nativo do miocárdio, medido por Ressonância Magnética Cardíaca (RMC), não necessita usar contraste. Até o momento não existe nenhum estudo que avalie fibrose miocárdica por meio do T1 nativo após o transplante renal.

Objetivo: Avaliar a variação do valor do T1 nativo do miocárdio, 6 meses após o transplante renal.

Métodos: Quarenta e quatro pacientes transplantados renais foram submetidos a dois exames de RMC: o primeiro nos primeiros 10 dias do transplante e o segundo 6 meses após. Todos os exames foram realizados sem contraste, no mesmo aparelho de Ressonância (3 Teslas).

Resultados: Foi observada redução estatisticamente significante no valor do T1 nativo, de $1331( \pm 52)$ ms para $1298( \pm 42)$ ms, 6 meses após o transplante, $p=0,001$. Os 44 pacientes foram divididos em 2 clusters: Cluster 1 , com 30 pacientes, e cluster 2 , com 14 pacientes. No cluster 1 não havia nenhum paciente com Diabetes Mellitus. No cluster 2 , por sua vez, todos os pacientes eram diabéticos $(p=0,001)$. A queda no valor de T1 foi significativa apenas no grupo do cluster $1(p=0,001)$. Além disso, a massa do ventrículo esquerdo indexada (MVEi) no momento inicial (nos primeiros 10 dias de transplante), foi significativamente maior no cluster 2 $(93 \pm 19 \mathrm{~g} / \mathrm{m} 2)$ do que no cluster $1(83 \pm 17 \mathrm{~g} / \mathrm{m} 2), \mathrm{p}=0,02$.

Conclusão: 0 tempo do T1 nativo do miocárdio diminuiu significativamente 6 meses após o transplante renal, demonstrando provável redução da fibrose miocárdica. $\mathrm{O}$ grupo de pacientes que não apresentaram queda significativa do T1 era composto na sua totalidade de diabéticos, com maior MVEi inicial.

Palavras-chave : Transplante Renal, Fibrose Miocárdica, Ressonância Magnética, T1 nativo 
CO05-001

ABO-INCOMPATIBLE KIDNEY TRANSPLANTATION: PORTUGAL'S EXPERIENCE

Rachele Escoli'; Sara Rodrigues ${ }^{2}$; Catarina Eusébio ${ }^{3}$; Manuela Almeida4; Sofia Pedroso ${ }^{4}$; La Salete Martins ${ }^{4}$; Leonídio Dias ${ }^{4}$; António Castro Henriques ${ }^{4}$; António Cabrita ${ }^{4}$

1 - Centro Hospitalar do Médio Tejo; 2 - Centro Hospitalar de Vila Nova de Gaia; 3 - Centro Hospitalar de Trás-os-Montes e Alto Douro; 4 - Centro Hospitalar do Porto

With the incessantly increasing number of patients on the waiting list for a renal transplant (RT), ABO-incompatible (ABOi) RT has been accepted as a valid option for end stage renal disease and can substantially increase the donor pool. The aim of this study was to report our experience with ABOi RT.

Methods: Retrospective observational study with all ABOi RT performed between 2014-2017. Preconditioning protocol consisted of: rituximab one-tothree weeks before RT, plasmapheresis (PP) in the week before transplantation and CMV hyperimmune intravenous (iv) immunoglobulin (Ig). Induction immunosuppression comprised basiliximab, tacrolimus, mycophenolate mofetil and prednisolone. Results: Seven patients received a ABOi RT. The mean age was $43,7 \pm 11,6(30-60)$ years and $71,4 \%$ were man. Six were already in dialysis ( 4 in hemodialysis, 2 in peritoneal dialysis) and it was a pre-emptive $\mathrm{RT}$ in one patient. All patients received a kidney from a living related donor. Mean HLA mismatches were 2,1 \pm 1 . Anti-blood group antibody titer varied from 1:8 to 1:128. Two also had donor-specific HLA-DQ antibodies with mean fluorescence intensity of 1187 and 1566 . The mean number of PP sessions was $4,1 \pm 5,3$. Within the first week, one cellular mediated rejection episode occurred resolved with methylprednisolone pulses and anti-thymocyte globulin (ATG). After an average follow-up period of 17,6 613 months(range 3-37), one rejection episode mediated by non-HLA antibodies occurred, which was reversed with methylprednisolone pulses, 6 PP sessions, CMV hyperimmune IV Ig and RTX. At present, all patients are alive and there was no graft loss. The mean estimated GFR in last follow-up was $55,4 \pm 10,5 \mathrm{~mL} / \mathrm{min} / 1,73 \mathrm{~m} 2$. Conclusions: Despite the small sample size and short follow-up, ABOi RT had favorable clinical outcomes. It allowed patients to be transplanted with a shorter dialysis time, to leave deceased donors waiting list, allowing other patients to get transplanted sooner.

Palavras-chave : $\mathrm{ABO}$ incompatible

\section{CO05-002}

TRANSPLANTE RENAL DE DADOR-VIVO: OUTCOMES DOS DADORES A LONGO PRAZO. EXPERIÊNCIA DE UM CENTRO.

Catarina Pereira Eusébio'; Sofia Correia2; Manuela Almeida²; Sofia Pedroso²; La Salete Martins ${ }^{2}$; Leonídio Dias ${ }^{2}$; António Castro Henriques ${ }^{2}$

1 - Serviço de Nefrologia, Centro Hospitalar de Trás-os-Montes e Alto Douro; 2 - Serviço de Nefrologia, Centro Hospitalar do Porto

Introdução: $O$ transplante renal (TR) de dador -vivo está associado a melhor sobrevida do enxerto e do receptor e permite diminuir o impacto da escassez de órgãos. Contudo a segurança dos dadores é prioritária, sendo fundamental documentar qual o impacto na função renal dos mesmos. Métodos: Estudo retrospectivo, unicêntrico, com revisão dos dadores de rim do nosso hospital. Foram colhidos dados demográficos, antropométricos e clínicos dos dadores, para caracterização desta população e seu follow-up a médio-longo prazo. Resultados: Entre 1987-2017 foram realizados 305 TR dador-vivo. A idade média dos dadores era 46士11anos [19-67anos] e a maioria eram do sexo feminino( $n=210 ; 69 \%)$. A fraternidade foi o principal grau de parentesco dos dadores $(n=45 ; 56 \%)$ até 2008 , altura em que a legislação portuguesa foi modificada. A partir desta data a maioria dos dadores eram não-aparentados $(n=82 ; 36 \%)$, e destes $82 \%$ cônjuges $(n=67)$. Dezoito dadores $(6 \%)$ tinham antecedentes de HTA e $38(12 \%)$ de dislipidemia, medicadas. O IMC médio era $25.3 \pm 3.2$ [17.4-34.0]. A CrS média pré-TR era $0.74 \pm 0.16 \mathrm{mg} / \mathrm{dL}[0.40-1.20 \mathrm{mg} /$ $\mathrm{dL}$ e a $\mathrm{CrCl}$ (Urina24h) $132 \pm 37 \mathrm{~mL} / \mathrm{min}[58-306 \mathrm{~mL} / \mathrm{min}$ ). Proteinúria média dos dadores no pré-TR: $128 \pm 63 \mathrm{mg} / 24 \mathrm{~h}$ [0-412mg/24h]. Em $85 \%$ dos casos $(\mathrm{n}=260)$ foi doado o rim esquerdo. A demora média do internamento foi $5 \pm 2$ dias [216 dias]. Após 1 ano a CrS média era $1.02 \pm 0.23 \mathrm{mg} / \mathrm{dL}[0.50-1.84 \mathrm{mg} / \mathrm{dL}]$. A mediana do follow-up foi 69 meses [1-353 meses]. Três doentes faleceram por motivos não relacionados com a doação e 29 perderam seguimento. Um dador evoluiu para DRC-5HD no contexto de transplante cardíaco pós-doação. Na última consulta de seguimento, a CrS média era $0.99 \pm 0.22 \mathrm{mg} / \mathrm{dL}[0.50-1.84$ $\mathrm{mg} / \mathrm{dL}$ ], a clearance da cistatina $84 \pm 16 \mathrm{~mL} / \mathrm{min}[38-130 \mathrm{~mL} / \mathrm{min}$ ] e proteinúria $106 \pm 123 \mathrm{mg} / 24 \mathrm{~h}[0-1300 \mathrm{mg} / 24 \mathrm{~h}$ ]. Trinta e três dadores (11\%) apresentaram HTA de novo e 52 (18\%) dislipidemia de novo. Conclusão: A doação renal, após selecção criteriosa, parece ser uma opção válida e segura para os dadores, com baixa probabilidade de progressão para DRC.

Palavras-chave : Transplante Renal, Dador-Vivo, Outcomes Dadores
CO05-003

LIVING-DONOR KIDNEY TRANSPLANT IN THE SETTING OF GLUCOSE-6PHOPHATE DEHYDROGENASE DEFICIENCY - A MEDICAL CHALLENGE

David Fiel1; André Weigert2; Rita Calça2; Eunice Cacheira2; Sara Querido2; Célia Nascimento2; Rita Birne2; Cristina Jorge2; Patrícia Matias2; Teresa Adragão2; Margarida Bruges2; Domingos Machado2

1 - Serviço de Nefrologia do Hospital do Espírito Santo de Évora; 2 - Serviço de Nefrologia do Hospital de Santa Cruz, CHLO

INTRODUCTION. Glucose-6-phosphate dehydrogenase (G6PD) is an enzyme with a critical role in preventing cellular damage due to oxidative stress, mainly in susceptible cells such as erythrocytes. Glucose-6-phosphate dehydrogenase deficiency (G6PDD), also known as Favism, is caused by an X-linked chromosomal mutation that results in acute hemolysis after exposure to an oxidative stressor. It is the most common enzyme deficit in humans and affects nearly $\mathbf{4 0 0}$ million people worldwide, mainly from African origin as it may confer survival advantage against malaria. We present a case that the particularities of this disease led to deviations of our renal transplant protocol.

CLINICAL CASE. A 31-year-old black male, CKD with membranous glomerulonephritis, started Renal Replacement Therapy in 2015 (peritoneal dialysis and then hemodialysis). History of Hypertension and G6PDD with an episode of a hemolysis crisis. In pre-transplant evaluation, a provocative test with mycophenolate mofetil (500mg po $12 / 12 \mathrm{~h}, 14$ days) was negative (without haptoglobin or hemoglobinemia variations), but tacrolimus (5mg po 12/12h, 14 days) caused some doubts as an increase of hemoglobinemia with normal haptoglobin and hemoglobin was detected. Patient received a living-donor kidney transplant from his mother, also with G6PDD, 2 mismatches (A and B), without DSAs, induction immunosuppressive therapy with Thymoglobulin, MMF and Prednisolone followed by Tacrolimus with tight analytic control, which did not unveil hemolysis. Eviction of some analgesic drugs (paracetamol, metamizol) and antibiotics (trimethoprim-sulfamethoxazole) usually prescribed in the post-transplant scenario but contraindicated in G6PDD was mandatory. Infection prophylaxis was achieved with atovaquone and valganciclovir.

CONCLUSION. We describe a successful case of a living-donor kidney transplantation in the setting of G6PDD in both donor and recipient, warning to its idiosyncrasies and obligatory drug readjustments.

Palavras-chave : Glucose-6-phosphate dehydrogenase, kidney, transplant

\section{CO05-004}

ESTADO NUTRICIONAL COMO PREDITOR DE DESFECHOS NO TRANSPLANTE RENAL

Milena Dos Santos Mantovani1; Nyara Coelho De Carvalho1; Thomáz Eduardo Archangelo1; Luis Gustavo Modelli De Andrade1; Silvia Justina Papini1; Sebastião Pires Ferreira Filho1; Ricardo De Souza Cavalcante1; Ricardo Augusto Monteiro De Barros Almeida1

\section{1 - Faculdade de Medicina de Botucatu-UNESP, Botucatu, SP, Brasil.}

A avaliação do estado nutricional pré-transplante renal (TxR) mostra-se bastante relevante. Porém, há escassa evidência científica sobre o assunto. $O$ objetivo deste estudo foi avaliar o estado nutricional como preditor de desfechos do TxR. Imediatamente antes do TxR, realizou-se avaliação do índice de massa corporal (IMC) e análise da composição corporal através de bioimpedância multifrequencial. Estas avaliações foram relacionadas aos desfechos função tardia do enxerto, complicações infecciosas e não infecciosas, reinternação, rejeição aguda e perda do enxerto, óbito e clearence de creatinina final. $\mathrm{O}$ seguimento foi de três meses. Foram incluídos 77 indivíduos. Serão apresentados neste resumo dados relacionados aos 56 indivíduos que já completaram o seguimento. Predominaram pacientes do sexo masculino (60,7\%). A idade média foi de 45,2 anos. Prevaleceram os doadores falecidos (78,6\%). A hemodiálise foi a terapia renal substitutiva mais prevalente $(85,7 \%)$. O esquema de indução da imunossupressão (IS) predominante foi a timoglobulina $(96,4 \%)$ e o esquema de manutenção da IS mais frequente foi tacrolimo/everolimo/prednisona (50,0\%). A avaliação do IMC pré-TxR indicou eutrofia em $41,1 \%$, sobrepeso em $35,7 \%$, obesidade em $16,1 \%$ e desnutrição em $7,1 \%$ dos pacientes. Em relação à composição corporal, $66,1 \%$ dos pacientes apresentavam massa de gordura $(\mathrm{kg})$ acima do recomendado e massa muscular $(\mathrm{kg})$ abaixo do recomendado em $17,8 \%$. A água corporal total (L) apresentava-se dentro da normalidade em $78,5 \%$ dos pacientes. Em 14,3\% dos pacientes, a água extracelular e intracelular apresentavam-se abaixo do recomendado. O IMC não se associou com qualquer desfecho. Massa muscular baixa mostrou-se associada ao óbito $(p=0,03)$, indivíduos com água intracelular abaixo do recomendado apresentaram maior frequência de infecção do sítio cirúrgico $(p=0,048)$ e os indivíduos com água extracelular abaixo do preconizado apresentaram clearance de creatinina final $<60 \mathrm{~mL} / \mathrm{min} / \mathrm{m}^{2}$ em maior proporção $(p=0,006)$. Apoio: processo no 2016/24745-3, Fundação de Amparo à Pesquisa do Estado de São Paulo (FAPESP).

Palavras-chave : Estado nutricional, Composição corporal, Transplante renal 


\section{CO05-005}

EVALUATION OF A PHYSICAL-CHEMICAL PROTOCOL FOR PORCINE TRACHEAL DECELLULARIZATION

Alberto Bruning Guimaraes'; Aristides Tadeu Correia'; Bruno Paulo Alves'; Ronaldo Soares Da Silva'; Juliana Kitagawa Martins²; Paulo Manuel PêgoFernandes²; Paulo Francisco Guerreiro Cardoso²; Natalia De Souza Xavier ${ }^{3}$; Marisa Dolhnikoff ${ }^{4}$

1 - Laboratorio de Investigaçao Médica - LIM 61, Instituto do Coração, Hospital das Clinicas HCFMUSP, SP, BR; 2 - Laboratorio de Investigaçao Medica - LIM 61, Instituto do Coração, Hospital das Clinicas HCFMUSP, SP, BR; 3 - Laboratório de Poluição Atmosférica Experimental (LIM05), Departamento de Patologia, FMUSP, SP, BR; 4 - Departamento de Patologia, FMUSP, SP, BR

Introduction/Objective: Tracheal resection with primary reconstruction is the definitive treatment for many tracheal benign and malignant diseases. When primary reconstruction is not deemed feasible as a result of the length of the stenosis, airway transplantation may become a solution. The tissue engineering field offers a new possible of treatment. The development of tracheal allograft transplantation includes the decellularized tracheal scaffolds made of extracellular matrix that are seeded with the receptor's cells. Many protocols are used to obtain a decellularized scaffold. Most of them consist of cyclical physical-chemical steps with enzymes. This study proposes a protocol for decellularization without the use of enzymes. Methods: Decellularization of pig tracheas segments was carried out using a standardized protocol consisting of freezing and thawing, and 10 cycles of agitation, exposure to sodium deoxycholate and washing. We determinate decellularization by quantifying the residual DNA using the TRIzol protocol and absorbance analysis in a Nanodrop equipment. We also analyzed the morphology under HE staining. Results: 32 porcine tracheal segments were decellularized. All scaffolds obtained showed less than $6 \%$ of residual DNA (mean $1105,7 \pm 690,5 \mathrm{ng} / \mathrm{mg}$ ) when compared to the fresh samples (mean $39474,6 \pm 2203,6 \mathrm{ng} / \mathrm{mg}$ ) $p=0,023$. Morphologica analysis showed that the epithelium was completely removed. It was possible to identify residual nuclear material inside the cartilaginous portion, as reported in literature. Conclusion: The tested protocol was able to provide effective decellularization of porcine tracheas.

Palavras-chave: Traqueia / Transplante / Descelularização

\section{C005-006}

DOAÇÃO DE ÓRGÃOS E TECIDOS PARA TRANSPLANTES: VARIÁVEIS DETERMINANTES NA TOMADA DE DECISÃO FAMILIAR.

Leonardo Borges De Barros Silva1; Edvaldo Leal Moraes1; Luis Augusto Sales Lima Pilan1; Paulo Roberto Gradella1; Eloisa Aparecida Avelino Lima1; Sônia Regina Theodoro1; Marcelo José Dos Santos1; Nair Cordeiro Dos Santos Paixão1

1 - Hospital das Clínicas da Faculdade de Medicina da Universidade de São Paulo

Introdução: Na atualidade, a temática sobre doação de órgãos e tecidos para transplantes encontra-se cada vez mais presente na vida de muitas famílias em todo o mundo, seja pela necessidade de decidir sobre o destino que darão aos órgãos e tecidos do parente falecido ou pela necessidade de um transplante. Dessa forma, a família é o elemento mais importante nesse processo, sendo apontada como o principal obstáculo à efetivação da doação. Objetivo: Conhecer quais são as variáveis determinantes na tomada de decisão familiar, frente à possibilidade de doação de órgãos e tecidos para transplante de um ente querido com diagnóstico de morte encefálica. Método: Estudo documenta obtido em uma Organização de Procura de Órgãos da cidade de São Paulo. Foram analisadas 529 entrevistas realizadas com familiares de doadores elegíveis em morte encefálica, nos anos de 2016 e 2017. Resultados: A taxa de autorização familiar foi de $64 \%$ e quando mais de três familiares estavam envolvidos na tomada de decisão havia maior probabilidade de doação $(p<0.001)$. Conhecer a vontade do falecido é fator determinante para recusar ou doar os órgãos e tecidos para transplante $(p<0.001)$. Cônjuge, filhas ou pais doam menos quando comparados com outro membro da família $(p=0.003)$. Conclusões: O presente estudo permitiu concluir que mais de três familiares envolvidos no processo de decisão e conhecer a vontade do falecido, em vida, são os únicos fatores determinantes para a tomada de decisão familiar.

Palavras-chave: Morte Encefálica; Transplante de Órgãos; Obtenção de Tecidos e Órgãos; Família; Tomada de Decisões.
CO05-007

A AUTONOMIA DA FAMÍLIA NO PROCESSO DE DOAÇÃO DE ÓRGÃOS E GAMETAS - UMA ANÁLISE ÉTICA E LEGAL

Luiz Antonio Da Costa Sardinha; Venancio Pereira Dantas Filho; Helder Jose Lessa Zambelli; Sebastião Araujo; Ilka De Fatima Santana Ferreira Boin UNICAMP - Brasil

A solicitação de coleta de sêmen post mortem não é algo novo na literatura. Nos anos 1980, Rothman (1980)1 descreveu a primeira coleta de sêmen em paciente em ME e a solicitação por parte dos familiares de coleta de material genetico. Todo o processo de doação de órgãos e tecidos em paciente com diagnóstico de $\mathrm{ME}$, encontra-se muito bem regulamentado e legalizado na maioria dos países, inclusive no Brasil. Objetivo: Relato de dois casos de pacientes masculinos em ME que foram notificados à Organização de Procura de Órgãos do Hospital de Clínicas da Unicamp (OPO-HC-Unicamp), e a solicitação de coleta de sêmen post mortem com finalidade de inseminação artificial, e realizar revisão de literatura sobre as questões éticas e legais referentes à doação de órgãos e gametas post mortem e situação ética enfrentada pelo médico. Metodo: Pesquisa documental por meio de levantamento bibliográfico com buscas em plataformas digitais (Google scholar, PubMed, Scielo Brasil, Lilacs). Avaliamos as legislações existentes em países latino-americanos que fazem parte da Organização Panamericana de Saúde, incluindo o Brasil, e comparamos com Espanha, Portugal, União Européia e Austrália. Discussão: Dividida entre a coleta de material germinativo post mortem de acordo com os personagens envolvidos no conflito: o falecido; parte solicitante, que pode ser a(o) esposa(o), a família; o médico envolvido no processo; a sociedade e a criança a ser gerada. Conclusão: A situação descrita no presente trabalho evidencia a necessidade de regulamentação e modernização das estruturas jurídicas e de seus conflitos. Necessário a continuidade da discussão com os personagens envolvidos no processo, médico, juristas e a família, frente a uma demanda crescente da sociedade e do destino de material genético do falecido. Uma decisão baseada em critérios éticos pode ser satisfatórias, mas pode estar em conflito com as legislações atuais.

Palavras-chave: doação de semen post mortem

\section{C005-008}

OS PLURAIS ASPECTOS DA ATUAÇÃO DO PSICÓLOGO NA DOAÇÃO DE ORGÃOS. Luiz Antonio Silva

Hospital Estadual Alberto Torres

Este estudo versa-se na atuação do psicólogo exclusivo de uma Cihdott no Rio de Janeiro Brasil com $95 \%$ de famílias demonstrando maior satisfação com a vida. Ações e dinâmicas acerca da psicologia cognitiva positiva comportamental envolve o ato do plantio de um Jasmim oferecido pelo Hospital onde o profissional atua como Cihdott representando a coragem e o órgão vivo a ser implantado no receptor. O objetivo deste estudo versa na participação e no conhecimento das demandas e impactos laborais da atuação do psicólogo na reelaboração do luto pós diagnóstico de morte cerebral, e na informação continuada dos familiares durante todo o processo que envolve o trabalho desse profissional na entrevista familiar.

A partir do marco da morte encefálica, tem-se o interesse de desenvolver uma pesquisa a fim de conhecer os principais elementos inerentes ao trabalho do psicólogo que se envolvem na informação da família, na empatia e envolvimento e nos limites, dificuldades e possibilidades que podem formar a atuação psicológica e seus impactos positivos.

Estudos reforçam que a doação por pressão dominante ou mercantilização (mais comum inter vivos) ou ainda a recepção de benefícios são bases muito distintas do altruísmo genuíno no doar. O medo de como a negativa será interpretada, a necessidade financeira de tomar a decisão e uma série de outros fatores concorrem nesses casos, em que o outro pode ser parte das considerações, mas não o seu centro. A dor, o sofrimento e a subjetividade do indivíduo podem ser suplantadas em avaliações superficiais, conduzindo a decisões que nem sempre se quadrem em sua realidade interior frente à doação.

Palavras-chave : Altruísmo; Psicologia Hospitalar; Doação de órgãos; Entrevista Familiar e Luto. 


\section{CO05-009}

A IMPORTÂNCIA DA INTRODUÇÃO DA VASOPRESSINA NA MANUTENÇÃO DO POTENCIAL DOADOR DE ÓRGÃOS EM UM HOSPITAL PUBLICO DO INTERIOR DE SÃO PAULO

Elizangela Carvalho Azevedo; Juliana Daniely Duarte; Felipe Jesus Gonçalves; Maria Cristina Pose Guerra; Fernanda Ferreira Macêdo; Renata Mantovani; José Maria Nascimento; Rogério Xavier Nascimento

Hospital Municipal José de Carvalho Florence

INTRODUÇÃO: A diferença entre a demanda por transplante de órgãos e a baixa realização de transplante é um grave problema de saúde pública. As atividades de reconhecimento de morte encefálica, a manutenção e a entrevista familiar são primordiais para mudar esse cenário'. Um estudo publicado em 2012 no The American Journal of Surgery com mais de 10 mil potenciais doadores (PD) conclui que o uso da vasopressina aumentou em torno de $30 \%$ o número de doadores efetivos de órgãos e em $15 \%$ os órgãos utilizados, com destaque para o uso do coração, órgão sensível a altas doses de drogas vasoativas como a noradrenalina e a dopamina, bem como o pulmão e outro órgão beneficiado com o uso da vasopressina ${ }^{2}$. Em 2017 introduzimos o uso da Vasopressina em nosso Hospital, para os Potenciais doadores, através de um protocolo institucional, o que resultou no hospital que mais doou corações no estado de São Paulo e o que mais foi efetivo na Organização de Procura de Órgãos (OPO) da Unicamp em 2017. OBJETIVO: Comparar a efetividade de órgãos captados entre os anos de 2016 e 2017, sendo o último ano o início do protocolo. RESULTADOS: 2016 foram 21 morte encefálicas notificadas, 7 doadores de órgãos. Das captações: 0 coração, 6 Fígados, 12 Rins, 10 Córneas. Já em 2017 notificamos 32 morte encefálicas, tivemos 13 doadores. Das captações em 2017: 9 corações, 12 Fígados, 25 Rins, 24 córneas. Houve uma mudança significativa em número de órgãos captados após a implantação da Vasopressina, evidenciando que a mesma corrobora para manutenção do potencial doador. REFERENCIAS: 1.Westphal GA, Caldeira FM, Vieira KD, Zaclikevis VR, Bartz HCM, Wanzuita, $\mathrm{R}$ et al. Diretrizes para manutenção de múltiplos órgãos no potencial doador adulto falecido. Parte I. Aspectos gerais e suporte hemodinâmico. Joinville: ver Brasileira de Terapia intensiva. 2011. 2.https://www.uptodate.com/contents/ vasopressin-drug information?source=search_result\&search=vasopressina\&s electedTitle $=1 \sim 150$

Palavras-chave : Morte Encefálica, Potencial Doador, Manutenção, vasopressina

\section{CO05-010}

\section{RETHINKING SCREENING FOR STRONGYLOIDIASIS BEFORE TRANSPLANT}

Sofia Correia'; Filipa Santos Silva'; Manuela Almeida'; Cristina Freitas'; Sandra Tafulo²; Ana França'; ${ }^{2}$ Josefina Santos'; Sofia Pedroso'; António Cabrita'; Leonidio Dias'; La Salete Martins'; António Castro Henriques'

\section{1 - Nephrology and transplant unit, Centro Hospitalar do Porto; 2 - IPST}

Testing for strongyloidiasis is appropriate in several occasions, because even a short courses of corticosteroids have led to overwhelming hyperinfection and death. Current indications for testing are: transplant candidates prior to immunosuppression if they have a potential exposure history and transplant donors from endemic areas. Since Portugal is not considered an endemic area, this test is not routinely used.

A 68-year-old male patient with chronic kidney disease stage 5 of unknown cause and hypertension was submitted to preemptive deceased donor kidney transplant in February'2018. Induction immunosuppression was based on basiliximab, mycophenolate mofetil (MMF), tacrolimus and prednisolone. The donor had known alcoholic habits and the cause of death was hemorrhagic stroke. Donor and receptor were CMV positive, B blood type, and he was treated with prophylactic valganciclovir. He had immediate diuresis and favorable evolution, at the date of discharged $\mathrm{Cr} 2.58 \mathrm{mg} / \mathrm{dl}$.

Two months later he went to the emergency department for vomiting and dyspnoea. He was hospitalized for septic shock with pneumonia, requiring mechanical ventilation. Bronchofibroscopy was performed, identifying Nematode larvae, later characterized and confirmed to be Strongyloides stercoralis. Despite the start of treatment with Ivermectin on the 3rd day of hospitalization, the patient died.

Subsequently, serology was requested in the blood of the donor, which was confirmed to be positive.

Discussion: After reporting sporadic cases, will it be beneficial to screen all candidates? In our point of view, the cost-benefit of preventing a potentially fatal infection is favorable to this screen. Transplant candidates should be tested and detection of donor strongyloides infection should prompt prophylaxis for recipients after transplantation.

Palavras-chave : serology; infection; immunosuppression; strongyloidiasis
C007-001

DIFERENCIAÇÃO IN VITRO DE CÉLULAS-TRONCO PLURIPOTENTES INDUZIDAS (IPS) CÉLULAS PROGENITORAS RENAIS

Patricia de Carvalho Ribeiro'; Fernando Henrique Lojudice ${ }^{2}$; Ida Maria Maximina Fernandes-Charpiot'; Maria Alice Sperto Ferreira Baptista'; Mari Cleide Sogayar²; Mario Abbud-Filho'; Heloisa Cristina Caldas'

1 - Faculdade de Medicina de São José do Rio Preto; 2 - Universidade de São Paulo - USP

Introdução: A terapia com células-tronco representa uma estratégia promissora para a insuficiência renal crônica (IRC), especialmente o uso de células progenitoras renais (RPCs) e células-tronco pluripotentes induzidas (iPS). Objetivos: os objetivos deste trabalho foram: 1) reprogramar geneticamente células humanas de sangue periférico em iPS; 2) induzir a diferenciação das iPS obtidas em células progenitoras renais. Metodologia: As células iPS geradas foram induzidas à diferenciação, durante 10 dias, através da utilização de meio de cultura basal acrescido de fatores nefrogênicos: ácido retinóico, activina-A, e BMP7. Após a diferenciação, houve alteração morfológica das células, as quais apresentaram-se semelhantes a podócitos. Para a caracterização celular, foram realizados ensaios de imunofluorescência e expressão gênica. Resultados: Após os 10 dias de diferenciação, as células obtidas apresentaram marcação positiva na imunofluorescência para as proteínas Wilms Tumor 1 (WT1), PAX2, Sinaptopodina (SYNPO) e Nefrina (NPHS1), e aumento da expressão dos genes PAX2, WT1, SIX2, SYNPO, NPHS1, além de diminuição da expressão do gene de pluripotência OCT4, indicando a diferenciação bem sucedida das células iPS em progenitoras renais. Conclusão: A geração de RPCs é possível e poderá ser utilizada para potencial tratamento da IRC, de formar a retardar ou reverter seu processo de cronificação.

Palavras-chave : Células-tronco, Insuficiência renal crônica, Terapia celular

\section{C007-002}

\section{MOLECULAR BIOMARKERS IN EXTENDED CRITERIA KIDNEY DONORS}

Greiciane Maria da Silva Florim; Naiane Nascimento Gonçalves; Ida Maria Maximina Fernandes-Charpiot; Maria Alice Sperto Ferreira Baptista; Heloisa Cristina Caldas

\section{Faculdade de Medicina de São José do Rio Preto}

Background. Changes to an organ can occur at the time of brain death and a series of inflammatory proteins are generated within that organ. It is not known whether this inflammatory similarly affects the kidneys from extended (ECD) and standard (SCD) criteria donors and because we have previously reported that preimplantation kidney biopsies from ECD donors have a heavier inflammatory profile when compared with SCD donors. In the present study we extended our results using great number of genes and seeking to identify some immunologic pathways involved in the mechanism of sterile inflammation. Methods. Pretransplant kidney biopsies ( $\mathrm{Bx}$ ) were obtained from $\operatorname{ECD}(n=40)$ and SCD $(n=40)$. Gene expression profile measured by Real Time qPCR Array representing expression levels of genes indicative of inflammation (IL-10, IL-1b, TNF- $\alpha$, MCP-1, NFK-b, TLR-4, HMGB1, IFN-gamma, TGF-b, MyD-88), cytoprotection (HO-1, HIF-1a), apoptose (CASP-1) and intercellular adhesion (ICAM-1 ) and correlated with donor variables. Results. ECD donors were older had more cerebrovascular accident, arterial hypertension and diabetes $(p<0.01)$ and recipients of ECD kidneys had renal function and $24 \mathrm{~h}$ proteinuria worst 1 year after transplantation $(p<0.006)$. Genes IL-10, IL-1 $\beta$, TLR-4, HMGB-1, HIF-1 and CASP-1 were significantly more expressed in biopsies from ECD than SCD. Presence of DGF, acute rejection, was not associated with any individual transcript. Conclusions: The present results confirm and expand our previous findings that ECD kidney is highly inflamed when compared with SCD and that a MyD-88 independent pathway of innate immunity may be activated.

Palavras-chave : Transplante renal, biomarcadores, doador de criterio estendido 


\section{CO07-003}

OS NIVEIS CÉLULAS PROGENITORAS ENDOTELIAIS CD133+ ASSOCIAM-SE DE FORMA INDEPENDENTE COM A FUNÇÃO ENDOTELIAL E COM A REDUÇÃO DA FILTRAÇÃO GLOMERULAR EM DOENTES TRANSPLANTADOS RENAIS

Susana Sampaio'; Janete Santos'; Luís Mendonça'; Sandra Martins'; Ana Cerqueira'; Manuel Pestana'

1 - Instituto de Investigação e Inovação em Saúde (i3S), Universidade do Porto, Portugal; 2 - Instituto de Engenharia Biomédica (INEB)- Nephrology and Infectious Diseases Group; 3 - Department of Renal, Urological and Infectious Diseases, FMUP, Porto, Portugal; 4 - Department of Nephrology, São João Hospital Center, Porto, Portugal

INTRODUÇÃO E OBJETIVOS: A disfunção endotelial está subjacente ao aumento da mortalidade cardiovascular na Doença Renal Crónica. Observações recentes sugerem que as células progenitoras endoteliais (CPE) podem funcionar como um sistema regenerador endógeno do endotélio.

O objetivo deste estudo foi avaliar a função endotelial (FE), os níveis circulantes de CPE's, níveis de eritropoetina, e terapêuticas concomitantes que possam influenciar esses níveis, numa coorte de doentes transplantados renais (TxR)

MÉTODOS: Os níveis de CPE's no sangue foram avaliados por citometria de fluxo multicolor. A FE foi avaliada por tonometria em que o Índice de Reatividade e Hiperemia (IRH) < 1.65 corresponde a disfunção. Os restantes dados foram obtidos dos registos clínicos.

RESULTADOS: Foram avaliados 57 doentes com mediana de idades $55+11.3$ anos e tempo pós-TxR 19+14anos. A mediana dos valores de IRH foi 1.74+0.45 e das CPE's CD133+ foi de 1.11+0.63 (\% em relação à fração total de células mononucleares do sangue periférico).

Foi observada uma associação linear positiva entre as CPE's CD133+ e o IRH $(r=0.387, p=0.008)$ e negativa entre as CPE's CD133+ e a Taxa de Filtração Glomerular (TFG) ( $r=-0.378, p=0.004$.).

A associação manteve-se significativa após ajuste para os níveis de eritropoetina, uso de estatinas, inibidores da enzima de conversão, antagonistas dos receptores da angiotensina II, valores de PCR e tipo de imunossupressores.

CONCLUSÕES: Os nossos resultados sugerem que as CPE's CD133+ são um bom biomarcador de função endotelial em doentes transplantados renais.

Palavras-chave: Célula progenitora endotelial, rim, função endotelial

\section{CO07-004}

TRANSPLANTECTOMIA NOS PRIMEIROS 3 MESES APÓS TRANSPLANTE RENAL: EXPERIÊNCIA DE UM CENTRO DE REFERÊNCIA

Ana Marinho'; Edgar Tavares-Da-Silva'; Pedro Simões'; Pedro Nunes'; Carlos Alberto Bastos'; Fernando Macárioº ; Rui Alves²; Arnaldo Figueiredo ${ }^{1}$

1 - Serviço de Urologia e Transplantação Renal do Centro Hospitalar e Universitário de Coimbra; 2 - Serviço de Nefrologia do Centro Hospitalar e Universitário de Coimbra

O transplante é o tratamento de eleição em doentes com doença renal crónica terminal. Contudo, existem complicações que exigem transplantectomia (T). Pretende-se avaliar factores de risco/protecção para T nos primeiros 3 meses após o transplante renal.

Este estudo retrospectivo incluiu 770 transplantes renais realizados entre Junho de 2011 e Junho de 2017. Aplicou-se a regressão logística para estudo da relação entre variáveis independentes, nominais e numéricas, e a ocorrência de $T$. Analisando variáveis dos receptores, verificou-se que a idade, índice de massa corporal, história de hemodiálise, diálise peritoneal, transplante prévio ou o tempo de diálise não interferiram com a ocorrência de T. Co-morbilidades como hipertensão arterial, diabetes mellitus, dislipidemia, doença arterial periférica ou história de episódio trombótico não se associaram ao evento. Estudando factores relativos aos dadores, concluiu-se que o uso de dadores cadáver não interferiu no evento, nem a sua idade ou causa de morte (TCE, AVC isquémico ou hemorrágico). $O$ recurso a dadores de critérios expandidos não aumentou o risco de T. Quanto a variáveis cirúrgicas, não se relacionaram com a necessidade de T o uso de um enxerto renal direito, a realização da cirurgia de madrugada, a necessidade de transfusão, o tempo de isquémia fria, a pressão venosa centra e pressão arterial sistólica na reperfusão. Por outro lado, a reoperação nos primeiros 10 dias $(B=-2,365 ; p<0,001 ; \operatorname{Exp}(B)=0,094(0,038-0,231))$, a pressão arterial diastólica na reperfusão $(B=-0,049 ; p=0,001 ; \operatorname{Exp}(B)=0,952(0,924-0,981))$ e a realização de anastomose urinária tipo Taguchi $(B=-1,116 ; p=0,008$ $\operatorname{Exp}(B)=0,328(0,143-0,749))$ relacionaram-se com $T$ aos 3 meses.

Concluiu-se que a reoperação nos primeiros 10 dias após o transplante e a realização de anastomose urinária tipo Taguchi diminuíram o risco de $T$ nos primeiros 3 meses. Por outro lado, quanto menores os valores de pressão arterial diastólica na reperfusão maior é o risco de T.

Palavras-chave: Transplantectomia renal; Factores preditivos; 3 meses
CO07-005

AVALIAÇÃO DAS COMPLICAÇÕES DAS NEFRECTOMIAS LAPAROSCÓPICAS NO DOADOR DE RIM PELA CLASSIFICAÇÃO CLAVIEN-DINDO

Paulo José Medeiros; José Hipólito Dantas Júnior; Cesar Araújo Britto; Rodrigo Trigueiro Morais Paiva; Rafael da Cruz Silva Sampaio; Nadson Frederico se Siqueira Medeiros; José Maximo Costa Pinto

Hospital Universitário Onofre Lopes - Universidade Federal do Rlo Grande do Norte

INTRODUÇÂO: A nefrectomia laparoscópica do doador tem se mostrado segura, apresentando resultados comparáveis com a nefrectomia aberta, com a vantagem da via laparoscópica de causar menos dor pós-operatória, maior precocidade na alta hospitalar e no retorno às atividades habituais, além de melhor resultado estético. Entretanto, apresenta algumas desvantagens, como maior tempo cirúrgico, maior tempo de isquemia quente e maior custo, e por ser realizada por vídeo laparoscopia, complicações inerentes ao acesso laparoscópico. Recentemente, há uma tendência na literatura mundial de avaliar as complicações cirúrgicas pela classificação de Clavien-Dindo. Apresentamos uma análise das complicações desta cirurgia nos 100 casos operados pela nossa equipe.

MÉTODOS: Estudo retrospectivo das nefrectomias laparoscópicas no doador, realizada em hospital universitário, pela mesma equipe, desde 2005 , analisando as complicações pela classificação de Clavien-Dindo.

RESULTADOS: O procedimento já foi realizado em 100 pacientes. O rim esquerdo foi utilizado em mais de $84 \%$ dos casos. A taxa de conversão para cirurgia aberta para cirurgia aberta foi 3\%. As complicações Clavien-Dindo II-IV ocorreram em $8 \%$ dos pacientes, sendo a maioria tipo II. Ocorreu somente um caso tipo III (reoperação) e um caso tipo IV (necessidade de UTI).

CONCLUSÂO: A nefrectomia laparoscópica pura em doadores vivos demontrase ser segura e efetiva na grande maioria dos casos, com mínima morbidade aos doadores.

Palavras-chave : Nefrectomia no doador vivo, Laparoscopia, Complicações

\section{C007-006}

COMPLICAÇÕES CIRÚRGICAS NO TRANSPLANTE SIMULTÂNEO RIM-PÂNCREAS

Nuno Moreira Fonseca'; Ana Messias'; Joana Coutinho'; Ana Carina Ferreira'; Ariana Azevedo1; Patrícia Cotovio1; Fernando Caeiro1; Cecília Silva'; Inês Aires'; Francisco Remédio'; Ana Pena²; Paulino Pereira²; Américo Martins²; Eduardo Barroso²; Aníbal Ferreira1; Fernando Nolasco

1 - Serviço de Nefrologia, Centro Hospitalar Lisboa Central; 2 - Serviço de Cirurgia, Centro Hospitalar Lisboa Central

INTRODUÇÃO: O transplante duplo de Rim-Pâncreas (TRP) é a modalidade terapêutica de eleição nos doentes diabéticos tipo 1 (DM1) com doença renal crónica terminal. O objetivo deste estudo é avaliar as complicações cirúrgicas no pós-operatório de um programa de transplantação nacional.

MÉTODOS: Análise retrospectiva de todos os doentes com DM1 submetidos a TRP no nosso centro. Foi utilizado software STATA e $p<0.05$ foi considerado estatisticamente significativo.

RESULTADOS: Entre 2008 e 2017 foram efectuados 72 TRP. A idade média dos receptores: $37+/-7$ anos, $64 \%$ eram do sexo masculino e o tempo de duração mediano de diabetes foi de 25,5 anos. O tempo médio de isquemia de frio para o pâncreas foi de 6,4h (3,3-16) e para o rim foi 8,8h (5-17).

As complicações cirúrgicas ocorreram em 38 receptores (53\%): 27 receptores com uma complicação, 9 com duas complicações e 2 com três complicações. As complicações mais frequentes foram hemoperitoneu (15\%), hematoma perirrenal (11\%), trombose venosa do pâncreas (11\%) e infecção intra-abdominal (11\%). 81\% das complicações cirúrgicas necessitaram de reintervenção cirúrgica, tendo-se procedido a 22 relaparotomias (31\%), com pancreatectomia em 10 receptores (14\%), nefrectomia em 4 receptores (5,5\%). A necessidade de pancreatectomia correlacionou-se estatisticamente com a presença de DSAs pré-formados $(p=0,03)$, não se tendo verificado uma correlação com o grau de mismatch HLA, tempo de isquémia fria e quente, obesidade do receptor, necessidade de reconstrução arterial no backtable, ou ocorrência de hemoperitoneu. No período do pós-operatório faleceram dois doentes $(2,8 \%)$ de causa cirúrgica associada ao transplante.

CONCLUSÃO: As complicações cirúrgicas no período pós-transplante imediato são frequentes. A necessidade de laparotomia ocorre $31 \%$ dos receptores. A necessidade de pancreatectomia por trombose venosa do pâncreas parece associar-se parece associar-se à existência de anticorpos DSA pré-formados. 


\section{C007-007}

OUTCOMES DOS DOENTES SUBMETIDOS A TRANSPLANTE RIM-PÂNCREAS

Ana Messias'; Nuno Moreira Fonseca'; Aníbal Ferreira1; Ana Pena²; Ana Marta Nobre$^{2}$; Paulino Pereira ${ }^{2}$; Américo Martins²; Ana Carina Ferreira'; Patrícia Cotovio'; Fernando Caeiro'; Cecília Silva'; Inês Aires'; Francisco Remédio'; Eduardo Barroso ${ }^{2}$; Fernando Nolasco ${ }^{1}$

1 - Serviço de Nefrologia - Hospital Curry Cabral - Centro Hospitalar Lisboa Central; 2 - Serviço de Cirurgia - Hospital Curry Cabral - Centro Hospitalar Lisboa Central

Introdução: O transplante rim-pâncreas (TRP) é a melhor opção de tratamento dos doentes com doença renal crónica terminal secundária à diabetes mellitus tipo 1 (DM). Objetivo: Analisar os resultados dos TRP realizados no nosso centro. Métodos: Análise retrospetiva dos resultados dos TRP realizados de Dezembro de 2007 a Dezembro de 2017, com período mínimo de follow-up de 6 meses. Resultados: 72 TRP, dos quais 6 foram em situação preemptive e 1 após falência do enxerto renal. A maioria dos recetores era do sexo masculino e a idade média na altura do transplante foi de $\sim 37$ anos. A DM apresentava, em média, 25,5 anos de evolução e o tempo médio de diálise foi de 2,8 anos. Os dadores apresentavam uma idade média de 34 anos e uma creatinina sérica (Scr) média de $0,8 \mathrm{mg} / \mathrm{dL}$ na altura do transplante. A maioria dos doentes recebeu um enxerto com 4 incompatibilidades HLA e 14,7\% com 6 . A terapêutica imunossupressora de indução consistiu em timoglobulina, tacrolimus, micofenolato de mofetil e corticoides em todos os doentes. 4 doentes morreram, 7 perderam o enxerto renal e 13 perderam o enxerto pancreático. Aos 1, 5 e 10 anos, as taxas de sobrevida ("death-censored") do enxerto renal foram de $91 \%$ aos 1, 5 e 10 anos e do enxerto pancreático foram de $80 \%$ aos 1,5 e 10 anos. As taxas de sobrevida dos doentes foram $96 \%$ aos 1,5 e 10 anos. No final do follow-up, apresentavam Scr média de $1,5 \mathrm{mg} / \mathrm{dL}$, hemoglobina média de $13,5 \mathrm{~g} / \mathrm{dL}$ e glicémica capilar média de $85 \mathrm{mg} / \mathrm{dL}$. Apenas 3 doentes estavam medicados com agente estimulador de eritropoiese e $4 \mathrm{com}$ insulina. Conclusão: O TRP apresenta bons "outcomes" relacionados com a sobrevida dos enxertos e do doente. Os resultados do nosso centro são semelhantes aos descritos na literatura.

Palavras-chave : Transplante Simultâneo Rim-Pâncreas

\section{CO07-008}

SIZE MATCHING DONOR-RECIPIENT PANCREAS IN KIDNEY-PANCREAS TRANSPLANTATION

Joana Coutinho'; Nuno Moreira Fonseca²; Ana Messias²; Patricia Cotovio; Fernando Caeiro²; Cecilia Silva²; Ines Aires ${ }^{2}$; Ana Pena' ${ }^{2}$ Sofia Carrelha²; Ana Marta Nobre ${ }^{2}$; Jorge Paulino²; Américo Martins ${ }^{2}$; Eduardo Barroso ${ }^{2}$; Francisco Remédio ${ }^{2}$; Aníbal Ferreira²; Fernando Nolasco ${ }^{2}$

\section{1 - HOSPITAL AMATO LUSITANO; 2 - HOSPITAL CURRY CABRAL}

Introduction: Size matching donor-recipient has proven relevant in liver transplantation. Consequences of implantation of large pancreas into small recipient has not been studied in simultaneous kidney pancreas (SKP) transplantation. Total pancreas volume is influenced by age, gender and obesity, though autopsy studies suggest organ weight and volume is more strongly correlated with body weight and body surface area (BSA). Methods and objectives: This observational study pretends to assess if there is a role for pancreas size matching in a cohort of SPK recipients $(N=57)$. Exclusion criteria were: lack of complete data, recipients with previous transplantation. All transplants were ABO compatible, performed between 2011-2017. BSA was calculated using Du Bois formula. First a multivariate analysis including known risk factors for early pancreas loss was performed to assess independent predictors of pancreatic surgical complications in our cohort of patients. Second, patients were divided into 2 groups for a comparative study of pancreatic surgical complications, namely early necrosis and venous thrombosis, which could be surrogates for compression of allograft and vascular compromise due to size mismatch. Group $1(\mathrm{~N}=17)$ included patients with a potentially large pancreas to small recipient (defined in this study as a percentual difference > $15 \%$ in BSA) and Group 2 were remnant patients $N=40$. All statistical analyses were performed on SPSS. Results: On multivariate analysis \% of BSA difference between donor and recipient was the only independent predictor with statistical significance ( $p$ value $<0,05$ ). For the comparative study, groups did not have normal distribution. In t-test for paired samples, although by very little, there was no statistical significance between groups regarding pancreatic surgical complications. Conclusion: In this cohort of patient BSA mismatch between donor and recipient seemed predictive of pancreatic surgical complications. There could be a role for pancreas size matching in SKP transplantation but further investigation is warranted.

Palavras-chave: Simultaneous Kidney-Pancreas Transplantation, Size matching, Body Surface Area
C007-009

O CROSSMATCH VIRTUAL (CV) NO TRANSPLANTE DE PÂNCREAS-RIM REDUZ TEMPO DE ISQUEMIA FRIA E A DURAÇÃO DA FUNÇÃO RETARDADA DO ENXERTO RENAL

Adriano Miziara Ginzalez'; Lucia Alejandra Alfaro Villanueva ${ }^{3}$; Renato de Marco'; Marcelo Moura Linhares'; Alcides Salzedas-Neto'; Maria Gerbase De Lima $^{2}$; Jose O Medina-Pestana ${ }^{3}$; Erika Bevilaqua Rangel ${ }^{3}$

1 - Departamento de Gastrocirurgia da UNIFESP-EPM; 2 - Laboratório de Histocompatibilidade/IGEN, UNIFESP-EPM; 3 - Departamento de Nefrologia da UNIFESP-EPM/Hospital do Rim e Hipertensão

Introdução: Os ensaios de fase sólida contendo moléculas únicas do HLA (Human Leukocyte Antigen) permitem detectar virtualmente a presença de anticorpos HLA específicos contra o doador quando comparados à análise do crossmacth real. O CV representa, portanto, uma ferramenta útil e segura para a alocação de órgãos. Métodos: O CV para as classes I e II de anticorpos HLA foi determinado pelo ensaio do Luminex-Single Antigen (HLA-A, -B, - C, -DRB1, -DRB3, -DRB4, -DRB5, -DQA1,-DQB1).Determinados o tempo de isquemia fria (TIF) e a incidência de função retardada do enxerto renal (FRER) antes e após a utilização do CV. As taxas de sobrevida do paciente e dos enxertos renal e pancreático foram calculadas pelas curvas de Kaplan Meier a partir de dez/2000 a maio/2018. Resultados: Foram realizados 486 transplantes de pâncreas-rim no nosso centro ( $56 \%$ sexo masculino; idade $35 \pm 7,6$ anos). Dados dos doadores: $63 \%$ sexo masculino, idade $25 \pm 8,9$ anos e $67 \%$, trauma. A sobrevida do paciente foi $78,2 \%$ (86,2\% Timoglobulina vs $72,9 \%$ sem indução, $P=0,021), 71,3 \%$ do enxerto renal (81,2\% Timoglobulina vs $65,6 \%$ sem indução, $P=0,017)$ e $65 \%$ do enxerto pancreático (70\% Timoglobulina vs $60,2 \%$ sem indução, $P=0,037$ ), em 16 anos. Em agosto/2013, foi instituído o CV, de modo que o TIF do enxerto renal reduziu de $14,8 \pm 0,2 \mathrm{~h}$ para $10,9 \pm 0,4 \mathrm{~h}(\mathrm{P}<0,0001)$ e do enxerto pancreático reduziu de $15,1 \pm 0,2 h$ para $10,6 \pm 0,2 h(P<0,0001)$. Houve correlação entre o TIF e a ocorrência de FRER $(P=0,044)$. Embora não tenha tido redução da incidência de FRER $(24 \pm 2 \%$ vs $22,6 \pm 1,7 \%, P=0,67)$ após utilização do $C V$, houve redução da duração da FRER $(9,7 \pm 0,7$ dias vs $6,5 \pm 0,9$ dias, $P=0,022)$. Discussão e Conclusões; A redução do TIF após a introdução do CV contribuiu para a redução da gravidade da FRER e deve contribuir para a melhor sobrevida dos enxertos renal e pancreático e também do paciente num seguimento a longo prazo.

Palavras-chave: Crossmtach virtual; transplante de pâncreas; função do enxerto renal; sobrevida; tempo de isquemia fria.

\section{C010-001}

C1Q COMO MARCADOR DE RESPOSTA AO TRATAMENTO: CASUÍSTICA DE UM SERVIÇO

Filipa Cardoso; Ana Messias; Mário Góis; Helena Viana; Marco Mendes; Inês Aires; Patrícia Cotovio; Fernando Caeiro; Marília Possante; Cecília Silva; Francisco Remédio; Aníbal Ferreira; Fernando Nolasco

Hospital Curry Cabral

Introdução: Um grande desafio no transplante renal (TR) é a ausência de marcadores que permitam aferir a resposta ao tratamento da rejeição humoral. A presença de anticorpos específicos contra o dador (DSA) que fixam C1q (C1q+) após tratamento apresenta-se como determinante independente de perda de enxerto. Métodos: Procedemos a uma avaliação analítica e morfológica dos últimos 5 anos de doentes TR com pesquisa de DSA com fixação C1q pré e pós tratamento, com follow-up de 6 meses. Utilizou-se software STATA e $p<0.05$ foi considerado estatisticamente significativo. O outcome primário foi creatinina $(\mathrm{pCr})$ aos 6 meses. Resultados: Identificaram-se 14 doentes, predominantemente homens $(92.8 \%)$, caucasianos $(92.8 \%)$ e receptores de dador cadáver $(64 \%)$. Observou-se relação entre o valor basal $\mathrm{pCr}$ e na rejeição $(p=0.02)$ com o outcome. A presença de C1q não influenciou o agravamento da função renal (FR) ou histológico, mas associou-se a valores mais elevados de proteinúria 3 meses após tratamento $(p=0.02)$ comparativamente aos não fixadores de C1q (C1q-) pré-tratamento e aos $\mathrm{C} 1 q$ - pré e pós $(p=0.03)$. Verificou-se também correlação entre o agravamento da FR e o valor basal de MFI $(p=0.001)$. O tratamento consistiu em metilprednisolona, plasmaferese, rituximab e imunoglobulina. Os doentes tratados com rituximab apresentaram tendência para uma pCr inferior $(p=0.06)$, sem diferença nos restantes. A terapêutica realizada não influenciou a negativação de $\mathrm{C} 1 \mathrm{q}$. A raça parece influenciar o outcome $(p<0.001)$, mas é necessário uma amostra maior para confirmar este resultado. idade, sexo, grupo sanguíneo, tempo em hemodiálise, tipo de dador, número de missmatch e terapêutica de indução não influenciaram o outcome. Conclusão: O pedido de Luminex com fixação de C1q não é pedido por rotina por motivos económicos e por falta de estudos que comprovem o seu benefício. Assim, a amostra obtida é manifestamente reduzida para obter conclusões. Adicionalmente, o tratamento não está protocolado, enviesando os resultados.

Palavras-chave : Transplante renal, rejeição humoral, Tratamento, C1q 


\section{CO10-002}

AXL EXPRESSION IN MIXED LYMPHOCYTE REACTIONS IN A POPULATION OF KIDNEY TRANSPLANT PATIENTS

Paula Xavier'; Paula Aires1; Susana Sampaio²; Gerado Oliveira ${ }^{3}$

1 - Instituto Português do Sangue e da Transplantação; 2 - Nefrologia, CHSJ; 3 - CINTESIS, Dep. Medicina, FMUP

Axl, a TAM receptor tyrosine kinases is expressed in macrophages, monocytes, dendritic cells and natural killer cells. Axl modulates the immune response: prevention of activation of antigen-presenting cells, down-regulation of proinflammatory cytokines and up-regulation of suppressor of cytokine signalling (SOCS) 1 and 3. We previously reported that in mixed lymphocyte reactions (MLR) done post-kidney transplantation ( $\mathrm{KTx}$ ) a group display a down-regulation while others do not on the addition of aspiration biopsy cultures supernatants $(\mathrm{s} / \mathrm{n})$ done on day seven post-KTx. We report our observations of $A x \mathrm{x}$, both on donor-recipient (R/D) or third-party recipient $(R / T)$ combinations.

MLR were done between six and 24 months post-transplant, stable, half of wells without $s / n$, the other with $100 \mu \mathrm{l}$ of $s / n$. At the end of MLR cytospins were stained for $A x l$ by immunoperoxidase using anti-human $A x l$ antibody from R\&D. The results are shown for R/D and R/T combinations and for MLR displaying a positive stimulation index (SI) and a negative SI. When $\mathrm{cpm}$ decreased by at least $30 \%$ as compared to wells not supplemented with $\mathrm{s} / \mathrm{n}$ we called it downregulation.

Patients were first cadaver KTX under CsA-MMF-Pred treatment. There was $12 \mathrm{R} / \mathrm{D}$ and $10 \mathrm{R} / \mathrm{T}$, eleven showed positive SI and 11 negative SI by addition of $\mathrm{s} / \mathrm{n}$. Axl expression (quartiles) was 88-619 and 454-1189 for R/D and R/T, respectively, $(p=0.064)$ and $87-636$ and $94-1189$ for stimulated and inhibited MLR, respectively $(P=0.12)$.

These findings show a trend for a higher expression of $A x l$ in $R / T$ as compared to $R / D$ and in inhibited MLR surmising a participation of $A x l$ in the modulation of this immune response. Previously we showed significant different in SOCS expression at the end of MLR in KTx and we speculate that AxI may be behind this observation. A further study encompassing rejecting cases and different treatments is of potential significance.

Palavras-chave : Imunomodulação, transplantação

\section{C010-003}

HIGH HLA-DPB1 EXPRESSION N PRE-IMPLANTATION KIDNEY BIOPSIES IS ASSOCIATED WITH POOR LATE GRAFT FUNCTION

Karina L. Mine'; Tuíla B. Mourão; Cláudia R. Felipe²; Gisele F. Rampim'; José O Medina-Pestana²; Hélio Tedesco-Silva²; Maria Gerbase-DeLima'

1 - Instituto de Imunogenética - Associação Fundo de Incentivo à Pesquisa, São Paulo, Brasil; 2 - Hospital do Rim, Fundação Oswaldo Ramos, Universidade Federal de São Paulo, São Paulo, Brasil

A previous gene expression microarray study (GeneChip ${ }^{\circledR}$ Human Gene 1.0 ST Arrays, Affymetrix; GEO accession number GSE54888), in pre-implantation biopsies (PIB) from kidneys of deceased donors showed association between high expression of HLA class II genes and poor (eGFR $<45 \mathrm{ml} / \mathrm{min} / 1.73 \mathrm{~m} 2$ ) graft function (GF), at 1-Y post-transplant (TX). In the present study we aimed to further investigate the relationship between DPB1 expression in PIB and late GF and to explore the influence of the single-nucleotide polymorphism (SNP) rs9277534, located in the 3'untranslated region of DPB1, on DPB1expression in PIB and on 1-Y GF. The investigation comprised two cohorts of adult transplant recipients $(R)$ : the microarray cohort, with $53 \mathrm{R}$, and the validation cohort, with 109 R. In the validation cohort, HLA-DP expression was measured by RTPCR (TaqMan Assays, Applied Biosystems). HLA-DPB1 typing was performed with PCR-SSO (One Lambda) and rs9277534 alleles were determined with the TaqMan Assay ${ }^{\circledR}$ C_29841700_20 (Applied Biosystems). Results: (1) in the microarray cohort, there was association between the high DPB1 expression in PIB and poor 5-Y GF ( $p=0.03)$; (2) the association between high DPB1 expression in PIB and poor $1-Y$ GF was confirmed $(p=0.037)$ in the validation cohort; PIB from donors homozygous for the high DPB1 expression allele (rs9277534G) presented higher DPB1 expression than PIB from donors homozygous for the low DPB1 expression allele ( $r$ 9277534A) $(p=0.008)$; no significant difference regarding 1-Y GF was observed between transplants where the high or the low expression allele was present in the mismatched DPB1 antigen. Conclusions: (1) there is association between increased expression of HLA-DPB1 in PIB and poor 1- and 5-Y graft function; (2) despite the association of the rs9277534G allele with high DPB1 expression in PIB, the presence of this allele in the mismatched DPB1 allele was not associated with poor 1-Y GF.

Palavras-chave: HLA-DP expression, Pre-implantation biopsies, Marker for poor late graft function
CO10-004

DIFFERENCES FOR T-CELLS SUBTYPES IN ASPIRATION BIOPSIES OF KIDNEY TRANSPLANT PATIENTS UNDER POLYCLONAL AND MONOCLONAL IMMUNOSUPPRESSIVE TREATMENTS

Paula Xavier'; Conceição Magalhães²; Susana Sampaio³; Tiago Guimarães²; Gerardo Oliveira ${ }^{4}$

1 - Instituto Português do Sangue e da Transplantação; 2 - Patologia Clínica, CHSJ; 3 - Nefrologia, CHSJ; 4 - CINTESIS, Dep. Medicina, FMUP

Thymoglobulin (ATG) and anti-IL-2 alpha chain receptor antibody (alpha-IL2RAb) achieve comparable good results notwithstanding different actions on immune cells. Our group has reported the usefulness of flow cytometry (FC) analysis of lymphocyte subsets present in peripheral blood sample (PBL) and fineneedle aspiration biopsies (FNAB) for clinical surveillance as it reaches very high predictive positive values for acute rejection diagnosis. We report FC study on two KTx groups under ATG $(n=19)$ and alpha-IL2RAb $(n=24)$ both further treated with CsA, MMF and Pred. There was no significant difference when comparing the demographics of both groups with the exception that ATG group had more second transplants. All remained rejection-free for the first six months. PBL and FNAB were collected on day seven post-KTx and we used a FACScan from $B D$ and monoclonal antibodies from BD and Coulter. We studied several $T$ lymphocyte subsets and B lymphocytes as we described previously. Analysis by $\mathrm{MW} U$ test (Statsoft). When comparing FNAB we observed a significant downregulation by ATG of $C D 3(P<0.001), C D 4(P=0.009), C D 4 C D 29(P=0.003)$ and $C D 2$ $(P=<0.001)$ and significant up-regulation of $D R(P=0.03), C D 3 C D 69(P<0.001)$ and CD3CD25 $(P<0.0001)$ as compared to alpha-IL2RAb treated groups. For $P B L$, the same trend was seen for CD3, CD4, CD2, CD3CD25, CD3CD69, CD4CD29 and DR plus a down-regulation of CD45RO $(P=0.001)$ and an upregulation of CD4CD45RA $(\mathrm{P}<0.0001)$ in alpha-IL2RAb. This study shows that among stable KTx, ATG as compared to alpha-IL2RAb induces a significant downregulation of a subset of T memory (CD4CD29) but an upregulaton of antigen-experienced cell (CD45RO). Further ATG decreases CD2, CD3, CD4 and naïve (CD45RA) and stimulate T cells as translated by CD3CD69 and DR. Of interest we saw no difference for CD8. As expected alpha-IL2RAb virtually eliminated CD25 cells.

Palavras-chave: Linfócitos, imunossupressão, monitorização

\section{C010-005}

INCREASE ON REGULATORY CELLS IN KIDNEY TRANSPLANTED PATIENTS PRESENTING DONOR-SPECIFIC ANTIBODIES.

Gabriella C. Maciel'; MI Fernandes'; Erick A. Barbosa²; Helcio Rodrigues'; Nicolas Panajotopoulos'; Fabiana Agena ${ }^{2}$; Elias David-Neto ${ }^{2}$; Veronica Coelho'; Maria Cristina Ribeiro De Castro

1 - Laboratório de Imunologia de Transplantes da FMUSP, São Paulo; 2 Serviço de Transplante Renal da FMUSP, São Paulo

The role of anti-HLA donor specific antibodies (DSA) in increasing the risk of graft rejection in kidney transplantation is known. However, not all patients with DSA develop rejection and DSA levels before transplantation are not good predictors. Our group has previously found that the increase on DSA levels after transplantation is associated with antibody-mediated rejection (ABMR), while the decrease is protective. Regulatory $T$ and $B$ cells (Treg and Breg) are reported to play an important role in the control of inflammatory response to allografts. The aim of this study was to evaluate the frequency of regulatory cells and its relation with DSA, ABMR occurrence and transplantation outcome. We analyzed DSA levels over two years (by Single Antigen) and the percentages of circulating Tregs, Bregs and memory cells (by flow cytometry) at 18 and 24 months post-transplant, in 60 patients: 31 $(51,7 \%)$ with PRA $=0,18$ (30\%) PRA > 0 and no DSA, and 11 (18,3\%) patients with pretransplant DSA. T-cell mediated rejection (TCMR) occurred in 14 patients $(23,3 \%)$ in a median time of 396 days. ABMR occurred in 7 patients $(11,7 \%)$ at a median of 19 days. Patients who presented rejection, showed a higher percentage of TCD4 memory (39,8 vs 31,2; $p=0,0279)$, Breg (6,92 vs 4,76; $p=0,0127)$ and Treg $(4,41$ vs 3,$68 ; p=0,0433$ ) compared to patients without rejection. Also, patients with $A B M R$, had higher percentages of Breg and lower B memory $(12,90$ vs 6,$21 ; p=0,0341$ and 8,12 vs 22,$45 ; p=0,0098$, respectively) compared to those with TCMR. Patients with post-transplant DSA showed higher Breg $(6,26$ vs 4,06; $p=0,0181)$ and lower of $B$ memory $(22,85$ vs 29,$80 ; p=0,0456)$ compared to patients without DSA. Patients who kept their grafts after decreasing DSA levels, following ABMR treatment, had higher Breg/Bmemory ratio (1,75 vs 0,$22 ; p=0,0036)$ and higher Treg cells $(3,76$ vs 1,$21 ; p=0,0010)$, despite higher TCD4 memory cells $(59,00$ vs 37,$80 ; p=0,0032)$, compared to those who decreased DSA levels without rejection. Sensitized patients without DSA failed to show any significant changes on regulatory cells subsets. We suggest that acute rejection and treatment (especially ABMR) led to the increase on circulating regulatory cells which can help controlling rejection, avoiding graft lost. Our data also point to a significant relationship between DSA presence, even in the absence of $A B M R$, and upregulation of an immune regulatory profile on $B$ cells. Palavras-chave: anticorpos anti-HLA-Células regulatórias- Rejeição 
CO10-006

DE NOVO DONOR-SPECIFIC ANTI-HUMAN LEUKOCYTE ANTIGEN ANTIBODIES AND RENAL TRANSPLANT OUTCOMES AT THE FIRST YEAR: A SINGLE CENTRE RETROSPECTIVE STUDY

Inês Coelho1; Luís Rodrigues2; Emanuel Ferreira2; António Martinho3; Catarina Romãozinho2; Lídia Santos2; Fernando Macário2; Rui Alves2; Arnaldo Figueiredo4

1 - Serviço de Nefrologia, Hospital Amato Lusitano; 2 - Serviço de Nefrologia, Centro Hospitalar e Universitário de Coimbra; 3 - Centro de Sangue e da Transplantação de Coimbra; 4 - Serviço de Urologia e Transplantação Renal, Centro Hospitalar e Universitário de Coimbra

Background: Despite the post-transplant monitoring of De novo donor-specific antibodies (dnDSAs), the utility of this strategy to diagnose antibody mediated rejection or to predict graft outcomes has not been clearly evaluated. Methods: To examine the relationship of dnDSAs with graft outcomes, we assessed clinical features and DSAs in serum specimens collected from a retrospective cohort of 218 patients from a single centre who received a renal transplant between 2014 and 2017, with a minimum follow-up of one year. DSAs were detected with a single-antigen bead assay and mean fluorescence intensity (MFI) value of $>1000$ was considered significant. Results: Of the 218 patients, $72.9 \%$ were males, 98.6\% Caucasian, 8.3\% where from living donors and $59.2 \%$ from expanded criteria donors. Induction therapy with basiliximab was performed in $81.6 \%$ and with thymoglobulin in $18.4 \%$. Mean follow-up time was 14 months \pm 16 . During the first year of follow-up $58 \%$ of recipients developed dnDSAs, and of these, $18 \%$ had a MFi $>1000 . \operatorname{dnDSAs}$ had the following characteristics: $30 \%$ Class I (6.9\% MFi> 1000), 31.7\% Class II (10.2\% MFi> $1000), 15.9 \%$ both Classes ( $2 \%$ MFi $>1000)$. .The time on dalysis $(p=0.009)$ and the number of HLA compatibilities $(p=0.041)$ correlated with the development of DSAs. At one-year of follow-up, patients with DSAs and a MFl> 1000 had more proteinuria, more acute rejection events and inferior graft function $(50,69 \mathrm{~mL} / \mathrm{min}$ vs $58,49 \mathrm{~mL} /$ $\mathrm{min}$ ) but these differences weren't statistically significant $(p>0.05)$. Patient and graft survival wasn't affected by the presence of DSAs with MFi> 1000. onclusions:The emergence of dnDSAs during the first year doesn't appear to affect graft function or survival. We hypothesize that these outcomes would be inferior with a longer follow up time, and believe that monitoring dnDSAs is essential, since its early detection can promote effective immunosuppression and prevent graft failure.

Palavras-chave : donor-specific antibodies, graft function, antibody mediated rejection

\section{CO10-007}

DISTRIBUTION OF B CELLS AND SUBTYPES UNDER DIFFERENT IMMUNOSUPPRESSION SCHEMES IN KIDNEY TRANSPLANTATION

Suzimar Rioja'; Gustavo Milson'; Nordeval Cavalcante Araújo Cavalcante Araújo'; Luís Cristóvão Moraes Sobrino Porto

1 - Hospital Universitário Pedro Ernesto - Universidade do Estado do Rio de Janeiro; 2 - Universidade do Estado do Rio de Janeiro

INTRODUCTION: At present, B cells have been the object of greater attention, given their importance in the participation in transplant rejection processes and infection control. Thus, this study was designed to verify the distribution of $B$ cells in kidney transplant recipients (RTxR), according to different immunosuppression regimens. METHODS: $B$ cells from 55 adult RTXR were quantified on a flow cytometer using CD19, CD27, IgM and IgD. The patients were divided into groups according to the immunosuppressive scheme: predMMF-CsA $(n=7)$, pred-MMF-CAT $(n=21)$, pred-MMF-SRL $n=7)$. The means of $B$ cells subtypes counts were compared by analysis of variance - ANOVA. $p$ $=0.1$ was accepted as trend and $p=0.05$ as significance. RESULTS: There was a trend towards inversion of the memory and naïve $B$ cells in the pred-MMF group compared to the pred-MMF-CsA group ( 2.18 and 1.17 , respectively, $p=$ $0.13)$, resulting from a high percentage of $B$ naïve cells and of reduction of the counts of B switched and CD27-IgD- cell, in the group pred-MMF ( $p=0.064$, 0.028 and $<0.001$, respectively). The findings were attributed to the higher dose of mycophenolate and the longer time of use of the drug in the pred-MMF group ( $p<0.001)$. CONCLUSION: Mycophenolate may be a factor that modifies the differentiation and proliferation of different $B$ cell subtypes in RTxR.

Palavras-chave : kidney transplantation, mycophenolate, B cells

\section{C010-008}

COMPARAÇÃO DE DOIS DIFERENTES PROTOCOLOS DE IMUNOSSUPRESSÃO EM TRANSPLANTE RENAL COM DOADOR PADRÃO: ESTUDO RETROSPECTIVO COM AVALIAÇÃO DE UM ANO.

Patricia Finni; Claudia Fagundes; Eloá Nunes; Alicia Imada; Maria Sueli Correa; Matuck Tereza; Deise Carvalho

\section{1 - Hospital São Francisco na Providência de Deus}

A eleição do esquema imunossupressor adequado é um desafio constante no transplante renal. Várias estratégias já foram propostas. Objetivo: Comparar desfechos de dois esquemas de imunossupressão. Métodos: estudo retrospectivo incluindo 424 transplantados com doador padrão, não hipersensibilizados (PRA negativo) e divididos de acordo com o esquema de imunossupressão: Grupo A ( $n=207)$ : Basiliximab + (corticoide+ micofenolato+ tacrolimus) e Grupo B ( $n=217)$ : ATG $(3 \mathrm{mg} / \mathrm{kg}$ ) + (inibidores de mTor+ tacrolimus+ corticoide). Resultados:Não houve diferença entre a doença de base e o tempo em diálise.A infecção por citomegalovírus foi superior no grupo $A 21 \%$ vs $3 \%$ no grupo $B, p<0,0001$. 0 tempo de Isquemia fria, assim como o tempo de internação foram superiores no grupo $B, 15 \pm 4,6$ vs $19 \pm 6,6$ horas e $16 \pm 13$ vs $19 \pm 14$ dias; $\mathrm{p}<0,01$. O grupo $A$ apresentou melhor função renal avaliada pela taxa de filtração glomerular calculada pelo MDRD aos 6 meses $71 \pm 31$ vs. $59 \pm 28 \mathrm{ml} /$ $\min / 1,73 \mathrm{~m} 2$ e aos 12 meses $72 \pm 30 v s 60 \pm 27$, comparado ao grupo $B(p<0,01)$. Não houve diferença entre a taxa de descontinuação do esquema inicial de imunossupressão, episódios de rejeição aguda e presença de função retardada do enxerto. A sobrevida do enxerto ao final do primeiro ano foi semelhante: 85 $\%$ grupo A vs $89 \%$ grupo B. Na análise multivariada dos fatores independentes correlacionados a TFG $<60 \mathrm{ml} / \mathrm{min} / 1.73 \mathrm{~m} 2$ aos 12 meses foram: idade do doador RR $1,02(1,01-1,039) p=0,021$, idade do paciente e esquema imunossupressor do grupo $\mathrm{A}$, sendo essas ultimas variáveis preditivas de melhor função renal; RR 0,98 (IC 95\% 0,96-0,99) p=0,019 e RR 0,49 (IC 95\% 0,2-0,43) p=0,001, respectivamente. Em conclusão, o uso de mtor no esquema imunossupressor de manutenção diminuiu significativamente a infecção pelo CMV com uma sobrevida do enxerto semelhante no primeiro ano. $\mathrm{O}$ acompanhamento desses pacientes a longo prazo se faz necessário para confirmar esses achados.

Palavras-chave : esquema imunossupressão

\section{C010-009}

\section{EFICÁCIA E SEGURANÇA DE REGIMES LIVRES DE ESTEROIDES APÓS O} TRANSPLANTE RENAL

Tainá Veras De Sandes Freitas ${ }^{1,2}$; Juliana Gomes Ramalho De Oliveira ${ }^{3}$; Marcel Rodrigo Barros De Oliveira'; Gilberto Loiola De Alencar Dantas²; Maria Luiza De Mattos Brito Oliveira Sales'; Celi Melo Girão'; Ronaldo De Matos Esmeraldo'

1 - Hospital Geral de Fortaleza; 2 - Universidade Federal do Ceará; 3 Universidade de Fortaleza - UNIFOR

Introdução: este estudo objetivou descrever os resultados de eficácia e segurança dos regimes livres de esteroides em um centro brasileiro onde esta estratégia é utilizada rotineiramente em pacientes de baixo risco imunológico. Metodologia: coorte retrospectiva incluindo todos os transplantes renais realizados em adultos entre Jun/2012-Jun/2016 cuja estratégia de imunossupressão consistiu em suspensão dos esteroides até o 7우 ( $n=266)$. Os pacientes foram divididos de acordo com o regime de imunossupressão inicial em: TAC-EVR $(n=201)$, TAC-MPA $(n=65)$ e TAC-EVR-MPA $(n=46)$. Foram avaliados os desfechos de 1 ano. Resultados: os pacientes eram predominantemente

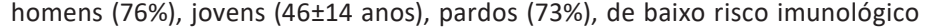
(mediana PRA 0\%, media MM-HLA 3,6 $6 \pm 1$ ), os quais receberam rins de doadores falecidos (95\%), jovens (32 12 anos). 263 pacientes (99\%) receberam indução com globulina anti-timócito, numa dose média de $5,4 \pm 1 \mathrm{mg} / \mathrm{Kg}$. Não houve diferenças entre os grupos quanto à demografia. A incidência de diabetes póstransplante foi de $20 \%$ e não houve diferença entre os grupos $(p=0,558)$. Digno de nota, não houve ganho de peso significativo ao fim de 1 ano em todos os grupos $(+1,0 \mathrm{Kg}$ vs. $-0,5 \mathrm{Kg}$ vs. $+0,1 \mathrm{Kg}, \mathrm{p}=0,090)$. Rejeição aguda comprovada por biópsia foi observada em $2,5 \%, 3,1 \%$ e $8,7 \%$, respectivamente $(p=0,117)$. Não houve diferenças entre os grupos quanto a sobrevida do paciente $(95 \%$, $p=0,434)$ e do enxerto $(93 \%, p=0,095)$ e na função renal (TFG-MDRD: $65 \pm 27$ $\mathrm{mL} / \mathrm{min}, \mathrm{p}=0,055)$. Apenas $7,4 \%$ dos pacientes necessitaram introduzir $\mathrm{o}$ corticoide em 1 ano (6,9\% vs. 7,7\% e 8,7\%) e o principal motivo foi rejeição aguda (48\%). Conclusão: a estratégia sem esteroides foi eficaz em todos os regimes imunossupressores de manutenção, com baixa incidência de rejeição e excelentes sobrevidas e função renal. Chama a atenção baixo ganho ponderal ao final de 1 ano, o que pode ser um benefício desta estratégia, além do baixo percentual de necessidade de reintrodução de esteroides.

Palavras-chave : Imunossupressão, Esteroides 


\section{C014-001}

NEFROPATIA ASSOCIADA AO POLIOMAVÍRUS: CASUÍSTICA DE UM SERVIÇO COM A CLASSIFICAÇÃO DE BANFF DE 2017

Filipa Cardoso1; Ana Messias1; Nuno Fonseca1; Ariana Azevedo1; Mário Góis1; Helena Viana1; David Navarro1; Marco Mendes1; Inês Aires1; Patrícia Cotovio1; Fernando Caeiro1; Marília Possante1; Francisco Remédio1; Aníbal Ferreira1; Fernando Nolasco1

\section{1 - Hospital Curry Cabral}

Introdução: A nefropatia do vírus polioma (NVP) é uma infecção frequente após o transplante renal, sendo causa importante de disfunção do enxerto. Em 2017 surgiu uma classificação morfológica dividindo a NVP em três classes, relacionadas com o prognóstico dos doentes. Métodos: Procedemos a uma análise retrospectiva de 10 anos aplicando a classificação de Banff aos doentes com NVP, com follow-up de 2 anos. Foi utilizado software STATA e $p<0.05$ foi considerado estatisticamente significativo. Resultados: Identificaramse 11 casos de NVP, predominantemente homens (81.8\%), caucasianos (63.6\%) e receptores de dador cadáver (72.7\%). Destes, $36.4 \%$ são classe 1 , $54.6 \%$ classe 2 e $9 \%$ classe 3 . Todos faziam terapêutica de manutenção com tacrolimus, micofenolato de mofetil e prednisolona e $72.7 \%$ fizeram indução com Timoglobulina. A CV na primeira virémia (PV) e na biópsia relacionou-se com a perda do enxerto (PE) ( $p=0.016$ e $p=0.028)$. Classes superiores estão associadas a $\mathrm{pCr}$ mais elevada na PV $(\mathrm{p}=0.06)$. Dois anos após diagnóstico histológico de NVP, apenas 5 doentes (45.45\%) negativaram a carga viral (CV); $6(54.55 \%)$ estavam em hemodiálise, dos quais $66.6 \%$ eram classes 2 e $33.3 \%$ classe 1 , mostrando pior prognóstico nas classes superiores. Existe relação entre a $\mathrm{pCr}$ à data da biópsia e o outcome $(p=0.04)$ : no final do seguimento, $\mathrm{pCr} 2.1 \mathrm{mg} / \mathrm{dL}$ para o grupo com enxerto funcionante e $3.7 \mathrm{mg} / \mathrm{dL}$ para o grupo com PE. O tempo entre a PV e a biópsia relacionou-se com pior prognóstico $(p=0.04)$. Nem a redução da imunossupressão nem o uso de terapêutica dirigida mostraram relação com a PE ou com negativação da CV. Conclusão: Os autores concluem existir uma relação entre classes superiores de Banff e necessidade de hemodiálise. A viremia tem também importância prognóstica, associando-se a PE. Um diagnóstico histológico atempado é essencial devendo ser adoptado sempre que possível. Perante ineficácia das estratégias adoptadas, é imperativo desenvolver novas terapêuticas.

Palavras-chave : Poliomavírus, Viremia, Transplante renal, Banff

\section{CO14-002}

PERFIL DOS PACIENTES COM INFECÇÃO POR CITOMEGALOVÍRUS EM UMA UNIDADE DE TRANSPLANTE RENAL

Kellen Micheline Alves Henrique Costa'; José Roberto Freire De Oliveira ${ }^{2}$; Luana Cristina Lins De Medeiros Oliveira ${ }^{3}$; Raquel Martins E Quinino'; Laíse Pereira Arcoverde Fechine Brito ${ }^{4}$; Pedro Henrique Cavalcante Vale ${ }^{4}$

1 - Hospital Universitário Onofre Lopes-Médica Nefrologista; 2 - Hospital Universitário Onofre Lopes-Médico Infectologista; 3 - Hospital Universitário Onofre Lopes-Farmacêutica; 4 - Hospital Universitário Onofre LopesResidente Nefrologia

Introdução: A infecção por citomegalovírus(CMV) continua sendo muito frequente após transplante de órgãos sólidos.O status sorológico é considerado o mais importante preditor de doença por CMV após o transplante.O uso de imunossupressores aumenta o risco de infecção principalmente com a utilização de fármacos depletores de linfócitos T. Objetivo:Avaliar o perfil sorológico de pacientes com infecção por CMV em uma unidade hospitalar de transplante renal que utiliza indução com anticorpo depletor de linfócito T e terapia preemptiva como estratégia de tratamento.Metodologia:Estudo retrospectivo realizado no Hospital Universitário Onofre Lopes-Natal/RN.Foram incluídos na pesquisa 34 pacientes,avaliados no período de Abril de 2017 à Abril de 2018 que fizeram uso de Ganciclovir.Nosso cut off para início do tratamento é antigenemia maior ou igual à 5 células para todos os pacientes induzidos ou não e realizamos profilaxia universal, apenas nos com perfil sorológico R-/D+.Avaliamos sorologia do doador/receptor,esquema imunossupressor,indução com Timoglobulina ou não, antigenemia ,tipo de doador,sexo e idade. Resultados:Estudamos 34 pacientes ,17 eram do sexo feminino (50\%) e 17 (50\%) do sexo masculino, 31(91\%) pacientes receberam rim de doador falecido. Quanto à idade , 29(85\%) pacientes tinham menos de 55 anos. Dos 34 pacientes ,20(59\%) foram induzidos com Timoglobulina e $14(41 \%)$ não usaram terapia de indução.Dos 14 pacientes não induzidos, $9(64 \%)$ apresentaram antigenemia maior que 10 células e 5(36\%) pacientes antigenemia entre 5-10 células.Dos pacientes que não receberam indução $8(57 \%)$ tinham o perfil sorológico R+/D+ , 2(14\%) R-/D+, 3(21\%) R+/D- e 1(8\%) R-/D-. Os pacientes induzidos com Timoglobulina foram 20 e destes 15(75\%) apresentaram antigenemia maior que 10 células e $5(25 \%)$ entre $5-10$ células.O perfil sorológico dos induzidos eram 9(45\%) D+/R+, 9(45\%), R+/D-, 2(10\%) R-/D+.Todos pacientes receberam esquema imunossupressor com Prednisona,Tacrolimo e Micofenolato. Conclusão:A infecção por CMV em nossa unidade foi muito elevada e novas estratégias de imunossupressão de manutenção precisam ser consideradas.

Palavras-chave : Transplante Renal, Citomegalovírus
C014-003

PNEUMONIA POR PNEUMOCYSTIS JIROVECII (PPJ) EM DOENTE TRANSPLANTADO RENAL (TR) APÓS 16 ANOS

Nídia Marques; Miguel Relvas; Palmira Sousa; Susana Sampaio; Manuela Bustorff; Manuel Pestana

\section{1 - Centro Hospitalar São João}

Introdução: A PPJ é causa de morbimortalidade em TR. O risco é superior nos primeiros 6 meses pós-TR, recomendando-se a profilaxia com TrimetoprimSulfametoxazol (TMP-SMX). A incidência a longo prazo não está definida. Fatores de risco incluem elevado grau de imunossupressão, linfopenia, infecção por citomegalovírus ou rejeição aguda do enxerto. Caso clínico: Homem, 65 anos, com doença renal crónica secundária a glomerulonefrite crescêntica, TR em fevereiro/2002, imunossuprimido com everolimus e prednisolona. Suspenso micofenolato mofetil pós-gastrectomia total por adenocarcinoma em fevereiro/2018, pT1bNORO. Admitido em maio/2018 por tosse mucopurulenta, febre e anorexia. Medicado anteriormente com amoxicilina/ clavunato e azitromicina, sem melhoria. Eupneico, sem alterações à auscultação. Analiticamente sem leucocitose, elevação da PCR e disfunção ligeira do aloenxerto. Hipoxemia. Radiografia tórax com hipotransparência difusa e TAC com áreas de densificação parenquimatosa em vidro despolido. Assumida pneumonia, medicado com piperacilina/tazobactam. Ao 30 dia associada vancomicina e ao 4으 dia escalada para meropenem por febre persistente. Iniciado TMP-SMX empiricamente ao 9o dia. Descida dos parâmetros inflamatórios e apirexia, mas evolução com insuficiência respiratória tipo 1, ao 10 dia introduzida prednisolona. O lavado broncoalveolar do 8 ㅇa dia foi positivo para PJ. Necessidade de admissão em UCl para ventilação mecânica invasiva durante 72 horas. Evolução favorável, readmitido em enfermaria ao 22ㅇ dia, completando 24 dias de antibioterapia. Conclusão: Apesar de pouco frequente, a PPJ é um diagnóstico diferencial a considerar nos TR de longa data. O atraso no início de terapêutica dirigida poderá resultar em evolução desfavorável. Apesar de após 16 anos de TR a terapêutica imunossupressora ser mais baixa, é de considerar o tipo e dose cumulativa, assim como outros fatores imunossupressores, como neoplasias, que poderão elevar risco de infeção. Este caso demonstra a dificuldade no diagnóstico e a importância da suspeição clínica da presença de agentes menos prováveis perante o tempo pós-TR em doentes com evolução desfavorável.

Palavras-chave : Pneumonia, Pneumocystis Jirovecii, Transplante renal

\section{CO14-004}

\section{LATENT TUBERCULOSIS DIAGNOSIS BEFORE KIDNEY TRANSPLANTATION IN A} HIGH BURDEN COUNTRY: IMPROVEMENT WITH SEROLOGICAL TESTS

Valter Garcia; Gisele Meinerz; Cynthia Silva; Alexandre Monteiro; Alessandro Pasqualotto; Elizete Keitel

\section{Santa Casa de Misericórdia de Porto Alegre}

Introduction: Diagnosing and treating tuberculosis after kidney transplantation is challenging, and mortality is high. In an epidemiological study performed at our Center, there was an increase in tuberculosis incidence in the last decade. Patients that received latent tuberculosis (LT) treatment with isoniazid had a lower incidence of active infection after transplantation. One concern was that the standard evaluation for LT before kidney transplantation was falling to detect patients, contributing to active infection cases under immunosuppresion. Objective: to present the results of interferon-gama release assays as an additional tool in the diagnosis of LT infection prior to kidney transplantation (KT), both in recipients and living donors. Results: from April, 2014 to Nov, 2017 we performed 798 adult KT, and collected 351 samples of the test (297 recipients and 54 living donors). Using our standard evaluation, 40 (5\%) patients would receive LT treatment: 16 for previous tuberculosis, 11 for positive TT, 7 for radiological abnormalities, 5 for donors' positive TT, one for donor's hepatic granuloma. Using Igra, we recommended treatment for 95 (11.9\%) patients: 77 positive recipients' tests and 13 positive donors' tests and 5 positive donor's and recipient's tests. Associating standard evaluation and Igra results, 107 (13.4\%) patients were referred to LT treatment (28 were referred for both indications). Twenty-two (20.5\%) patients failed to receive isoniazid: 3 died shortly after transplantation, one transferred to another center, 4 developed active tuberculosis before initiating treatment (in the first month after KT); the remaining 14 had clinical complications or a medical contra-indication for isoniazid therapy. There were $13(1.6 \%)$ cases of tuberculosis during the study period. Five of the 13 had positive Igra: 4 did not start isoniazid due to active disease early after KT and one had a diagnosis of arthritic tuberculosis during isoniazid treatment. One of the 13 received isoniazid treatment for 6 months due to donor's positive Igra and developed disseminated tuberculosis 18 months after the end of treatment. The remaining 7 did not have LT evidence. Amongst the 13 patients with tuberculosis, $3(23 \%)$ died, 3 (23\%) experienced graft loss and 7 (53.8\%) were cured. Conclusion: incorporating Igra as a diagnostic tool to detect LT before KT increases isoniazid treatment recommendation to avoid active tuberculosis cases.

Palavras-chave : transplante renal, tuberculose latente 


\section{C014-005}

POST TRANSPLANT URINARY INFECTION: THE NEW CHALLENGE IN THE IMMEDIATE POST TRANSPLANT MANAGEMENT

Joana Monteiro Dias; Hugo Silva; João Gonçalves; Marta Neves; Sofia Jorge; Alice Santana; José Guerra

Hospital de Santa Maria, Centro Hospitalar de Lisboa Norte

Infections are well-known complications following kidney transplant (KT). Although acute rejection (AR)is the most dreaded concern of the immediate post KT period, it is nowadays rare in this setting. In contrast, urinary tract infections (UTI) remain an important complication following KT even with UTI prophylaxis, leading to higher morbidity and delayed hospital discharge.

The authors present a review of UTI of patients submitted to KT in our center, in the year 2017, from day 0 post-transplant to first hospital discharge. We performed $60 \mathrm{KT}$ this year, mostly from diseased donors (92\%, n-55). Most recipients were men $(65 \%, n-39)$, Caucasian $(68 \%, n-41)$ and with a mean age of 52 years ( 27 to 70 years).

We found that $25 \%(n-15)$ of these patients had a UTI in the immediate posttransplant period, with severity ranging from acute cystitis to pyelonephritis and urinary sepsis. This high incidence contrasts with AR incidence, in which only one case was noted (1.6\%). All UTI were due to Gram negative microorganisms, except for one candida infection. Although E. coli remain an important cause of ITU in our population ( $27 \%$ of UTI, n-4) there were several other microorganisms involved, notably Pseudomonas aeruginosa $(27 \%, n-4)$ and carbepenemaseproducing Klebsiella pneumoniae $(13.3 \%, n-2)$. These are particularly important because of their increasing incidence and because of their associated extended antibiotic resistance. Our post KT UTI patients had longer hospital admission days -medium 32 days vs 15 days in the non UTI patients- and higher serum creatinine at discharge $(1.43 \mathrm{mg} / \mathrm{dL}$ vs $1.3 \mathrm{mg} / \mathrm{dL})$.

Our work demonstrates the current importance of UTI in the immediate post KT period, possibly reflecting higher morbidity, longer hospital admissions and consequently higher costs per admission. It is essential to further characterize these infections and discuss new forms of prophylaxis as to cover the now frequent microorganism with extended antibiotic resistance.

Palavras-chave : kidney transplant, urinary tract infections, immediate post transplant, complications

\section{C014-006}

O IMPACTO DO TEMPO DE TRATAMENTO NO RISCO DE DESENVOLVER INFECÇÕES DO TRATO URINÁRIO RECORRENTE PÓS-TRANSPLANTE RENAL

Lorena Zaine Matos Martinho; Maristela Freire; Clara V. Mendes; Flavio J De Paula; Willian C. Nahas; Elias David-Neto; Willian C. Pierrotti

Hospital das Clinicas da Faculdade de Medicina da Universidade de São Paulo

Estima-se que de $3 \%$ a $47 \%$ dos receptores de transplante renal (TR) apresentem infecção do trato urinário recorrente (ITUr).

O objetivo deste estudo é identificar fatores de risco para recidiva de ITU e ITUr após TR.

Este foi um estudo de coorte retrospectivo que incluiu os pacientes TR de jan/2013 a jun/2016, os pacientes foram seguidos até perda do enxerto ou jun/2017. Foram incluídos todos os episódios de ITU identificadas por vigilância ativa, revisão de prontuários e relatórios de culturas. Foram utilizados os critérios do IDSA para definição de ITU; para avaliação da adequação da duração do tratamento foram utilizadas as recomendações do GESITRA. Foram definidos dois desfechos: ITUr (3 episódios de ITU em um ano ou 2 episódios de ITU em 6 meses) e recidiva de ITU (nova UTI com isolamento do mesmo agente com mesmo perfil de sensibilidade em cultura obtida com $\geq 2$ após termino de tratamento). Foram avaliadas variáveis relacionadas ao tratamento, características da ITU, do receptor de TR e do procedimento do TR. A análise estatística uni e multivariada foi feita por regressão de Cox em dois níveis (10 variáveis relacionadas ao episódio de infecção, 2 o variáveis relacionadas ao sujeito).

Foram identificadas 317 ITUs, em 152 pacientes. 109(34.4\%) episódios foram considerados recidiva, e 139(43.8\%) episódios foram ITUr, 155(48.9\%) das ITUs tinham uma bactéria multidroga-resistente. Os fatores de risco relacionados a ITUr foram refluxo vesicoureteral $(p<0.001$ HR1.91) e DM(p0.006 HR1.61); infecção por E. coli multi-sensível (p0.02 HRO.61) e duração de tratamento adequada(p0.02 HR0.61) foram fatores protetores. Para recidiva de ITU os fatores de risco foram refluxo vesicoureteral(p0.04 HR1.52), Infecção polimicrobiana(p0.002 HR1.98), infecção nos primeiros 6 meses pós-TR(p0.05 HR1.36) e DM(p0.006 HR1.75); duração de tratamento adequada foi fator protetor(p0.02 HR0.55).

A duração do tratamento adequada foi o único fator protetor para recidiva de ITU e ITUr.

Palavras-chave: infecção do trato urinário, bactéria multiresistente, tempo de tratamento, E. coli, recidiva de infecção, transplante renal
C015-001

ACURÁCIA DOS MODELOS PREDITIVOS DE FUNÇÃO TARDIA DO ENXERTO RENAL

Silvana Daher Costa'; Francisco Victor Carvalho Barroso²; Cláudia Maria Costa De Oliveira'; Elizabeth De Francesco Daher'2; Paula Frassinetti Castelo Branco Camurça Fernandes²; Ronaldo De Matos Esmeraldo³; Tainá Veras De Sandes Freitas'

1 - Universidade Federal do Ceará, Hospital Geral de Fortaleza; 2 - Universidade Federal do Ceará; 3 - Hospital Geral de Fortaleza

Introdução: Prever a probabilidade da ocorrência de função tardia do enxerto (DGF) pode auxiliar o planejamento dos cuidados trans e pós-operatórios. Diversos modelos preditivos foram desenvolvidos, mas nenhum foi validado na população brasileira. Objetivos: avaliar a acurácia dos principais modelos preditivos de DGF em uma cidade brasileira onde predominam os transplantes com doadores ideais. Métodos: foram incluídos todos os transplantes renais (TXR) com doador falecido em receptores adultos de 2 centros entre Jan/14Dez/17. Foram excluídos os TxR onde foi utilizada máquina de perfusão pulsátil ( $n=443$ ). A acurácia dos modelos de predição disponíveis (Irish et al., Jeldres et al., Chapal et al. e Zaza et al.) foi avaliada através da área sob a curva ROC (AUC-ROC). DGF foi definida como a necessidade de diálise na primeira semana pós-TxR. Resultados: A amostra foi composta predominantemente por homens(57\%), jovens(44 anos), pardos(84\%), com 34 meses em diálise, baixo risco imunológico ( $8 \%$ Re-TxR, PRA $0 \%$, MM 3,6, DSA $6 \%$ ) os quais receberam rins de doadores jovens (31 anos), com morte traumática (71\%) e creatinina final $1,1 \mathrm{mg} / \mathrm{dL} .4,3 \%$ eram transplantes com doador de critério expandido segundo os critérios UNOS. O KDPI e o KDRI médio foi de $32 \%$ e 0,86, respectivamente, e o tempo de isquemia fria de $21 \mathrm{~h}$. A incidência de DGF foi de $53 \%$, com necessidade mediana de 4 sessões de diálise e 7 dias até a última sessão. 0 preditor com melhor acurácia foi o de Irish et al. (AUC 0,686 IC 95\% 0,637-0,735), seguidos por Chapal et al. (AUC 0,638 IC 95\% 0,586-0,689), Jeldres et al. (AUC 0,613 IC $95 \%$ 0,561-0,666) e Zaza et al (AUC 0,591 IC 95\% 0,539-0,644). Conclusões: Os modelos de predição de DGF disponíveis tem pobre acurácia quando validados nesta amostra da população brasileira, apontando para a necessidade de construção de modelos que contemplem as peculiaridades locais.

Palavras-chave : Transplante renal, Predição, Função tardia do enxerto

\section{C015-002}

AVALIAÇÃo DO PERFIL GLOBAL DE METILAÇÃO DO DNA EM RINS DE DOADORES DE CRITÉRIOS ESTENDIDOS

Naiane Nascimento Gonçalves'; Lidia Maria Rebolho Batista Arantes; Greiciane Maria Da Silva Florim '; Ida Maria Maximina Fernandes-Charpiot'; Maria Alice Sperto Ferreira Baptista'; Heloisa Cristina Caldas'; Mario AbbudFilho'

1 - Faculdade de Medicina de São José do Rio Preto; 2 - Hospital de Câncer de Barretos

Introdução: As enzimas DNA metiltransferases DNMT1, DNMT3A e DNMT3B estão associadas à metilação do DNA e podem alterar a regulação epigenética e modificar os desfechos observados em rins de doadores falecidos sujeitos aos fenômenos da isquemia. Objetivos: Avaliar o perfil de metilação global do DNA e dos níveis de expressão das DNMTs em biópsias pré-transplante dos rins de doadores de critério padrão (SCD) e estendido (ECD) e o impacto na função tardia do enxerto renal (DGF). Materiais e Métodos: 18 BxT0 foram avaliadas, sendo $\operatorname{SCD}(n=10)$ e $E C D(n=8)$. Essas amostras foram submetidas à extração de DNA e posterior conversão por bissulfito de sódio. Após a conversão, o padrão de metilação das amostras das sequências LINE-1 foi quantificado por meio do pirosequenciamento e os níveis de expressão das DNMTs foram determinados por PCR em tempo real. Todos estes parâmetros foram correlacionados com os dados demográficos dos pacientes e com as características dos transplantes. Resultados: Nossos resultados mostram que doadores ECD quando comparados aos SCD apresentam aumento da metilação global $(p=0,03)$, enquanto que as DNA Metiltransferases 1, 3A e 3B foram significativamente mais expressas em ECD quando comparados a $S C D(p=0,04 ; p=0,009$ e $p=0,002$ respectivamente)

A metilação do DNA não foi associada com DGF, rejeição aguda e tempo de isquemia fria. Conclusão: Rins ECD apresentam aumento da metilação da sequência LINE-1 e aumento da expressão das DNMTs. Esses achados sugerem que hipermetilação pode ser um fator adicional para explicar piores desfechos de rins ECD.

Palavras-chave : Transplante Renal, Metilação 


\section{CO15-003}

KIDNEY TRANSPLANTATION (KT) FROM UNCONTROLLED CIRCULATORY DEATH DONORS (UDCD) WITH NORMOTHERMIC REGIONAL PERFUSION (NRP) IN COMPARISON WITH BRAIN DEATH DONORS (DBD)

José Silvano'; Hugo Diniz'; Luís Mendonça'; Manuela Bustorff'; Susana Sampaio'; Gerardo Oliveira ${ }^{2}$; Roberto Roncon-Albuquerque Jr. ; ${ }^{3}$ Manuel Pestana ${ }^{4}$

1 - Nephrology Department, Centro Hospitalar de São João, Porto, Portugal; 2 - Harvest and Transplantation Coordination Unit, Centro Hospitalar de São João, Porto, Portugal; 3 - Department of Emergency and Intensive Care Medicine, Centro Hospitalar de São João, Porto, Portugal; 4 - Renal Transplantation Unit, Centro Hospitalar de São João, Porto, Portugal

KT from UDCD contributed to augment the pool of cadaveric donors. How outcomes of KT from UDCD compares to DBD with extended (ECD) or standard ( $S C D)$ criteria donors remains a focus of debate. We conducted a retrospective cohort study between January 1st 2016 and March 31st 2018, including all patients submitted to KT from UDCD $(n=44)$, and from SCD $(n=33)$ and ECD $(n=31)$ who could be eligible for the uDCD program. Median follow-up time was 10 months (2-16). As expected, ECD donors and recipients were older. Waiting time on dialysis was longer for SCD. Cold-ischemia time (CIT) was lower for UDCD

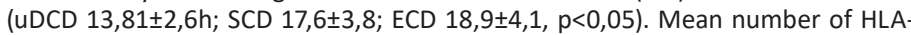
mismatches was not different between groups. Delayed graft function was higher for uDCD (uDCD 68\%; SCD 36\%; ECD 38\%, p<0,05). Biopsy-proven acute rejection did not differ between groups. Median hospitalization time was: UDCD 23 days (17-31), SCD 12 days (8-18), ECD 17 days (11-30), $p=0,35$. Graft loss from primary non-function did not differ: uDCD 2,27\%, SCD 0\%, ECD 0\%, ( $p=0,36)$. Twelvemonth death-censored graft and patient survival rates were $95 \%$ for SCD, 80\% for ECD, $87 \%$ for $u D C D(p=0,28)$ and $100 \%$ for SCD, $93 \%$ for ECD, 100\% for uDCD ( $p=$ 0,31 ) respectively. Median estimated GFR (eGFR) was significantly lower for UDCD at one month, but was not significantly different at twelve-month, even after covariate-adjustment (recipient age, gender, CIT): SCD 72,5 $\pm 6,9$; ECD 61,5 \pm 6.1 ; uDCD $58.5 \pm 6.1 \mathrm{ml} / \mathrm{min} / 1.73 \mathrm{~m} 2$. From month 1 to 12 , uDCD showed the greatest improvement in function ( $\triangle$ eGFR: $26 \pm 5.8 \mathrm{ml} / \mathrm{min}, \mathrm{p}<0,05$ ). In conclusion, one year patient and death-censored graft survival from UDCD with NRP did not differ from DBD. UDCD had a deleterious impact on allograft function early, but not one year after KT. More patients with longer follow-up must confirm these findings.

Palavras-chave: kidney transplant, graft survival, brain death donor, circulatory death donor

\section{C015-004}

\section{AVALIAÇÃO DO ÍNDICE KDPI (KIDNEY DONOR PROFILE INDEX) EM UMA} COORTE BRASILEIRA

Claudia Fagundes'; Patricia Finni'; Livia Assis'; Marilia Reis'; Denise Glasberg'; Tereza Matuck'; Deise Carvalho'; Vinicius Layter Xavier ${ }^{2}$

1 - Hospital são Francisco na Providencia de Deus; 2 - Instituto Matematica e Estatistica /Departamento Estatistica/UERJ

Com o crescente desafio de reduzir o desequilíbrio entre a escassez de órgãos e o número dos candidatos em lista de espera, enxertos antes não utilizados, estão cada vez mais sendo implantados. Recentemente, índices de risco de doadores específicos, como o KDPI, foram desenvolvidos para avaliação da qualidade do enxerto. $O$ presente estudo trata-se de analise retrospectiva com 698 transplantes renais doador falecido com o objetivo de utilizar o KDP como ferramenta de avaliação prognóstica do enxerto, usando como referência os dados da OPTN. Na amostra a mediana de KDPI foi de 62\% (IQ 33\%-85\%); sendo que 110 pacientes com KDPI < 20\%, 72 (KDPI 21-34\%), 341 (KDPI35-85\%) e 175 (KDPI > 85\%). A sobrevida do enxerto em 12 meses, de acordo com as faixas de KDPI, foi de $89 \%$ (KDPI <20\%), 87\% (KDPI 21-34\%), 81\% (KDPI 35-85\%) e $73 \%(K D P I>85 \%)(p<0,0006)$. Ao analisarmos a função renal do enxerto pela equação do MDRD, observamos que os grupos KDPI entre $35-85 \%$ e KDPI > $85 \%$ apresentam um desempenho inferior comparado aos grupos de KDPI mais baixos, sendo o grupo KDPI > $85 \%$ o que apresenta o pior prognostico aos 12 meses (mediana 69(56-76) vs 65(62-78) $\mathrm{ml} / \mathrm{min} / 1,73 \mathrm{~m} 2, \mathrm{p}=0,0051$ ). Por outro lado, os grupos de KDPI mais baixos apresentam função renal semelhante ao final do primeiro ano mediana de 76(65-81) para KDPI $34-20 \%$ e $74(63-80) \mathrm{ml} /$ $\mathrm{min} / 1,73 \mathrm{~m} 2$ para $\mathrm{KDPI}<20 \%$. A análise multivariada demostrou que o KDPI é o único fator preditivo independente de perda de enxerto aos 12 meses (RR 1,015 (IC 95\% 1,009-1,021) p<0,001). Nosso estudo demostrou que o KDPI é útil para avaliação da qualidade de doador em uma coorte brasileira, e que mesmo nos grupos de KDPI mais elevados a função e sobrevida do enxerto a 12 meses são aceitáveis.

Palavras-chave : KDPI
CO15-005

THE EFFECT OF DELAYED GRAFT FUNCTION ON SHORT-TERM OUTCOMES AFTER KIDNEY TRANSPLANTATION FROM UNCONTROLLED CIRCULATORY DEATH DONORS WITH NORMOTHERMIC REGIONAL PERFUSION SUPPORT

Hugo Diniz'; Luís Mendonça'; José Silvano'; Susana Sampaio ${ }^{1,2}$; Gerardo Oliveira $^{3}$; Roberto Roncon-Albuquerque Jr. ${ }^{4}$; Francisco Cruz2; Manuel Pestana ${ }^{1,2}$ 1 - Nefrologia - Centro Hospitalar de São João; 2 - Centro de Referência Transplante Renal Adultos - Centro Hospitalar de São João; 3 - Gabinete de Coordenação de Colheita de Orgãos e Transplantação - Centro Hospitalar de São João; 4 - Emergência e Medicina Intensiva - Centro Hospitalar de São João Kidney transplantation from uncontrolled donation after circulatory death ( $U D C D)$ is associated with a higher risk of delayed graft function (DGF) due to increased warm ischemia time (WIT). The effect of DGF on allograft function is still controversial. A prospective follow-up of uDCD-nRP (Maastricht II) kidney transplanted patients from our center was conducted between January, 1st 2016 and April, 30th 2018. In this period, 44 kidney transplants were performed. Donors (M:F; 21/5) had a median age of 51 [43.25-55] years. Mean WIT was 91 \pm 19.2 minutes and the median time on nRP was 180 [150-195] minutes. Cold ischemia after kidney retrieval was managed with static cold storage. Mean cold ischemia time (CIT) was $14.05 \pm 2.57$ hours. Receptors (M:F 28/16) had a median age of 54 [47-60.75] years and all had low immunological risk. $68 \%$ had DGF and $9.1 \%$ primary nonfunction. $95.4 \%$ received anti-thymocyte globulin as induction immunosuppressive therapy. $22.7 \%$ of the population had an episode of acute rejection ( $40 \%$ borderline changes). Our median patient follow-up time is 11 [3-16] months. In a binary logistic regression model regarding the occurrence of DGF, no significant association between CIT $(p=0,824)$ or WIT $(p=0,088)$ and DGF was found. In another logistic regression model regarding the likelihood of attaining a 3-month eGFR $\geq 60 \mathrm{ml} / \mathrm{min} / 1.73 \mathrm{~m} 2$, a significant association with the number of hemodialysis performed after transplantation was not found $(p=0,134)$. Also, there was no significant association between DGF and 3-month $(p=0,427)$ and 6 -month mean eGFR $(p=0,357)$. There was a significant association with DGF and acute rejection $(p=0,049)$ and between DGF and the number of hospitalization days (29.6 vs. 12.6 days, $p<0,001)$. DGF does not seem to impact short-term UDCD-nRP kidney function but there is an association with acute rejection and it significantly increases the number of post-transplant hospitalization days.

Palavras-chave : Kidney transplant, uDCD, ECMO, Maastricht II

\section{C015-006}

O IMPACTO DOS ACHADOS HISTOLÓGICOS EM BIÓPSIAS PROTOCOLARES NO 3 MÊS PÓS TRANSPLANTE NA FUNÇÃO DO ENXERTO RENAL.

Rosangela Munhoz Montenegro'; Henrique Bertin Rojas²; Gabriel Joelsons ${ }^{2}$; Tuany Domenico²; Andrea Carla Bauer²; Roberto Ceratti Manfro ${ }^{2}$

1 - Hospital de Clinicas de Porto Alegre; 2 - Universidade Federal do Rio Grande do Sul

Introdução. As agressões sub-clínicas aos enxertos renais são somente diagnosticadas em biópsias protocolares e seu papel na evolução da função dos enxertos não é bem conhecido, especialmente em médio e longo prazos. Objetivou-se avaliar o impacto na função dos enxertos renais das alterações constatadas em biópsias renais de protocolo realizadas no terceiro mês após o transplante.

Pacientes e Métodos. Foram avaliados pacientes com função estável do enxerto e que realizaram biópsias protocolares no período de 01/2011 a 06/2013. Foram avaliadas as características demográficas e variáveis relacionadas ao transplante. A função do enxerto foi avaliada pela taxa de filtração glomerular estimada [eTFG] pela equação CKD-EPI até o 50 ano pós-transplante.

Resultados: Foram avaliados 135 pacientes com média de idade $47 \pm 13,4$ anos, sendo $52,6 \%$ mulheres e $83,7 \%$ receptores de rim de doadores falecidos. Disfunção inicial do enxerto (DGF) ocorreu em 56,3\% dos receptores de rins de DF. $46 \%$ das biópsias foram consideradas alteradas: (1) alteração borderline em 33 pacientes (24,4\%); (2) rejeição aguda em 6 pacientes (4,4\%); (3) IFTA em 18 pacientes (13,3\%); (4) outros achados em 5 pacientes (3,6\%). Aos 12, 24 e 60 meses pós-transplante as eTFG foram $62,1 \pm 21,4 ; 67,4 \pm 24,1 \mathrm{~mL}$ e $64,4 \pm$ $21,1(\mathrm{~mL} / \mathrm{min} / 1,73 \mathrm{~m} 2)$ no grupo de pacientes sem alterações sub-clínicas nas biópsias e $52,2 \pm 25,3 ; 56,4 \pm 27,0$ e $54,3 \pm 22,8(\mathrm{~mL} / \mathrm{min} / 1,73 \mathrm{~m} 2)$ no grupo de pacientes com alterações sub-clínicas $(P \leq 0,017)$

Conclusões. Biópsias protocolares realizadas no 30 mês pós transplante em pacientes com função renal estável evidenciam uma elevada freqüência de alterações sub-clínicas e essas estão associadas TFG estimadas significativamente inferiores em médio prazo. As biópsias protocolares podem potencialmente levar a intervenções que propiciem melhor evolução da função dos transplantes renais.

Palavras-chave : agressões sub-clinicas, biopsia, renal, protocolo, eTGF 
CB01-001

HISTOPLASMOSE DISSEMINADA EM CRIANÇA APÓS TRANSPLANTE RENAL RELATO DE CASO

Raquel Martins E Quinino; Ana Karina Da Costa Dantas; Kellen Micheline Alves Henrique Costa

\section{HOSPITAL UNIVERSITÁRIO ONOFRE LOPES- UFRN/ NATAL- BRASIL}

Relato do caso : paciente LLBT, feminina, 13 anos, apresentou quadro de úlceras e hipertrofia gengival dolorosa durante 2 semanas, associado a febre, conjuntivite e edema periorbitário bilateral cerca de 2 dias antes do internamento (setembro 2016). Transplantada renal em junho/2015 com doador falecido, imunossupressão com Prednisona, Micofenolato Sódico e Tacrolimo. Ao exame físico apresentava placas brancas em mucosa gengival e amígdalas não raspáveis, com pontos de hiperplasia gengival, além de placas brancas que recobriam mucosa de fossa nasal e conjuntiva de ambos olhos, com um edema periorbitário bilateral (pseudomembranas). Foi realizado biópsia incisional da mucosa gengival superior e amígdala que demonstrou leveduras sugestivas de Histoplasma capsulatum. Antes do resultado antomo-patológico a paciente foi tratada com Caspofungina por 21 dias com pequena melhora do quadro. Após o resultado foi trocado esquema para Anfotericina B Lipossomal que recebeu durante 15 dias, com importante melhora clínica. Fez uso de Itraconazol (7mg/ $\mathrm{kg} / \mathrm{dia}$ ) por mais um ano. Discussão: A Histoplasmose disseminada é uma infecção rara, mais comumente afetando pacientes imunossuprimidos, apesar do Histoplasma capsulatum ser uma micose endêmica. A maior concentração do fungo encontra-se em cavernas e casas abandonadas, nas quais o fungo prolifera em dejetos de aves e morcegos. Fatores de risco para histoplasmose disseminada incluem idade menor que um ano, AIDS, transplante de orgãos sólidos e uso de imunossupressores. O quadro clínico inclui febre, tosse, dispnéia, perda de peso, podendo haver hepatoesplenomegalia e linfonodomegalia. A apresentação na mucosa oral pode ser através de úlceras dolorosas, podendo também haver lesões em pele (pápulas, úlceras). O tratamento é feito com Anfotericina B ou Itraconazol. Conclusão: Este relato mostra a importância de considerar a Histoplasmose como diagnóstico diferencial em pacientes transplantados que apresentem lesões de cavidade oral e febre, além de descrever a boa resposta ao tratamento específico com a Anfotericina B e Itraconazol.

Palavras-chave : TRANSPLANTE RENAL / INFECÇÃO APÓS TRANSPLANTE / TRANSPLANTE PEDIÁTRICO

\section{CB01-002}

TREINAMENTO MUSCULAR INSPIRATÓRIO E CAPACIDADE FUNCIONAL EM PACIENTES PEDIÁTRICOS SUBMETIDOS A TRANSPLANTE RENAL: DADOS PRELIMINARES

Raquel Carbonera; Clotilde Garcia; Ana Paula Barbosa; Tatiana Normann; Janice Luisa Lukrafka

\section{CURSO PPG PEDIATRIA UNIV. FEDERAL CIÊNCIAS DA SAUDE PORTO ALEGRE}

Objetivo: avaliar os efeitos do treinamento muscular inspiratório (TMI) na capacidade funcional (teste de caminhada de 6 minutos - TC6) em pacientes com doença renal crônica pediátricos após transplante (Tx) renal. Metodologia: ensaio clínico randomizado duplo-cego, em pacientes transplantados renais recentes (primeiros 6 meses após Tx) em acompanhamento ambulatorial em hospital referência. O protocolo de TMI domiciliar utilizou o aparelho ThresholdTM IMT, durante 6 semanas, para treinamento de força muscular inspiratória. Os pacientes foram randomizados em dois grupos, grupo intervenção (GI), treinamento com carga de $40 \%$ da PImáx (pressão inspiratória máxima) e grupo controle (GC), treinamento com a carga mínima ofertada pelo aparelho $(9 \mathrm{cmH} 2 \mathrm{O})$, considerada placebo. Resultados: amostra preliminar composta por 19 pacientes, sendo 9 do Gl e 10 do GC. A média de idade foi $10,78 \pm 3,67$ anos no $G l$ e $10,6 \pm 3,5$ anos no GC, sendo $44,4 \%$ do Gl e $60 \%$ do GC do sexo masculino. Dos 42 dias de treinamento, a média de dias realizados pelo $\mathrm{GI}$ foi de $35,33 \pm 5,34$ (83,33\%) e $25,9 \pm 11,88$ dias $(59,52 \%)$ no GC. Não foram encontradas diferenças significativas entre os grupos na linha de base. Os valores de TC6, de acordo com referências para gênero e idade

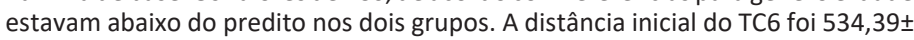
$23,87 \mathrm{~m}$ no $\mathrm{Gl}$ e $473,8 \pm 26 \mathrm{~m}$ no GC sem diferença significativa entre os grupos. Após o treinamento, a distância percorrida no Gl aumentou para $547,56 \pm 23,13 \mathrm{~m}$ e para $496,4 \pm 19,91 \mathrm{~m}$ no GC porém sem diferença significativa intra $(p=0,068)$ e entre os grupos $(p=0,576)$. Após o treinamento, a distância percorrida predita foi de $97,79 \%$ para o $\mathrm{Gl}$ e de $89,13 \%$ para o $\mathrm{GC}(\mathrm{p}=0,292)$. Conclusões: a distância inicial do TC6 estava abaixo do predito em ambos os grupos e aumentou após o TMI, independente de grupo. Contudo, o TMI não apresentou benefícios na capacidade funcional em comparação ao grupo controle. O pequeno número amostral pode justificar esses achados. Os dados seguem sendo coletados para posterior análise, contudo, percebe-se a importância da Fisioterapia para complementar a assistência às crianças após Tx renal.

Palavras-chave: transplante renal pediatrico, fisioterapia, exercícios respiratórios

\section{CB01-003}

RESULTADOS DO TRANSPLANTE RENAL PEDIÁTRICO EM CRIANÇAS MENORES DE 15 KG

Maria Fernanda Camargo'; Paulo Cesar Koch Nogueira²; Camila Genzani²; Mariana Barcia; Luciana Santis Feltran'

1 - Hospital Samaritano São Paulo; 2 - Hospital Samaritano Sao Paulo; 3 Hospital Samaritano

Introdução: A maioria dos centros transplantadores não realiza transplantes renais em crianças menores de $15 \mathrm{Kg}$

Objetivo: Comparar os resultados do transplante renal pediátrico de crianças menores de $15 \mathrm{Kg}$ ao de crianças maiores, em centro especializado.

População e métodos: Comparamos curva de sobrevida de pacientes e de enxerto em dois grupos de crianças transplantadas renais de 2009 a 2017, de acordo com peso no transplante, sendo grupo $A \leq 15 \mathrm{Kg}$ e grupo $B>15 \mathrm{Kg}$. Características dos dois grupos foram comparadas por t teste se variável contínua e qui quadrado se variável categórica. Curva de Kaplan Meier e log rank test foram utitizados para a comparação das sobrevidas.

Resultados: Foram transplantadas 136 crianças do grupo $\mathrm{A}(11,8 \pm 2,3 \mathrm{Kg}$, $73 \%$ masc.) e 214 do grupo B $(29.5 \pm 12.3 \mathrm{Kg}, 56 \%$ masc.). A causa de DRC foi malformação do trato urinário em $66 \%$ no grupo $A$ e $43 \%$ no grupo $B(p=0.01)$. $80 \%$ dos transplantes nos dois grupos foi realizado com doador falecido. A sobrevida do paciente em 1 e 3 anos foi de $96 \%$ (90\% - 99\%) e $96 \%$ (90\% - 99\%) no grupo A e $98 \%(95 \%$ - 100\%) e $97 \%$ (92\% - 99\%) no grupo B e a sobrevida do enxerto $91 \%$ ( $84 \%-95 \%$ ) e $93 \%$ ( $88 \%$ - $96 \%$ ) no grupo A e $98 \%$ (95\% - 100\%) e $89 \%$ $(83 \%-93 \%)$ nos mesmos períodos ( $p=N S)$. Os grupo não diferem no retardo de função do enxerto ou necessidade de reoperação.

Conclusão: Crianças menores de $15 \mathrm{Kg}$ apresentam ótima sobrevida e sobrevida do enxerto após transplante renal, semelhante às de crianças maiores, em centro especializado.

Palavras-chave : Transplante Renal Pediátrico

\section{CB01-004}

\section{DIFERENÇA NO TEMPO DE PREPARO PARA TRANSPLANTE EM CRIANÇAS} MENORES 15 KG

Maria Fernanda Camargo; Luciana Santis Feltran; Miriam De Fatima Morais Cunha; Simone Maria R Perentel; Erica Francisco Silva; Maria Fernanda Hamamoto1; Fernando Hamamoto; Paulo Cesar Koch Nogueira

Hospital Samaritano Sao Paulo

Introdução: Crianças $<15 \mathrm{Kg}$ têm menor acesso ao transplante renal (TxR) no Brasil.

Objetivo: Comparar o tempo de preparo para TxR em crianças de pesos diferentes e identificar fatores de atraso.

Método: Coorte de crianças encaminhadas ao TxR em serviço especializado, de 2009 a 2017, tiveram os seguintes dados considerados: nome, data nascimento, sexo, estado de origem, causa DRC, data da primeira consulta, peso na entrada, preparo cirúrgico urológico para TxR, gastrostomia, mais de uma modalidade de diálise no encaminhamento. A criança foi considerada apta ao TxR na data de sua inscrição em lista para transplante com doador falecido ou de realização de transplante com doador vivo (a que ocorresse primeiro). 0 tempo decorrido entre essa data e a data da primeira consulta foi comparado entre 3 grupos de crianças, de acordo com seu peso inicial: grupo $A: \leq 7 \mathrm{Kg}$, grupo B: $7-15 \mathrm{~kg}$ e grupo $\mathrm{C}$ : $>15 \mathrm{~kg}$. Análise de sobrevida com fatores concorrentes associados (óbito ou perda de seguimento) foi realizada para comparar os 3 grupos. Análise multivariada foi utilizada para identificar fatores de demora no preparo da criança.

Resultados: 441 crianças ( $66 \%$ meninos, mediana 15,8Kg) foram incluídas no estudo, sendo 52 no grupo A, 165 no grupo B e 224 no grupo C. Causa de DRC mais comum foi malformação do trato urinário (68\% nos menores $15 \mathrm{Kg}, 40 \%$ nos demais). O tempo necessário para preparar uma criança para o TxR foi comparável nos grupos B e C (5,4 e 4,4meses) e maior no grupo A (11,2meses). Peso $<7 \mathrm{Kg}$ e malformação do trato urinário se correlacionaram a aumento nesse tempo.

Conclusão: Em serviço especializado, crianças de 7 a $15 \mathrm{Kg}$ ficam aptas ao TxR num mesmo curto espaço de tempo que crianças $>15 \mathrm{Kg}$. Peso $<7 \mathrm{Kg}$ e malformação do trato urinário foram fatores relacionados à demora nesse preparo.

Palavras-chave : Transplante renal, Criança baixo peso 


\section{CB01-005}

TRANSPLANTE RENAL COM DOADORES EM CRITÉRIOS EXPANDIDOS: AMPLIANDO POOL DE DOADORES

Brunno Raphael lamashita Voris; Marilda Mazzali; Marcelo Lopes De Lima Universidade Estadual de Campinas (UNICAMP) - Brasil

INTRODUÇÃO: O transplante renal é considerado a terapia de escolha para pacientes com doença renal crônica em tratamento dialítico. Entretanto, o número de doadores ainda é insuficiente para a demanda de receptores. Na tentativa de aumentar o pool de doadores renais, os critérios para doador insuficiência renal aguda durante a hospitalização da etiologia da morte encefálica. Estes doadores foram evitados por muitos anos, porém estudos recentes mostraram sobrevida em 1 ano e função renal comparável a dos receptores de rim de doador padrão.

OBJETIVOS: Determinar os resultados a longo prazo de receptores de rins de doador falecido com critério expandido.

MÉTODOS: Informações coletadas em fichas próprias (Apêndice A), a partir de prontuários médicos e de registro específico do programa de transplante renal do Hospital das Clínicas da UNICAMP. Comparados os resultados dos grupos em critério expandido e grupo de doadores padrão no mesmo período. A análise estatística foi realizada utilizando o programa GraphPad Prisma 6.0

RESULTADOS: A creatinina média dos pacientes durante o primeiro ano de acompanhamento manteve-se ao redor de $2 \mathrm{mg} / \mathrm{dL}$. A avaliação da taxa de sobrevida dos pacientes $(90,4 \%$ vs $91,2 \%$ em 6 meses) e dos enxertos $(84,1$ vs. 83,6 em 6 meses) entre os grupos: doador padrão x doador em critério expandido não tiveram diferenças estatísticas em um e três anos. A principal causa de perda de enxerto foi óbito, nos primeiros 6 meses pós transplante, de causa infecciosa ou cardiovascular.

CONCLUSÃO: O aumento do pool de doadores é possível com a utilização de rins de pacientes com critérios expandidos e/ou insuficiência renal aguda com taxa de sobrevida semelhante tanto do paciente e quanto do enxerto.

Palavras-chave : transplante, rim, doador expandido vêm sendo ampliados, utilizando doadores de critérios expandidos e em

CB01-007

DELAYED GRAFT FUNCTION AFTER DECEASED DONOR KIDNEY TRANSPLANTATION: OUTCOMES ACCORDING WITH DGF DURATION

Sofia Correia'; Catarina Eusébio ${ }^{2}$; Fernando Pereira ${ }^{3}$; Miguel Oliveira ${ }^{4}$; Miguel Gonçalves ${ }^{5}$; Jorge Malheiro'; Manuela Almeida'; Sofia Pedroso'; António Cabrita'; Leonidio Dias'; La Salete Martins'; António Castro Henriques'

1 - Nephrology and transplant unit, Centro Hospitalar do Porto;

2 - Nephrology department, Centro Hospitalar de Trásos- Montes e Alto Douto;

3 - Nephrology department, Hospital Prof. Doutor Fernando Fonseca;

4 - Nephrology department, Centro Hospitalar Tondela Viseu;

5 - Nephrology department, Hospital Central do Funchal

DGF remains a frustratingly persistent problem. We aimed to study our population with and without DGF, the impact on allograft and patient outcomes and the association between DGF duration and rejection. This retrospective analysis included all deceased donor kidney transplants performed between January/2010 and December/2014(n=279). DGF was defined as the need for dialysis within the first 3 days posttransplant. Patients were grouped in terciles according to DGF duration (1-4,5-11and>12 days). The overall DGF incidence was $39 \%(n=109)$ and its median duration was 7 days. DGF patients were more likely to require biopsy, to have acute rejection $(17 \%$ vs $2 \%, P<0.001)$, had longer length of stay, higher creatinine at discharge $(2.10 \mathrm{vs} 1.56 \mathrm{mg} /$ $\mathrm{dL}, \mathrm{P}<0.001)$ and worst eGFR at 12 months $(51.8 \mathrm{vs} 70.1 \mathrm{ml} / \mathrm{min} / 1.73 \mathrm{~m} 2, \mathrm{P}<0.001)$. Among the characteristics studied, donor's age was associated with higher risk for DGF(OR1.02,CI95\%1.001-1.042,P<0.05). Multivariable analysis showed that DGF was an independent risk factor for graft loss(OR2.924,CI95\%1.45$5.88, \mathrm{P}<0.01)$ and death $(\mathrm{OR} 3.05, \mathrm{Cl} 95 \% 1.22-7.62, \mathrm{P}<0.02)$. At 84 months, overall graft survival $(86 \% v s 66 \%, \mathrm{P}<0.01)$ and patient survival $(91 \%$ vs $73 \%, \mathrm{P}<0.04)$ was higher in patients without DGF. The same was not observed for censored graft loss. Survival curves are presented in Figure1. Among DGF patients, 33 had DGF1-4days,39 had DGF5-11days,37 had DGF>12days. Survival curves according to DGF length are presented in Figure2. DGF $>12$ was an independent risk factor for overall graft $\operatorname{loss}(\mathrm{HR} 7.21, \mathrm{Cl} 95 \% 2.96-17.55, \mathrm{P}>0.01)$, censored graft loss(HR 8.71,Cl95\% 2.51-30.14,P>0.01), and death(HR5.85,Cl95\% 1.6520.79,P>0.01).DGF5-11 was an independent risk factor for overall graft loss(HR $3.65, \mathrm{Cl} 95 \% 1.56-8.53, \mathrm{P}>0.01)$ and death(HR4.40,Cl95\%1.54-12.53,P>0.01). The incidence of acute rejection was higher in DGF>12days:41\% in this group had rejection(vs8\% in DGF5-11 and 0\% in DGF1-4). DGF had a clear impact on overall patient survival. DGF for more than 12 days predicted death-censored graft loss. The threshold mark to predict patient survival and overall kidney survival was 5 days of DGF. Acute rejection has to be considered from day 5 of DGF. In our study it was significantly more common after 12 days.
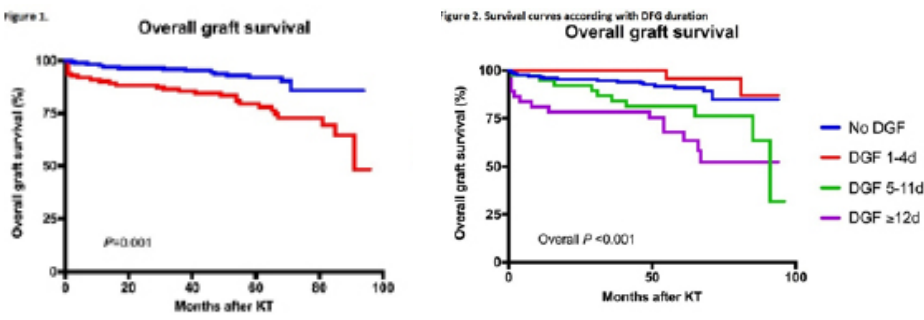
FAMERP, São Jose do Rio Preto, SP, Brazil.; 2 - Kidney Transplant Unit, Hospita de Base, FAMERP/FUNFARME, São Jose do Rio Preto, SP, Brazil.; 3 - Urology and Nephrology Institute, São Jose do Rio Preto, SP, Brazil.

Background: It is possible that donor renal tissue characteristics determine the initial graft function and kidney transplant (KTX) outcomes. Objective: To evaluate risk factors for delayed graft function (DGF) based in 106 paired KTx performed in a single center. Methods: The 53 kidney pairs were grouped according to the presence (+) or absence (-) of DGF in the mate recipients: DGF $(-/-) n=5 ; D G F(+/+) n=39 ;$ DGF (+/-) n=9. Results: Donors were predominantly males $(58 \%)$ and $70 \%$ were standard criteria type (SCD); median age was $42 \pm$ 15 years, with a hospitalization time of $6 \pm 5$ days. KTx recipients had an overall DGF rate of $82 \%$, lasting $12 \pm 7$ days. Comparing pairs, recipient age of pairs DGF $(+/+)$ were older $(50 \pm 11$ years) vs. DGF (-/-) $(40 \pm 9$ years); $p=0.008$ and Cold ischemia time (CIT) was significantly shorter in the group without DGF $(-/-)$ CIT $22 \pm 7$ hours vs. DGF (+/+) $26 \pm 5$ hours; $p=0.003$. HLA mismatch and hypersensitized number of patients (PRA $>30 \%$ ) were not different among the 3 groups. One-year serum creatinine, 24 hours proteinuria, glomerular filtration rate and acute rejection rate were also similar. Kidney Donor Risk Index (KDPI) of pairs were significantly higher in DGF $(+/+) 67 \%$ vs. DGF $(-/-) 48 \%$; $p=0.01$. One year patient survival were DGF $(+/+) 88 \%$ vs. DGF $(-/-) 100 \% ; p=0.1$ and graft survival DGF (+/+) $84 \%$ vs. DGF $(-/-) 95 \% ; p=0.2$. Multiple logistic analysis showed that recipient age $(\mathrm{OR}=8, \mathrm{IC}=2-34 ; \mathrm{p}=0.003)$ and $\mathrm{CIT}(\mathrm{OR}=4, \mathrm{IC}=1.2-14$; $p=0.03$ ) influenced the DGF rate. Conclusion: Pairs that developed DGF were associated with higher KDPI and prolonged $\mathrm{CIT}$ and older recipient age were the main risk factors for DGF in our study.

Palavras-chave : Kidney transplant, delayed graft function, paired kidneys
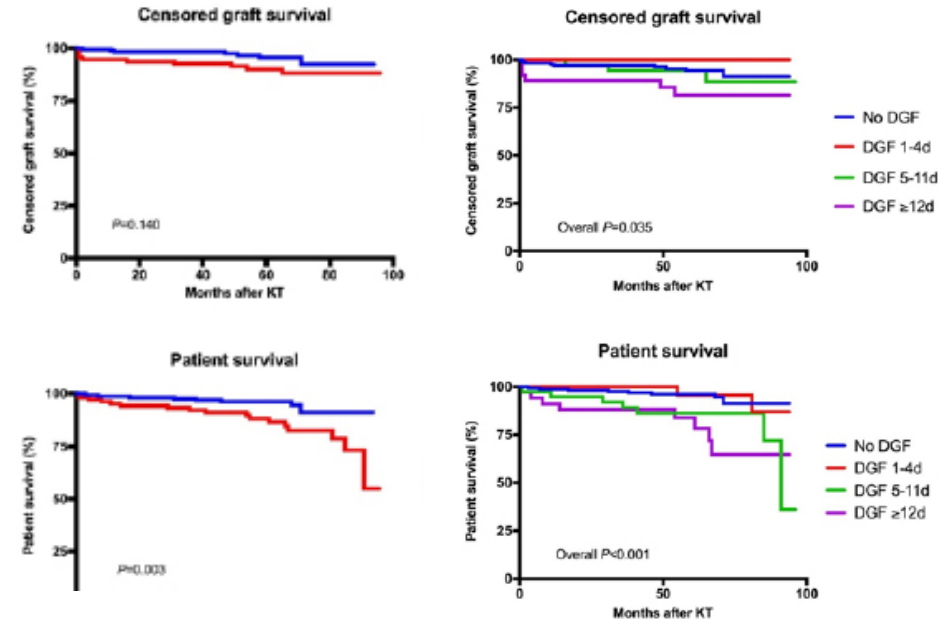


\section{СB01-008}

IMPACT OF DELAYED GRAFT FUNCTION ON LONG TERM OUTCOMES OF KIDNEY TRANSPLANTATION

Hugo Antunes; Belmiro Parada; João Carvalho; Edgar Tavares-Da-Silva; Luís Rodrigues; António Roseiro; Carlos Ferreira; Arnaldo Figueiredo

Serviço de Urologia e Transplantação Renal, Centro Hospitalar e Universitário de Coimbra, Portugal

Introduction: Delayed graft function (DGF) is a common complication experienced by kidney transplant recipients. It is often considered a risk factor for acute rejection and worse long-term outcomes. However, this association is not confirmed in some studies. Objective: To evaluate the impact of DGF on renal transplantation outcomes. The secondary objective was to analyze risk factors for DGF. Material and Methods: We performed a cross-sectional study of 1398 kidney transplants performed in our Renal Transplantation Department between 2006 and 2016. We analyzed the impact of DGF on the various functional outcomes of kidney transplantation. We evaluated the association of factors such as characteristics of the donor, characteristics of the recipient time of cold ischemia and others with the development of DGF. Results: The mean age of the recipients was $49.1 \pm 13.2$ years, with $68.3 \%$ corresponding to male patients. Two-hundred and thirty $(16,5 \%)$ recipients presented DGF. There was no significant difference between the gender of the receptors and the development of DGF. The median follow-up time was 83 months (range, 15-147 months). Factors associated with DGF were: deceased donor transplants, higher recipient and donor age, time on dialysis and cold ischemia time $(p<0.001)$. The donor creatinine value at the time prior to transplantation was higher in the group of patients who developed DGF, $1.03 \mathrm{mg} / \mathrm{dl}$ vs. 0.86 $\mathrm{mg} / \mathrm{dl}(\mathrm{p}<0.001)$. The DGF group showed a higher incidence of acute rejection, $13.5 \%$ vs. $5.1 \%, p<0.001$. Patients with DGF showed significantly lower rates of graft survival and overall survival $(p<0.01)$. Overall survival at 1 and 5 years was $93.7 \%$ and $87.6 \%$ in DGF group and $97.9 \%$ and $91.8 \%$ in non-DGF group, respectively. Conclusion: DGF is associated with worse clinical outcomes. We therefore emphasize the importance of clinicians trying to minimize the risk factors associated with this situation.

Palavras-chave : Delayed graft function, Renal Transplantation.

\section{CB01-009}

\section{REFRACTORY ANEMIA IN A KIDNEY TRANSPLANT PATIENT}

Inês Duarte; Joana Gameiro; Cristina Outerelo; Estela Nogueira; José António Lopes

\section{Centro Hospitalar Lisboa Norte}

Anemia is a common finding after kidney transplant (KT). The authors present the case of a 34 year-old Pakistanis male with chronic kidney disease due to an IgA nephropathy. He had a deceased-donor KT in 2017. Induction immunosuppression therapy was with thymoglobulin, tacrolimus (TAC) and methylprednisolone and maintenance therapy with mycophenolate (MMF) $500+500 \mathrm{mg}$, TAC $4+4 \mathrm{mg}$ and prednisolone (PD) $5 \mathrm{mg}$. Baseline creatinine was $2.3 \mathrm{mg} / \mathrm{dL}$. One year after $\mathrm{KT}$ he developed dyspnea and fatigue. He denied fever, loss of appetite, gastrointestinal blood loss or any other symptoms. Laboratory revealed hypochromic microcytic anemia with $\mathrm{Hb} 5.8 \mathrm{~g} / \mathrm{dL}, \mathrm{Htc}$ $18.6 \%$, VGM 75.4fL, HGM 23.6pg, serum iron $125 \mathrm{ug} / \mathrm{dL}$. ferritin $321 \mathrm{ng} / \mathrm{L}$, normal LDH and haptoglobin. Upper endoscopy and colonoscopy were were normal. Anemia was unresponsive to increasing doses of darbepoetin. Myelogram revealed erythroid hyperplasia with numerous proerythroblasts. Viral load of cytomegalovirus and Epstein-Barr virus was negative. Parvovirus B19 (PVB19) IgM was positive with a viral load of $777.500 \mathrm{UL} / \mathrm{mL}$. Immunosuppression was reduced and he was treated with immunoglobulin $0.5 \mathrm{mg} / \mathrm{kg} / \mathrm{day}$ for 7 days. After one week $\mathrm{Hb}$ was $8 \mathrm{~g} / \mathrm{dL}$ and on a 2 month follow-up patient remains asymptomatic with $\mathrm{Hb} 10 \mathrm{~g} / \mathrm{dL}$, medicated with MMF $250+250$, TAC $4+4$ and PD $5 \mathrm{mg}$. Although rare, PVB19 infection is a clinically significant infection which often presents as aplastic anemia in the post-transplant period. This is the first reported case of anemia due to PVB19 infection presenting with erythroid hyperplasia in a KT patient. In vitro, erythropoietin has been shown to markedly increase PVB19 replication in bone marrow. The use of high dose darbepoetin possibly exacerbated the infection and led to an increased yet ineffective erythropoiesis causing the erythroid hyperplasia. This case illustrates the importance of considering PVB19 in the diagnosis of anemia and the ineffectiveness of erythropoietin therapy in treating this infectious disease.

Palavras-chave : Refractory anemia, kidney transplant, Parvovirus B19 infection
CB01-010

INFLUENZA VACCINE-INDUCED RHABDOMYOLYSIS IN A KIDNEY TRANSPLANT PATIENT

Larissa Pizzolotto1 Valter Duro Garcia1 Rosana Mussoi Bruno1Santa Casa de Porto Alegre

A 52-yr-old white female received a cadaveric kidney in 2000. Her basal creatinine $0,9 \mathrm{mg} / \mathrm{dL}$. She had persistent hyperlipidemia and in 2017 was diagnosed with angina and 20 days before the admission in May 2018 she had an uneventful angioplasty. She presented for one week history of progressive weakness and myalgia. Muscle pain and weakness started in the thighs and spread to calves, arms until she was unable to walk. She also noticed red/brown urine but normal urine output. The symptoms had begun 12 hours after the influenza vaccine. Her daily medications included cyclosporine $75 \mathrm{mg}$, azathioprine $50 \mathrm{mg}$, prednisone $5 \mathrm{mg}$, aspirin $100 \mathrm{mg}$, amlodipine $5 \mathrm{mg}$,enalapril $5 \mathrm{mg}$, levothyroxine $75 \mathrm{mcg}$,clopidogrel $75 \mathrm{mg}$ and simvastatin $40 \mathrm{mg}$. She had taken the statin for at least 10 years and her creatine kinase (CK) had always been normal. Her physical exam showed only generalized muscle weakness and tenderness. Admission laboratories (normal in parenthesis) showed creatinine 1,2mg/dL (0,3-1,3), CK $27969 \mathrm{U} / \mathrm{L}$ (33-211), aldolase 97,9 U/L $(<7,6)$ aspartate transaminase (TGO) $838 \mathrm{U} / \mathrm{L}(<$ 34) (alanine transaminase (TGP) $254 \mathrm{U} / \mathrm{L}$ (10 to 49). Urinalysis showed no red cells and positive dipstick for albumin + and Hemoglobin 4+. Simvastatin was stopped; she received hydration with bicarbonate and fully recovered after 7 days. Fifteen days after the event her creatinine was $1 \mathrm{mg} / \mathrm{dL}, \mathrm{CK} 68$ $\mathrm{U} / \mathrm{L}$ aldolase 5,5 U/L, TGO $27 \mathrm{U} / \mathrm{L}, \mathrm{TGP} 34 \mathrm{U} / \mathrm{L}$, normal urinalysis. Given the time course of events and the absence of other causes, this may represent an immunologically mediated response to the vaccine similar to the first case described by Raman and col in 2006 while the vaccine acted as a trigger for the development of rhabdomyolysis on a background of statin therapy. We conclude that there is a risk of rhabdomyolysis developing following influenza vaccinations in patients who receive concomitant myotoxic drugs.

Palavras-chave : vaccine, rhabdomyolisys, kidney transplant

CB01-011

CRESCENTIC IGA NEPHROPATHY AFTER KIDNEY TRANSPLANT: A RARE CASE REPORT

Joana Monteiro Dias; Noélia Lopez; Hugo Silva; João Gonçalves; Marta Neves1; Sofia Jorge; Alice Santana; José Guerra

Hospital de Santa Maria - Centro Hospitalar Lisboa Norte

gA Nephropathy (IgAN) is a known cause of recurrent disease after kidney transplant (KT). Its severity can range from asymptomatic hematuria or proteinuria to frank kidney disfunction (KD) and graft loss. Although graft loss is relatively common, rapidly progressive forms are unusual and crescentic formation is extremely rare - possibly tempered by these patients' chronic immunosuppressive milieu. In result of the small number of reported cases, prognosis and best course of treatment remain undefined.

The authors present a case of a 49 -year-old man submitted to KT from a diseased donor 10 years ago for stage 5 kidney disease secondary to IgAN. He had stable renal function thereafter, maintaining serum creatinine $(\mathrm{sCr}) 1.8 \mathrm{mg} / \mathrm{dL}$. At 9 years post-transplant, while on long-term immunosuppression with prednisolone, tacrolimus and mycophenolate mofetil, he developed de novo hematuria, nephrotic proteinuria of $9 \mathrm{~g} / 24 \mathrm{hours}$ and mild $\mathrm{KD}$ with $\mathrm{sCr} 1.9 \mathrm{mg} / \mathrm{dL}$. At that time a kidney biopsy (KB) confirmed recurrent IgAN with moderate inflammation and moderate interstitial fibrosis/tubular atrophy (IF/TA). He was treated conservatively with antiproteinuric measures, resulting in proteinuria reduction to $3 \mathrm{~g} / 24 \mathrm{~h}$ and stabilization of $\mathrm{sCr}$ at $2.2 \mathrm{mg} / \mathrm{dL}$. Six months later he developed rapidly progressive $\mathrm{KD}$, with $\mathrm{s} C \mathrm{C}$ rising from 2.2 to $3.5 \mathrm{mg} / \mathrm{d} \mathrm{L}$ over 7 months. $\mathrm{A}$ second KB identified crescentic IgA nephropathy, maintaining moderate IF/TA.

Given the lack of compelling evidence favoring either cyclophosphamide or Rituximab in recurrent IgAN after $\mathrm{KT}$, the high cumulative immunosuppression to which KT patients are subjected as well as this patient age and oncogenic risk, the clinical team opted for treatment with pulse methylprednisolone and Rituximab. Crescentic IgAN after KT is rare and best treatment approach is challenging. The expected treatment results mimicking results in native kidney IgAN are lacking. The known additional oncogenic risk of transplanted patients and prolonged immunosuppression may favor Rituximab in this setting, but additional data is needed

Palavras-chave : Nefropatia IgA, Crescêntica, Pós Transplante Renal 
CB02-001

QUALIDADE DO DOADOR RENAL FALECIDO EM UMA UNIDADE DE TRANSPLANTES DO BRASIL: A APLICAÇÃO DE UM NOVO ÍNDICE DE RISCO

Claudia Maria Costa De Oliveira'; Beatriz De Souza Sampaio²; Iana Fernanda De Sousa Machado²; Silvana Daher Costa ${ }^{3}$; Ronaldo Matos Esmeraldo ${ }^{3}$ Centro Universitário Unichristus; 3 - Hospital Geral de Fortaleza-HGF-Ceará

Introdução: O KDPI (Kidney Donor Profile Index) pode ser um escore mais fidedigno para avaliação da qualidade e sobrevida dos enxertos. Sua utilização no Brasil não é rotineira e a seleção de doadores segue o critério da compatibilidade HLA. Objetivo: Classificar os doadores de órgãos de um centro de transplantes (TX) do Brasil segundo o critério expandido de doação (CED) e o KDPI, avaliando o impacto destes na função do enxerto renal. Métodos: Foram incluídos 217 receptores de TX renal com doador falecido, sendo avaliada a função renal pós-TX segundo a presença do CED e o KDPI. Resultados: A idade média dos receptores foi $41,1 \pm 13,7$ anos; $65 \%$ masculinos. Quanto aos doadores, $71,4 \%$ masculinos; idade média 32,2 $\pm 14,4$ anos; creatinina terminal 1,56 $\pm 1,1 \mathrm{md} / \mathrm{dl}$ $(0,2-6,5)$; causa mortis TCE em $65 \%$. A prevalência de doador com CED foi $9 \%$ e com $\mathrm{KDPI} \geq 85 \%$ foi $5,5 \%$. Observou-se diferença significativa no tempo de internamento segundo o CED (25,2 vs 17,4 dias; $p=0,003)$ e o KDPI $(27,1$ vs 17,6 dias; $p=0,004)$. A taxa de filtração glomerular foi significativamente inferior no grupo com CED aos 6, 12 e 24 meses pós-TX e segundo o KDPI $\geq 85 \%$ somente aos 6 meses. Nove pacientes com CED tinham KDPI inferior a $85 \%$, mas somente 1 paciente sem CED tinha KDPI $\geq 85 \%(p=0,000)$. Conclusão: A prevalência de doadores com KDPI elevado ou com CED foi baixa, refletindo uma politica local de não aceitação rotineira destes doadores. O KDPI não revelou superioridade em relação ao CED na função renal ao longo de 24 meses de TX, mas associouse a maior tempo de internamento. A concordância na classificação segundo os dois critérios foi significativa. Estudos adicionais locais são necessários para melhor esclarecimento da utilização destes índices.

Palavras-chave : transplante de rim, doador, qualidade, risco
1 - Centro Universitário UniChristus e Hospital Geral de Fortaleza-Ceará; 2 -

\section{CB02-003}

\section{TERCEIRO E QUARTO TRANSPLANTE DE RIM: EXPERIÊNCIA DE UM CENTRO}

Luís Loureiro; Manuela Almeida; Arlindo Matos; Rui Machado; Miguel Ramos; Leonídeo Dias; António Castro-Henriques; Rui De Almeida

\section{Centro Hospitalar Universitário do Porto}

A retransplantação renal está associada a maior risco de complicações médicas e cirúrgicas. Contudo, cada vez mais, temos doentes em lista para transplante já submetidos a transplante prévio. Neste contexto avaliamos retrospetivamente todos os doentes submetidos a terceiro e quarto transplantes na nossa unidade. Foram contabilizados 22 transplantes, 19 terceiros e 3 quartos, entre 1995 e 2018. Foram revistos os dados demográficos, técnicas cirúrgicas, complicações e resultados.

A idade média no dia do transplante é de 36 anos, sendo $59 \%$ homens. 0 tempo de transplantação com enxertos funcionantes incluindo o atual é de 7,1 anos (mediana), necessitando em média de 23 anos de terapêuticas de substituição renal. A abordagem cirúrgica foi retroperitoneal em $53 \%$ dos doentes, sendo $47 \%$ transperitoneal por acesso mediano. As artérias recetoras foram a ilíaca externa em $59 \%$ dos casos e a ilíaca comum nos restantes. As veias recetoras foram a ilíaca externa (53\%), ilíaca comum $(23,5 \%)$ e cava inferior $(23,5 \%)$. 0 procedimento foi realizado em média por 2 cirurgiões vasculares e 1 urologista. Dois enxertos nunca apresentaram função. Apenas houve necessidade de re-intervenção cirúrgica em 2 doentes (1 transplantectomia às 12 horas pósimplantação por rejeição aguda e 1 pontagem ilíaca-renal com veia grande safena por kinking da artéria renal). A maioria (55\%) dos doentes teve diurese imediata, sendo que os restantes iniciaram diurese até ao $13 \%$ dia. Em $23 \%$ dos doentes o enxerto foi de dador vivo (apenas terceiros transplantes). A sobrevivência dos enxertos aos 12 meses foi de $78 \%$ e aos 24 meses de $70 \%$. A mediana de sobrevivência dos enxertos é de 40 meses. Um doente faleceu no período de seguimento (mortalidade 4,5\%), 96 meses após ter sido transplantado.

Na população analisada a retransplantação de um terceiro e quarto enxerto teve uma baixa morbilidade (9\%), apresentando estes enxertos uma elevada sobrevivência.

Palavras-chave: transplante renal, re-transplante renal

\section{CB02-004}

\section{CB02-002}

HIGH-URGENCY RENAL TRANSPLANTATION FOR PATIENTS WITH VASCULAR ACCESS FAILURE: A SINGLE-CENTER EXPERIENCE

\section{Joana Gameiro; Sofia Jorge; Marta Neves; José Guerra; Alice Santana}

\section{Centro Hospitalar Lisboa Norte, EPE}

In face of access failure for renal replacement therapy or severe complications despite or due to dialysis, high urgency renal transplant (HU-RT) allocation is possible. Vascular access failure patients have multiple comorbidities and a higher risk of cardiovascular and thrombotic events; thus, it is presumed that graft and patient survivals might be worse for these patients. The aim of this paper was to analyze the characteristics and outcomes of HU-RT patients due to access failure for renal replacement therapy, comparing to a population of deceased-donor renal transplant (DDRT) patients. We analyzed data from our Renal Transplantation Unit from January 2006 to April 2017. In this period 374 patients had a renal transplant. Of these, 11 patients received a HU-DDRT. Comparing with patients who had a DDRT, HU-DDRT patients were predominantly female ( $54.5 \%$ vs $43.5 \%, p=0.007)$ and younger (41.6 $\pm 7.9 \mathrm{vs} 49.4 \pm 11.8, \mathrm{p}=0.031)$. HU-DDRT patients were not significantly more sensitized than DDRT $(14.1 \pm 27.4$ vs $13.5 \pm 24.1, p=0.935)$, and had comparable number of human leukocyte antigen (HLA) mismatches $(3.4 \pm 1.4$ vs $3.6 \pm 1.2$, $p=0.343)$. Despite the higher incidence in hypertensive $(90.9$ vs $73.5 \%, p=0.196)$ and diabetic patients $(27.3 \%$ vs $15.7 \%, p=0.305)$ in the HU-DDRT group, this difference was not statistically significant. The percentage of retransplantation was similar in both groups $(9.1 \%$ vs $7.2 \%, p=0.808)$. Donor characteristics were similar between the groups, namely regarding donor gender, age and baseline serum creatinine. There was an increased proportion of expanded criteria donors in HU-DDRT $154.5 \%$ vs $25.1 \%, p=0.028)$. There were no differences in cold or warm ischemia time, nor in serum creatinine at discharge or during the first two years of follow-up. In both groups a similar proportion of patients experienced acute rejection episodes. Comparable to DDRT patients, HU-DDRT patients had a high proportion of graft survival at one and two years of follow-up. Mean follow-up for both groups was comparable $(78.5 \pm 46.7$ vs $68.4 \pm 40.8$ months, $p=0.424)$. Overall, graft loss occurred in approximately $36.4 \%$ of HU-DDRT patients and $20.9 \%$ of DDRT patients, however this difference was not statistically significant $(p=0.219)$. Both groups had an overall mortality rate of around $9 \%$. The differences were not statistically significant probably due to the limited number of patients. More comorbidities and reported worse cardiovascular prognosis of access failure (AF) patients and use of expanded criteria donors did not reflect in worse short-term outcomes in our cohort, which highlights the importance of HU-RT in prolonging the survival of AF patients.

Palavras-chave: renal transplant, vascular access failure, high urgency, outcomes
RISCO DE DOENÇA RENAL CRÓNICA TERMINAL EM DADORES VIVOS DE RIM: ESTUDO DE COORTE

Nuno Moreira Fonseca1; Ana Messias1; Ana Carina Ferreira1; Cecília Silva1; Ana Pena2; João Sousa1; Fernando Nolasco1

1 - Serviço de Nefrologia, Centro Hospitalar Lisboa Central; 2 - Serviço de Cirurgia, Centro Hospitalar Lisboa Central

Introdução: Os objectivos deste trabalho são: 1) avaliar o risco de desenvolver DRCT pré-doação da população dadora do nosso centro a 15 anos; 2) avaliar o risco de DRCT aos 15 anos pós-doação.

Métodos: O risco de doença renal crónica terminal pré-doação foi calculado com recurso ao modelo desenvolvido pelo CKD prognosis group (CKDPG). O risco pós-doação aos 15 anos pós-doação foi calculado de acordo com o modelo CKD prognosis group, de Muzaale et al, e de Mjøen et al. Foi utilizado software STATA e $p<0.05$ foi considerado estatisticamente significativo.

Resultados: Entre 2006 e 2016, houve 42 doações de rim no nosso centro. $71 \%$ dos dadores eram do sexo feminino, com uma mediana de idade de 47,5 anos (21-65), IMC mediano de $24.3 \mathrm{Kg} / \mathrm{m} 2$ (21.6 - 26.3). 15 apresentavam HTA $(35,7 \%)$; 8 sob um fármaco antihipertensor (19\%) e 1 sob 2 fármacos $(2,38 \%)$. 8 eram fumadores ativos (19\%) e 2 ex-fumadores $(4,8 \%)$. A TFGe mediana prédoação era de $114 \mathrm{~mL} / \mathrm{min} / 1,73 \mathrm{~m} 2$ (88-124). A proteinúria de mediana (urina 24h) $137,5 \mathrm{mg} / 24 \mathrm{~h}(68-175)$.

Nesta população o risco pré-doação de desenvolver DRCT a 15 anos (CKDPG) é em mediana de $0,15 \%(0,1-0,24)$. De acordo com os modelos do CKD prognosis consortium, de Muzaale e Mjøen o risco de desenvolvimento de DRCT aos 15 anos após a doação aumenta em mediana para 0,58\% (0,08-4), 1,2\% (1,6-6,6), $1,7 \%(0,2-9,6)$. De acordo com estes modelos a percentagem de dadores que apresenta um risco de desenvolvimento de DRCT aos 15 anos $>1 \%$ é de $21 \%$ ,57\% e $78 \%$, respectivamente.

Conclusão: A disparidade do risco entre os vários modelos reforça a necessidade de follow-up dos dadores a longo termo.

Palavras-chave : Dador vivo, Rim, Doença Renal Crónica Terminal 
CB02-005

\section{UMA ANÁLISE DE SOBREVIDA DO TRANSPLANTE RENAL DE DADOR VIVO}

Sara Rodrigues ${ }^{1}$; Rachele Escoli² ${ }^{2}$ Catarina Eusébio ${ }^{3}$; Leonídio Dias ${ }^{4}$; Manuela Almeida ${ }^{4}$; La Salete Martins ${ }^{4}$; Sofia Pedroso ${ }^{4}$; António Castro Henriques ${ }^{4}$

1 - Centro Hospitalar Vila Nova de Gaia e Espinho; 2 - Centro Hospitalar Médio Tejo; 3 - Centro Hospitalar Trás-os-Montes e Alto Douro; 4 - Centro Hospitalar do Porto

Introdução: O transplante renal de dador vivo (TRDV) proporciona, a curto e longo prazo, uma melhor sobrevida do enxerto quando comparado com transplante de dador cadáver. A identificação dos fatores relacionados com o prognóstico nestes recetores poderá permitir uma melhoria adicional dos resultados já alcançados.

Objetivo: Analisar a sobrevida do enxerto e fatores de impacto no TRDV nos últimos 14 anos.

Método: Estudo retrospetivo dos doentes submetidos a TRDV, num centro, entre 2004 e 2017.

Resultados: 278 doentes foram submetidos a TRDV, $65 \%$ homens, com idade média $40+-12$ anos. Os dadores tinham $46+-10$ anos de idade, $68 \%$ mulheres. 0 follow-up teve uma mediana de 4 anos $(0-13) ; 11.2 \%$ apresentaram pelo menos um episódio de rejeição ao longo do follow-up, $6.7 \%$ perderam o enxerto e $1.4 \%$ faleceram. A sobrevida global do enxerto foi de $97 \%$ aos 10 anos e de $86 \%$ aos 14 anos. Associaram-se significativamente a uma pior sobrevida a presença de MM HLA em DR $(p=0.04)$ e sexo feminino do recetor $(p=0.01)$, particularmente com dadoras igualmente mulheres. A idade, TSFR prévia, NTA e/ou necessidade de diálise no pós-transplante ou presença de DSA prévio não apresentaram impacto significativo na sobrevida do enxerto. Na Regressão de Cox, a presença de MM HLA em DR ( $p=0.02$, HR 4.0) manteve-se associada a um pior prognóstico. Após ajuste para as complicações vasculares precoces do enxerto, o impacto do sexo feminino do recetor na sobrevida deixou de ser significativo.

Conclusão: Os doentes submetidos a TRDV apresentaram no global uma boa sobrevida do enxerto ( $97 \%$ aos 10 anos). A presença de MM HLA em DR mostrou-se consistentemente associada a pior prognóstico a longo prazo. A idade e a NTA associaram-se a complicações a curto mas não a longo prazo. Não foi possível obter conclusões seguras acerca do impacto do género no presente estudo.

Palavras-chave: sobrevida

\section{СВ02-006}

AVALIAÇÃO DE DOADORES VIVOS COM CLEARANCE DE CREATININA A PARTIR DA URINA DE 24 HORAS, ESTIMATIVAS DE TAXA DE FILTRAÇÃO GLOMERULAR E RBP URINÁRIA: CORRELAÇÕES COM A FUNÇÃO RENAL APÓS A DOAÇÃO.

Lúcio Requião-Moura; Paula Rebelo Bicalho; Alvaro Pacheco-Silva

\section{Hospital Israelita Albert Einstein}

Introdução: a avaliação da função renal de doadores de rim deve ser feita de forma bastante criteriosa para minimizar os riscos de doença renal crônica (DRC) após a doação. Objetivo: correlacionar taxa de filtração glomerular (TFG) e RBP urinária (RBPu) com evolução de função renal após a doação em vida. Metodologia: avaliamos 397 doadores vivos acompanhados em média por 87 meses. Avaliações pré nefrectomia: clearance de creatinina urina 24h (U24CrCl-ml/min,) MDRD e CKD-EPI (ml/min/1,73m2); dosagem de RBP urinária (RBPu-mg/L). Resultados: Demografia: idade-43,3+/-10,5 anos, feminino-62\%, negros-11,6\%, BSA-1,7+/-0,2m2. Função renal pré doação (92,7\%): U24CICr-116,4+/-22,2; MDRD-102,6+/-21,0; CKD-EPI-103,3+/-15,2. A massa de creatinina foi de $20,4+/-4,9 \mathrm{mg} / \mathrm{kg}$, sendo maior em homens $(20,7+/-$ $8,8$ vs. $16,6+/-6,5, p=0,007)$. Não houve correlação entre massa de creatinina e $\operatorname{MDRD}(p=0,99)$ ou CKD-EPI $(p=0,59)$. A melhor correlação ocorreu entre MDRD e CKD-EPI: R2=0,79, $\mathrm{p}<0,0001$. Medida de RBPu (mg/L) estava disponível em $65,7 \%$ da coorte inicial: 0,16 [IIQ: 0,05-0,53], sendo $63,1 \%<=0,4,36,1 \%$ entre $0,4-1,0$ e $0,8 \%>1,0$. Não houve correlação entre $\operatorname{RBPu}$ e MDRD $(p=0,90)$ ou CKD-EPI ( $p=0,75)$. O CKD-EPI após a doação foi 70,6+/-16,9: redução de 33,6ml/ min/1,73m2 ou $32,6 \%$. Não houve correlação entre RBPu inicial e redução da TFG após a nefrectomia $(p=0,77)$. A amplitude dessa redução correlacionou-se com o CKD-EPI em 1 ano: R2=0,08, p<0,0001. Utilizando pareamento tempotempo, observamos significativa redução na TFG após 1 ano, em comparação com a basal: $105,+/-71,8$ vs. $71,8+/-16,3$ ( $N=265, p<0,0001)$, não havendo variação entre 1-3 $(N=178, p=0,22)$ e $3-5$ anos $(N=112, p=0,69)$. Conclusões: $A$ urina de 24 horas para avaliação de função renal não acrescentou informações em relação às estimativas de TFG. A RBPu não predisse evolução da função renal após a nefrectomia. Observou-se significativa redução na TFG logo após a nefrectomia e a amplitude dessa redução correlacionou-se com função renal em longo prazo.

Palavras-chave: Doador vivo, Nefrectomia, Função renal, Clerance de creatinina, MDRD, CKD-EPI, RBP urinária
CB02-007

CHANGES IN RENAL FUNCTION ONE YEAR AFTER RADICAL NEPHRECTOMY FOR CANCER COMPARED TO KIDNEY DONATION.

Cristiano Trundade Andrade1; Wagner Eduardo Matheus2; Ubirajara Ferreira2; Marilda Mazzali1; Marcelo Lopes De Lima1

1 - Programa de Transplante Renal- Universidade Estadual de CampinasUnicamp; 2 - Divisão de Uro-Oncologia- Universidade Estadual de CampinasUNICAMP

Purpose: Adaptive changes to acute reduction in renal mass after radical nephrectomy can cause chronic kidney disease more frequently in patients with renal cancer compared to kidney donors. The aim of this study was to compare changes in eGFR 1-year after radical nephrectomy and to identify risk factors for CKD. Methods: Medical records from 79 patients submitted to nephrectomy from January 2008 to September 2013, divided into 2 groups, according to the indication of nephrectomy: kidney donor $(n=39)$ and renal tumor $(n=40)$ were analyzed for demographic data, presence of comorbidities, tumor size and glomerular filtration rate (GFR) estimated by the CKD-EPI formula, at baseline and 12 months post nephrectomy. Results: In donor group there was a reduction of $31.3 \%$ in e-GFR within 1 -year, and $25.6 \%$ of were classified as CKD-3 (eGFR $<60 \mathrm{ml} / \mathrm{min} / 1.73 \mathrm{~m} 2$ ). Risk factors were baseline e-GFR $<90 \mathrm{ml}$ $\min / 1.73 \mathrm{~m} 2(p=0.0330)$ and overweight $(p=0.0268)$. In tumor group reduction in e-GFR was of $18.8 \%$, but $57.5 \%$ of patients became CKD-3. The only risk factor was the presence of comorbidities $(p=0.0354)$. Analysis of tumor size showed a significant reduction in e-GFR for tumors $\leq 7 \mathrm{~cm}$, while for tumors $>15 \mathrm{~cm}$ eGFR remained similar to baseline levels. Conclusion: Risk factors for CKD, 1-year after radical nephrectomy, were presence of hypertension or diabetes in patients with renal cancer, and overweight and baseline e-GFR lower than 90 $\mathrm{ml} / \mathrm{min} / 1.73 \mathrm{~m} 2$ for kidney donors. The increased loss of eGFR for tumors $<7 \mathrm{~cm}$ suggest that partial nephrectomy should be considered when possible.

Palavras-chave : radical nephrectomy; Kidney donation; Renal function, renal cell carcinoma

\section{CB02-008}

TRANSPLANTE RENAL DE DADOR VIVO: A EXPERIÊNCIA DE UM CENTRO DE TRANSPLANTAÇÃO EM PORTUGAL

Ana Messias'; Filipa Cardoso'; Nuno Moreira Fonseca1; João Sousa1; Ana Pena $^{2}$; Ana Marta Nobre ${ }^{2}$; Sofia Carrelha²; Paulino Pereira²; Américo Martins ${ }^{2}$; Patrícia Cotovio'; Fernando Caeiro'; Cecília Silva'; Inês Aires1; Aníbal Ferreira'; Francisco Remédio'; Eduardo Barroso²; Fernando Nolasco'

1 - Serviço de Nefrologia - Hospital Curry Cabral - Centro Hospitalar Lisboa Central; 2 - Serviço de Cirurgia - Hospital Curry Cabral - Centro Hospitalar Lisboa Central

Introdução: O transplante renal de dador vivo (TR DV) é a melhor opção de tratamento dos doentes com doença renal crónica (DRC) terminal quando na presença de um dador compatível. Associa-se a melhor prognóstico quando comparado com o transplante renal de dador cadáver. Objectivos: Analisar os resultados dos TR_DV realizados no nosso centro. Métodos: Análise retrospectiva dos TR_DV realizados de Julho de 2006 a Dezembro de 2016, com período mínimo de follow-up de 12 meses. Resultados: 42 TR_DV, dos quais 13 foram em situação preemptive e 1 após falência do enxerto de dador cadáver. A maioria dos receptores era do sexo masculino (30) e a idade média na altura do transplante foi de $\sim 39$ anos. A etiologia da DRC era presuntiva na maior parte dos casos e a duração média da diálise dos 28 doentes em diálise (7 em diálise peritoneal) foi de 1,5 anos. A maioria dos dadores era do sexo feminino (30) e aparentado ao recetor (26), com idade média de 46 anos e com creatinina sérica média de $0,77 \mathrm{mg} / \mathrm{dl}$ na altura da doação. A maioria dos doentes recebeu um enxerto com 3 incompatibilidades HLA e $\sim 5 \%$ com 6 . A terapêutica imunossupressora de indução consistiu em basilixmab em 56,1\% e timoglobulina em $41,5 \%$ dos doentes associado a tacrolimus, micofenolato de mofetil e corticoides. 8 doentes fizeram imunoglobulina poliespecífica. 3 doentes morreram e 6 perderam o enxerto renal. Aos 1, 5 e a 10 anos, as taxas de sobrevida do enxerto renal ("death-censored") foram de 100\%, 92,5\% e $84,6 \%$ e as taxas de sobrevida dos doentes foram de $97,6 \%, 95,2 \%$ e $92,4 \%$. Conclusões: O transplante renal de dador vivo apresenta bons "outcomes" relacionados com a sobrevida do enxerto e do doente. Os resultados do nosso centro são semelhantes aos descritos na literatura.

Palavras-chave : Dador Vivo 
CB02-009

DADOR VIVO DE RIM, A REALIDADE DE UM CENTRO DE TRANSPLANTAÇÃO PORTUGUÊS

Catarina Carvalho1; Ricardo Pinto1; Sandra Tafulo2; Fátima Freitas2

1 - Serviço de Imuno-Hemoterapia, Instituto Português de Oncologia do Porto Francisco Gentil, EP; 2 - Instituto Português do Sangue e da Transplantação do Norte - Área da Transplantação, IP

Introdução: A transplantação renal a partir de dador vivo apresenta duas grandes vantagens em comparação com o dador cadáver: maior probabilidade do transplante ser bem-sucedido devido a melhores resultados e dispensa de inscrição do doente em lista de espera para transplantação. Atualmente qualquer pessoa pode ser dador de órgão em vida, quer se se verifique ou não relação de consanguinidade.

Objetivo: Avaliação do perfil de dador vivo de rim num centro de transplantação na última década.

Material e Métodos: Estudo retrospetivo e descritivo da população de dadores vivos de rim, com transplante realizado entre os anos de 2008 e 2017. Foi avaliado o número de dadores, género, mediana de idades, relação de parentesco dadorrecetor e incompatibilidades HLA -A, -B e -DR em dadores não aparentados. A compilação de dados foi realizada mediante a consulta da aplicação LUSOT $^{\circledR} \mathrm{e}$ decorreu em maio de 2018.

Resultados:

\begin{tabular}{|c|c|c|c|c|c|c|c|c|c|c|c|}
\hline & 2008 & 2009 & 2010 & 2011 & 2012 & 2013 & 2014 & 2015 & 2016 & 2017 & Total \\
\hline Deadores & 20 & 24 & 21 & 19 & 24 & 29 & 39 & 99 & 36 & 40 & 291 \\
\hline Ferninine & 14 & 17 & 16 & 15 & 9 & 21 & 30 & 18 & 26 & 33 & 199 \\
\hline Mascullina & 6 & 7 & 5 & 4 & 15 & 8 & 9 & 21 & 10 & 7 & 92 \\
\hline modliarla idtacks & 48 & 45 & 50 & 46 & 48,5 & 47 & 51 & 49 & 47,5 & 51 & 48 \\
\hline minimo & 27 & 26 & 32 & 21 & 30 & 32 & 25 & 23 & 23 & 23 & 21 \\
\hline maximo & 60 & 65 & 62 & Б的 & 67 & (E) & 67 & 66 & CAB & 6.5. & E8 \\
\hline Aparentodos & 28 & 21 & 11 & 10 & 10 & 19 & 24 & 28 & 19 & 20 & 180 \\
\hline Imma & 8 & 7 & 2 & 2 & 1 & 8 & 7 & 8 & 6 & 9 & 58 \\
\hline Mác & 5 & 6 & 5 & 5 & 0 & 7 & 6 & 7 & 6 & 2 & 48 \\
\hline Pni & 2 & 2 & 3 & 0 & 5 & $\mathbf{3}$ & 0 & 5 & 1 & 3 & 24 \\
\hline Ims̄on & 3 & 4 & 1 & 1 & 1 & $\mathbf{0}$ & 2 & 6 & 5 & 1 & 24 \\
\hline Fillta & 0 & 2 & 0 & 1 & 1 & 1 & 1 & 1 & 0 & 2 & 9 \\
\hline Tia & 0 & 0 & 0 & 0 & 1 & $\mathbf{0}$ & 3 & 0 & 0 & 2 & 6 \\
\hline Prima & 0 & 0 & 0 & 1 & 0 & n & 2 & 0 & 0 & 1 & 4 \\
\hline Primo & 0 & 0 & 0 & 0 & 0 & 0 & 2 & 1 & 0 & 0 & 3 \\
\hline Fillhe & 0 & 1 & 0 & 0 & 1 & 0 & 0 & 0 & 0 & 0 & 2 \\
\hline Eobrnha & a & 0 & D & D & 0 & $\mathbf{0}$ & a & 0 & 1 & o & 1 \\
\hline Tio & 0 & 0 & 0 & 0 & 0 & $\mathbf{0}$ & 1 & 0 & 0 & 0 & 1 \\
\hline Who aparentalos & 2 & 3 & $\mid 10$ & 9 & 14 & 10 & 15 & 11 & 17 & 20 & 111 \\
\hline Esposa & 1 & 3 & 9 & 6 & 6 & 4 & 11 & 2 & 11 & 15 & 68 \\
\hline Mando & 1 & 0 & 1 & 3 & 4 & 5 & 2 & 3 & 1 & 0 & 20 \\
\hline Outro & 0 & 0 & 0 & 0 & 4 & 1 & 2 & 2 & 3 & 2 & 14 \\
\hline Ciwado & 0 & 0 & 0 & 0 & 0 & 0 & 0 & 1 & 2 & 3 & 9 \\
\hline
\end{tabular}

Tabela 1: Caracterização dos dadores em género, idade e parentesco

\begin{tabular}{|l|c|}
\hline Sem incompatibilidade A, B, DR & 0 \\
\hline Sem incompatibilidade B e DR & 1 \\
\hline Uma incompatibilidade B ou DR & 1 \\
\hline Uma incompatibilidade B e uma DR & 15 \\
\hline Mais de duas incompatibilidades B e DR & 94 \\
\hline
\end{tabular}

Tabela 2: Incompatibilidade HLA -A, -B e -DR em dadores não aparentados ( $n=111$ )

Conclusão: Durante esta década foram realizados transplantes renais de uma população de 1045 dadores, sendo que os dadores vivos representaram $28 \%$. O aumento do número de dádivas em vida é notório, consequência das campanhas de sensibilização que ocorreram ao longo do tempo. O dador vivo de rim é na sua maioria do sexo feminino. O número de incompatibilidades HLA nos dadores não aparentados é elevado; no entanto, apesar do outcome não ter sido avaliado, a literatura descreve resultados superiores quando comparados com o dador cadáver.

Palavras-chave : Dador Vivo, Transplante Renal

\section{СB02-010}

ANÁLISES DOS TRANSPLANTES RENAIS DE DOADOR VIVO PREEMPTIVOS REALIZADOS NO PERÍODO DE 2011 A 1017.

Jose Osmar Medina- Pestana; Melissa Gaspar; Maria Lucia Vaz; Marina Cristelli; Bruna Beraldo; Claudia Felipe; Helio Tedesco

1 - Hospital do Rim, UNIFESP

$\mathrm{O}$ transplante renal é o tratamento de escolha para pacientes com doença renal crônica terminal. Idealmente, o transplante deve ocorrer antes de iniciar a diálise, o que é chamado de transplante preemptivo. Quando realizado com uma taxa de filtração glomerular menor que $15 \mathrm{ml} / \mathrm{min} / 1.73 \mathrm{~m} 2$, tem uma melhor sobrevida do paciente e do enxerto, especialmente com doador vivo. Estima-se que este seja o tratamento inicial em apenas 2,5\% dos pacientes nos Estados Unidos. No entanto, apesar dos benefícios claros, poucos transplantes preemptivos são realizados. 0 objetivo deste estudo é avaliar a incidência e a sobrevida do transplante renal preemptivo realizado no Hospital do Rim. Foram analisados todos os pacientes transplantados renais no período de 2011 a 2017 realizados no Hospital do Rim com tempo de seguimento de 5 anos. Foram excluídos pacientes com idade inferior a 18 anos, transplantados de outros órgãos, retransplante renal e pacientes transferidos para outro centro. No período de 2011 a 2017, foram realizados 5375 transplantes renais. Foram transplantados 3348 pacientes de doador falecido, 1405 pacientes de doador vivo e destes, 177 foram transplantes preemptivos. Este valor corresponde a 3,2 \% do total dos transplantes realizados. A média da idade dos receptores preemptivos foi 39,4 anos e $62,7 \%$ eram do sexo masculino. A etiologia da doença renal crônica foi desconhecida em $40,6 \%$ dos pacientes e em $20,3 \%$ a causa foi Glomerulonefrite crônica. A idade média do doador foi de 45,2 anos e $58,7 \%$ era do sexo feminino. Com relação ao parentesco, $48,5 \%$ foi entre irmãos e em $28,8 \%$ um dos pais. A sobrevida do receptor preemptivo em 5 anos foi maior quando comparada aos outros receptores ( $96 \%$ versus $84 \%, p<0,001$ ). Entre os receptores de doador vivo, não houve diferença na sobrevida entre os pacientes preemptivos e aqueles que iniciaram diálise antes do transplante (96\% versus $93 \%$; p 0,302). A Incidência de transplante renal preemptivo foi de 3,2 \%. Esses pacientes tiveram melhor sobrevida quando comparados aos não preemptivos. Apesar dos reais benefícios, o transplante preemptivo ainda é pouco realizado no Brasil e no mundo. O diagnóstico precoce, a preparação oportuna para a doença renal terminal e a identificação dos potenciais doadores vivos devem ser encorajadas em todos os pacientes com doença renal crônica avançada para aumentar a chance de transplante renal preemptivo.

Palavras-chave : transplante renal, preemptivo.

\section{CB04-001}

SINGLE-CENTER EXPERIENCE WITH SOFOSBUVIR-BASED HCV TREATMENT IN KIDNEY TRANSPLANTAT RECIPIENTS

Valter Garcia; Gisele Meinerz; Cynthia Keitel Da Silva; Rosana Mussoi Bruno; Elizete Keitel

\section{Santa Casa de Misericórdia de Porto Alegre}

Chronic hepatitis C (HCV) infection is an important clinical challenge after kidney transplantation. This is the initial report of a single-center experience with sofosbuvir-based HCV treatment after KT. Results: 38 patients initiated treatment: 34 completed, 3 are undergoing therapy and 1 discontinued. From the 33 with complete charts, 15 were female $(45.5 \%), 22$ caucasian $(66.7 \%)$, 27 treatment näive $(81.8 \%), 6(18.2 \%)$ had cirrhosis, one had a combined kidney-liver transplant. Mean age was $52.2 \pm 9.1$ years. Median time from transplantation was 138.0 (13-476) months. HCV genotypes 1/1a/1b, 2 and 3 corresponded to $69.6 \%, 3.0 \%$ and $18.2 \%$; and $3(9.1 \%)$ genotypes were not registered. Mean viral load was log $6.28 \pm 0.78$. Therapy consisted of sofosbuvir and daclatasvir for 24 weeks in $1(3 \%)$ patient, for 12 weeks in 27 patients $(81.8 \%)$, and associated with ribavirin in 5 patients $(15.2 \%)$. There was no statistical difference in eGFR during treatment using ANOVA $(F(4,140)=0.170$, $p=0.953$ ) (Table 1). There was a significant decrease in aminotransferases from baseline to treatment week 4 , that remained throughout treatment $(p$ $<0.05$, data not shown). In $12 / 23$ patients on calcineurin inhibitors the seric level decreased by more than $30 \%$, and dosage adjustments were necessary. Treatment was well tolerated, with 5 cases of symptomatic anemia (4 with ribavirin, 3 discontinued the drug and 1 had hemotransfusion); depressive symptoms (2), atypical chest pain (1), myalgias and arthralgia (2) and headache (2) that did not require intervention. One patient had an acute rejection episode 2 months after the end of treatment that occurred in a context of low immunosuppression (low dose MPA and steroids), and returned to dialysis after 12 months. The patient that discontinued treatment had baseline fluctuating creatinine levels and decided to interrupt treatment; creatinine levels remain the same after one year. All patients had undetectable viral loads by the end of treatment and available results from $23 / 33$ patients remain undetectable after 12 weeks. Conclusion: sofosbuvir-based HCV treatment was well tolerated after KT with sustained virological response. This is an initial experience report with encouraging results for the KT population.

Palavras-chave : hepatitis $\mathrm{C}$, kidney transplant 
CB04-002

CUPRIAVIDUS PAUCULUS CAUSING A RESPIRATORY TRACT INFECTION IN A POST-KIDNEY-TRANSPLANT PATIENT

David Fiel; Rita Calça; Eunice Cacheira; Nuno Rombo; Sara Querido; Célia Nascimento; Cristina Jorge; André Weigert; Rita Birne; Belarmino Clemente; António Martinho; Cistina Toscano; Margarida Bruges; Domingos Machado

1 - Serviço de Nefrologia do Hospital do Espírito Santo de Évora; 2 - Serviço de Nefrologia do Hospital de Santa Cruz, CHLO; 3 - Serviço de Cirurgia do Hospital de Santa Cruz, CHLO; 4 - Serviço de Patologia Clínica do Hospital de Santa Cruz, CHLO

INTRODUCTION. Cupriavidus pauculus is a gram-negative aerobic bacillus usually isolated from bottled mineral water, water from ultrafiltration systems in hospital setting and medical devices like intravascular catheters, systems of ECMO and invasive ventilation. Infections in humans are rare but usually severe, with described cases of bacteriemia, pneumonia, meningitis and sepsis. We describe a rare case of a Cupriavidus pauculus infection in a post-kidney-transplant context. CLINICAL CASE. A 60-year-old man, CKD due to chronic glomerulonephritis, initiated hemodialysis (HD) in 1991 and received a cadaveric-donor kidney transplant in 1997. The graft functioned until 2008, when he returned to HD. After 2 years he transited to Peritoneal Dialysis (PD) because of vascular access failure. He remained on PD for 7 years and received a new kidney transplant (KT) in 2018 after Sclerosing Encapsulating Peritonitis: 64-year-old donor after circulatory death, 4 mismatches ( 1 in A, 2 in B, 1 in DR), cold ischemia time $22 \mathrm{~h} 10 \mathrm{~m}$, no preformed anti-HLA antibodies, induction immunosuppressive therapy with Antithymocyte globulin (ATG), MMF and Prednisolone followed by Tacrolimus. The graft never gained function, so he remained PD dependent. A few days after transplantation, peritonitis ensued (Enteroccocus faecium, Serratia marcescens). Even after PD catheter removal, the clinical condition deteriorated, with need for continuous hemodiafiltration. The diagnose of a cecum perforation was made followed by hemicolectomy. Due to persisting respiratory and abdominal infections despite antibiotic regimens, and no kidney graft function, nephrectomy of the graft was performed, suspending immunosuppressive drugs. Later, a Cupriavidus pauculus was isolated in sputum, confirmed in two samples. Bacterial examination of the dialysis unit water system and equipment as well as of the ventilator used by the patient were negative. CONCLUSION. We present a rare case of a respiratory tract infection associated with Cupriavidus pauculus. To our knowledge, this is the first case described in a post-kidney-transplant patient.

Palavras-chave : Cupriavius, pauculus, kidney, transplant

\section{СB04-003}

PREVALÊNCIA DOS MICROORGANISMOS ISOLADOS EM UROCULTURAS EM UMA UNIDADE DE TRANSPLANTE RENAL

José Roberto Freire De Oliveira1; Mizael Augusto Diógenes Bessa5; Jefersson Matheus Maia De Oliveira5; Manoella Do Monte Alves3; Rosemary Alvares De Medeiros4; Luana Cristina Lins De Medeiros Oliveira2; Kellen Micheline Alves Henrique Costa6

1 - Hospital Universitário Onofre Lopes. Médico Infectologista.; 2 - Hospital Universitário Onofre Lopes. Farmacêutica Clínica do Transplante Renal. 3 - Hospital Universitário Onofre Lopes. Médica Infectologista; 4 - Hospital Universitário Onofre Lopes. Enfermeira do Controle de Infecção.; 5 - Hospital Universitário Onofre Lopes. Acadêmico do Curso de Medicina da UFRN.; 6 Hospital Universitário Onofre Lopes. Médica Nefrologista.

Introdução: A infecção no trato urinário é a infecção mais comum no pós-transplante renal, sendo importante o reconhecimento dos agentes microbianos envolvidos. Objetivo: Identificar os principais agentes microbianos isolados em urocultura dos pacientes transplantados renais internados em um hospital universitário no Rio Grande do Norte. Metodologia: Trata-se de um estudo retrospectivo com análise descritiva dos dados de urocultura do setor de transplante renal enviados pelo laboratório à Comissão de Controle de Infecção Hospitalar $(\mathrm{CCIH})$ no período de março/2017 a março/2018. Resultados: Foram analisadas 179 uroculturas, das quais $36(20,1 \%)$ foram positivas, $114(63,6 \%)$ negativas e $30(16,7 \%)$ contaminadas. Dentre as uroculturas positivas, teve-se como microrganismos isolados: 35 (97,2\%) bactérias e 01 (2,8\%) fungo (leveduras e hifas). As principais bactérias isoladas foram: 16 Klebsiella sp (45,7\%), 06 Escherichia coli $(17,1 \%), 06$ Pseudomonas sp (17,1\%), 04 Enterococcus sp (11,5\%), 02 Enterobacter $(5,7 \%)$ e 01 Streptococcus agalactiae $(2,9 \%)$. Das cepas E. coli, apenas uma era ESBL $(2,9 \%)$. Quanto à Pseudomonas $\mathrm{sp}$, 03 cepas tinham resistência a carbapenêmicos $(8,6 \%)$. E dentre as Klebsiella sp, 08 tinham resistência a carbapenêmicos $(22,9 \%)$ e 01 resistência à carbapenêmico e polimixina B (2,9\%). Conclusão: Os dados apontam para um aumento na resistência a carbapenêmicos da Pseudomonas sp e Klebsiella sp, que juntas somam 34,3\% (12) dos microrganismos isolados. Destarte, planejamento de ações corretivas nas políticas de uso racional de antimicrobianos, no programa do paciente seguro e no programa da cirurgia segura, precisam ser prioritárias para que este perfil de resistência não aumente ao longo dos anos.

Palavras-chave: Urocultura, Transplante Renal, Infecção Urinária, Microorganismo
CB04-004

HEPATITE C EM DOENTES EM LISTA ATIVA (LA) PARA TRANSPLANTE RENAL

Henriqueta Nanduva, Sofia Homem, Manuela Bustorff, Susana Sampaio, Hugo Ferreira, Palmira Sousa, Leocadia Lobo Carlos

Departamento de Nefrologia do Centro Hospitalar de São João, Porto, Portugal

O virus da hepatite $\mathrm{C}(\mathrm{VHC})$ é um vírus RNA com tropismo hepático e para órgãos linfóides, evoluindo frequentemente para a cronicidade. Estima-se que atinja $1-1,5 \%$ da população portuguesa. Entre os doentes renais, a sua prevalência é cerca de 3 vezes superior. O terapêutica com os antiviricos de aç̧ão direta tornou possivel o tratamento do VHC de forma eficaz e segura antes ou após o transplante renal (TR). Objetivo: avaliar os doentes com anticorpo para o $\mathrm{VHC}(\mathrm{VHC}+$ ) em lista activa na Unidade de Transplante Renal do Centro Hospitalar S. João. Métodos: Estudo retrospectivo, com dados obtidos pela consulta dos processos clínicos. Resultados: Identificaram-se 14 doentes com VHC+ em 448 doentes em lista ativa (3.1\%), com idade média de $53,3+12.1$ anos, 8 do género masculino. A forma de transmissão mais frequente foi parentérica relacionada com transfusão ou transplante prévio ( 9 doentes tinham recebido pelo menos $1 \mathrm{TR}$ ) ou transmissão horizontal na diálise $(n=3)$. Em 2 casos a transmissão decorreu de consumo de drogas endovenosas. Em 5 casos a carga vírica era negativa (CVneg) antes de qualquer tratamento por provável cura espontânea. Os 9 restantes necessitaram de tratamento e à data atual todos eles com CVneg. Seis casos eram do genótipo tipo 1, 2 genotipo tipo 3 e 1 com informação omissa. Nove casos acompanharam-se de alterações da função hepática, dois doentes foram submetidos a biópsia hepática e 2 realizaram fibroscan. Cinco doentes foram tratados com regimes incluindo IFN, 2 doentes desabuvir+piritaprevir, 1 doente com glecaprevir+ribuntavir e 3 casos com informação omissa. Conclusão: Atualmente no nosso centro todos os doentes VHC+ têm sido colocados em lista ativa após CVneg. Tendo em conta a disponibilidade actual de terapêutica eficaz para o VHC, estrategias para diminuir o tempo de espera, utilizando dadores $\mathrm{VHC}+$ com tratamento dos doentes após o TR, poderão ser equacionadas.

Palavras-chave : Doença Renal Crónica; Hepatite C; Transplante Renal; Antívirus de Acção Directa

CB04-005

RECEPTORES DE TRANSPLANTE RENAL COM INFECÇÃO PELO VÍRUS DA HEPATITE C: EVOLUÇÃO DE PACIENTE E ENXERTO APÓS O ADVENTO DA TERAPIA COM ANTIVIRAIS DE AÇÃO DIRETA (AAD)

Carla Feitosa Do Valle'; Raquel V.B. Stucchi'; Marilda Mazzali ${ }^{1}$

1 - Programa de Transplante Renal -Universidade Estadual de CampinasUNICAMP; 2 - Disciplina de Moléstias Infecciosas - Universidade Estadual de Campinas- UNICAMP

Tratamento da infecção pelo vírus da Hepatite C (VHC) após o transplante renal (TXR) com interferon e ribavirina tem baixa eficácia, alta incidência de efeitos colaterais e rejeição. O desenvolvimento de antivirais de ação direta (AAD) mostrou resposta virológica sustentada (RVS) em TxR superior a 90\%.

Objetivo: avaliar evolução de função renal, interação medicamentosa e complicações no tratamento de TxR infectados pelo VHC, com AAD.

Estudo retrospectivo, incluindo $87 \mathrm{TxR}$ em acompanhamento ambulatorial entre Janeiro/2016 e Dezembro/2017, com sorologia positiva ou duvidosa para o VHC. Destes, 15 perderam seguimento por óbito ou perda do enxerto e 24 apresentavam carga viral não detectável. Dos 46 com carga viral detectável, 14 completaram o tratamento com AAD no período de estudo. Os genótipos de VHC mais frequentes foram 1a (64\%), $3(22 \%)$ e 1 b (14\%). Cronicidade hepática, avaliada por elastografia e correlacionado com estágio Metavir mostrou $42 \%$ estágio F3, seguido dos estágios F1 com $25 \%$, F0 com $17 \%$ e F2 e $\mathrm{F} 4$ ambos com $8 \%$. Todos os pacientes receberam Sofosbuvir e Daclatasvir, com associação de Ribavirina em 10. Função renal permaneceu estável durante o tratamento em 13/14 pacientes. Em 1 caso o uso de AAD foi interrompido com 8 semanas por aumento de creatinina. Um paciente apresentou proteinúria nefrótica e elevação de creatinina após o termino da terapia, com biopsia do enxerto compatível com GESF. Marcadores de função hepática permaneceram inalterados durante o tratamento. Anemia ocorreu em 3 casos, com interrupção da ribavirina em 2. Quando possível, a dose de micofenolato foi reduzida na introdução do AAD. Neste período, os 14 pacientes apresentaram RVS em 12 semanas e 8 pacientes em 24 semanas.

$O$ tratamento com AAD foi eficaz em TxR infectados pelo VHC. Adequação de dose de micofenolato e monitoramento de função renal cursaram com baixa incidência de eventos adversos.

Palavras-chave : transplante renal, Hepatite $C$, antivirais de ação direta 


\section{СB04-006}

EMPREGO SELETIVO DE TRATAMENTO PREEMPTIVO CONTRA CITOMEGALOVÍRUS EM RECEPTORES DE TRANSPLANTE RENAL EM USO DE INIBIDORES DA MTOR.

Jose Osmar Medina Pestana; Marina Cristelli; Paulo Ssp Kimar; Vega Azevedo1; Laila Viana; Melissa Tavares; Daniel Santos; Mayara Ivani Paula; Claudia Rosso Felipe; Hélio Tedesco

\section{Hospital do Rim, UNIFESP}

Introdução: Profilaxia farmacológica contra citomegalovírus (CMV) pode ser dispensável em receptores de transplante renal em uso de inibidores de mTOR, mas não está claro se, para esses pacientes, o tratamento preemptivo ainda está indicado.

Objetivo: Descrever a incidência de infecção por CMV em receptores de transplante renal em uso de inibidor da mTOR everolimo (EVR), com emprego seletivo do tratamento preemptivo.

Método: Análise retrospectiva de um único centro, incluindo todos os pacientes submetidos a transplante renal entre 09/15/2015-07/31/2017, recebendo 3mg/ $\mathrm{kg}$ de dose única-rATG, seguido de tacrolimo/EVR. Tratamento preemptivo foi usado somente (1) na combinação sorológica-CMV D +/R-; (2) após tratamento contra rejeição aguda; (3) após descontinuação do EVR.

Resultados: Entre os 230 pacientes incluídos, tratamento preemptivo foi iniciado em apenas 77 (33,5\%: 13 D +/R-; 30 pacientes após rejeição aguda; 34 pacientes após descontinuação do EVR). A incidência global da primeira infecção por CMV foi de $6,1 \%$. Não houve episódios de infecção por CMV entre os 217 pacientes que não cumpriram critérios para tratamento preemptivo. A incidência de infecção por CMV foi de $46,1 \%$ em D +/R-, 13,3\% após rejeição aguda (todos os pacientes também descontinuados EVR), e 11,8\% após descontinuação de EVR. A incidência global de rejeição aguda comprovada por biopsia foi de $5,6 \%$. A mediana global de eGFR em 12 meses foi de $47 \mathrm{~mL} / \mathrm{min} / 1.73 \mathrm{~m} 2$. As sobrevidas globais do paciente e do enxerto censorada por óbito em 12 meses foram de $97,4 \%$ e $98,1 \%$, respectivamente.

Conclusão: Este estudo de coorte de centro único sugere que uma proporção substancial de receptores de transplante renal que recebe TAC/PRED/EVR pode não precisar de nenhuma estratégia preventiva contra a infecção por CMV.

\section{CB04-007}

ACTINOMICOSE EM RECEPTOR DE TRANSPLANTE RENAL: À PROPOSITO DE UM CASO

Isabela Orieta De Oliveira Macedo; Eveline Santana Girão; Sonia Leite Da Silva; Paula Frassinetti Castelo Branco Camurça Fernandes; Claudia Maria Costa De Oliveira; Francisco Daniel Bezerra Amorim

\section{Universidade Federal do Ceará}

Introdução: A actinomicose é uma doença rara, infecciosa, granulomatosa crônica e progressiva, causada, na maioria dos casos, pela bactéria Grampositiva anaeróbica Actinomyces israelii, sendo mais freqüente no sexo masculino. A actinomicose primária de extremidades é rara, sendo descrito menos de 50 casos na literatura.

Objetivo: Relatar caso de actinomicose em transplantado renal e sua evolução/ tratamento

Relato do caso: Paciente feminina, 54 anos, tendo como doença renal primária a Síndrome do Anticorcorpo Antifosfolipídico. Foi submetida a um segundo transplante renal com doador falecido em 2013, com Terapia de indução com timoglobulina e manutenção com tacrolimus, micofenolato e prednisona. Em Abril de 2017, apresentou lesão em região hipotenar da mão direita, indolor, inicialmente eritematosa, evoluindo com nodulações, áreas hemáticas e pustulosas. Sem sintomas constitucionais. Investigou com exames de imagem e biópsia da lesão, com diagnóstico actinomicose cutânea primária, não havendo comprometimento dos ossos da mão. Praticava jardinagem, que pode ter contribuído como porta de entrada para a doença. Realizou excisão cirúrgica combinada ao tratamento antimicrobiano, inicialmente penicilina cristalina por 21 dias, ampicilina-sulbactam endovenoso por mais 7 dias, e manutenção com amoxililina/clavulanato por 12 meses. No 3o mês, as lesões regrediram completamente, mas evoluiu com suspeita de nefrite intersticial por amoxicilina, sendo convertida para clindamicina oral, com boa resposta

Conclusão: Os autores relatam um caso de actinomicose de extremidades, em paciente do gênero feminino, sendo um processo infeccioso pouco descrito em receptores de transplante renal. A patologia é de difícil diagnóstico e requer histopatologia e testes de cultura apropriados. O trauma pode ter sido um importante mecanismo de infecção, e o comprometimento ósseo por contiguidade não foi observado. 0 diagnóstico e a instituição da terapia adequada foram imprescindíveis para resolução do quadro no presente caso.

Palavras-chave : Actinomicose, Cutâneo, Transplante renal
CB04-008

PREVALÊNCIA DOS MICROORGANISMOS CAUSADORES DE INFECÇÃO DA CORRENTE SANGUÍNEA EM UMA UNIDADE DE TRANSPLANTE RENAL

José Roberto Freire De Oliveira; Manoella Do Monte Alves; Marcelle Leandro Da Silva Pereira; Luana Cristina Lins De Medeiros Oliveira; Lorena Mara Nóbrega De Azevêdo; Layane Azevedo De Medeiros; Raquel Martins E Quinino Hosp Universitário Onofre Lopes

Introdução: As infecções de corrente sanguínea são responsáveis por aumento da letalidade em pacientes transplantados renais. Conhecer o perfil dos agentes isolados em hemocultura é essencial para a otimização das terapêuticas empíricas instituídas em unidades de internação destes pacientes. Objetivo: Identificar os principais agentes microbianos causadores de infecção da corrente sanguínea nos pacientes transplantados renais internados em um hospital universitário no Rio Grande do Norte. Metodologia: Trata-se de um estudo retrospectivo com análise descritiva dos dados de hemocultura do setor de transplante renal no período de março/2017 a março/2018. Resultados: De 2.539 hemoculturas realizadas no hospital, $169(6,7 \%)$ foram do setor de transplante renal. Dessas, 142 foram negativas $(84 \%), 8$ foram contaminadas $(4,7 \%)$ e 19 foram positivas (11,2 \%). Os microorganismos encontrados foram 07 Klebsiella sp (36,84\%), 05 Staphylococcus coagulase negativo $(26,32 \%)$, 01 Enterobacter sp (5,26\%), 01 Serratia sp $(5,26 \%)$, 01 Candida sp $(5,26 \%)$, 01 Acinetobacter sp (5,26\%), 01 Stenotrophomonas maltophilia $(5,26 \%), 01$ Pseudomonas sp $(5,26 \%)$ e 01 Escherichia coli $(5,26 \%)$. Das 07 Klebsiellas, 04 apresentavam resistência a carbapenêmicos, o que corresponde a $21 \%$ dos nossos isolados. De todos os agentes, 9 corresponderam a infecções de corrente sanguínea de pacientes vindo da comunidade, 8 foram infecções hospitalares e 2 casos não informados. Conclusão: Os dados revelam o aumento de isolados resistentes a carbapenêmico responsáveis por infecções de corrente sanguínea, se fazendo premente o controle das infecções associadas à assistência a saúde, o do uso racional de antimicrobianos e do programa de segurança ao paciente, com ênfase na higienização das mãos, para diminuição das cepas resistentes.

Palavras-chave : Hemocultura, Transplante Renal, Microorganismo, Infecção da Corrente Sanguínea

CB04-009

\section{A RARE MANIFESTATION OF TUBERCULOSIS IN RENAL TRANSPLANT}

Inês Coelho'; Catarina Romãozinho²; Catarina Teixeira²; Emanuel Ferreira² ${ }^{2}$ Luís Rodrigues²; Lidía Santos²; Fernando Macário²; Rui Alves²; Arnaldo Figueiredo $^{3}$

1 - Serviço de Nefrologia, Hospital Amato Lusitano; 2 - Serviço de Nefrologia, Centro Hospitalar e Universitário de Coimbra; 3 - Serviço de Urologia e Transplantação Renal, Centro Hospitalar e Universitário de Coimbra

Cutaneous lesions in the presence of fever in patients undergoing immunosuppressive therapy are a diagnostic challenge, and may represent manifestations of multiple diseases, such as fungal infections, nocardiosis, lymphoproliferative diseases, zoonosis and tuberculosis. The authors report a case of a 66-year-old Caucasian man with chronic kidney disease since 2014 (chronic pyelonephritis) who had a renal transplant six months ago. Induction therapy was performed with thymoglobulin and current immunosuppression scheme included tacrolimus, mycophenolate mofetil and prednisolone. No history of pulmonary tuberculosis. The patient presented with 2 cutaneous lesions, localized at the back and abdomen, that appeared firm, painful, subcutaneous, erythematous nodules, approximately with $5 \mathrm{~cm}$ of diameter overlying an infected focus, with purulent material inside. The patient had also fever, fatigue. On physical examination, vital signs were within normal limits, the skin demonstrated no other significant changes, and the patient had no notable lymphadenopathy. Blood analysis showed pancytopenia with elevation of inflammatory markers and graft dysfunction. There was performed tissue cultures and skin biopsy with histological analysis. Histopathology of the lesion showed inespecific inflammatory infiltrate, without granulomas, but acid-fast bacillus staining was positive, and polymerase chain reaction confirm the presence of Mycobacterium tuberculosis, which confirm the diagnosis of cutaneous tuberculosis (CTB). The patient was referred to infectious disease to rule out active TB infection. Serum QuantiFERON testing was positive. Sputum cultures were positive and a chest xray showed no active pulmonary disease. The patient was treated by infectious disease with multidrug TB therapy (pyrazinamide, rifampin, ethambutol, and isoniazid) resulting in lesion clearance after three weeks. The immunosuppressive therapeutic was adjusted.

Tuberculosis is a serious infection especially in high-risk patients, such as those in an immunocompromised state. The incidence of CTB is rare, but it should be considered in patients presenting with atypical skin lesions suggestive of an underlying infectious aetiology.

Palavras-chave : renal transplant, cutaneous tuberculosis, Immunosuppression 


\section{CB04-010}

LEFLUNAMIDE AS AN EFFECTIVE THERAPY IN AN HIGHLY SENSITIZED PATIENT WITH A BK-POLYOMA DISEASE

Teresa Pena1; Sara Leite1; Liliana Rocha2; Paula Matos2; Sameiro Faria2; Leonídio Dias3; Conceição Mota2

1 - Unidade de Nefrologia Pediátrica do Centro Materno Infantil do Norte; 2 Unidade de Nefrologia Pediátrica do Centro Materno Infantil do Norte, Centro de Referência de Transplante Renal Pediátrico; 3 - Serviço de Nefrologia do Centro Hospitalar do Porto

We report a case of a 17-year-old with a renal dysplasia leading to end-stage renal disease that received a kidney transplant in September/ 2013. After 3 years, he returned haemodialysis therapy due to chronic allograft dysfunction. He was highly sensitized with a calculated panel-reactive antibodies $>85 \%$. He received a 2th renal transplant from deceased-donor in August/2017 and he had done induction with basiliximab. A positive BKV viremia was detected (level of 725 copies $/ \mathrm{ml}$ ) at 15th day after transplant. Imunossupression was lowered with the suspension of mycophenolate mofetil and maintenance therapy only with tacrolimus and prednisolone. Renal function remained stable until November/2017 (PCr 1.5mg/dL). The renal function evaluation 8 days after the remotion of the ureteric stent showed an increased $\mathrm{PCr} 9.7 \mathrm{mg} / \mathrm{dL}$. Haemodialysis was reinitiated. A renal biopsy revealed acute cellular rejection (Banff IB) and suggested coexistence of viral versus bacterial infection. He was started on methylprednisolone pulses followed with EV immunoglobulin. Renal ultrassound showed mild pyelic dilatation (renal pelvis with $15 \mathrm{~mm}$ ). Decompression with nephrostomy was performed with no improvement in renal function. On the 13th day of hospitalisation, SV40 antibody testing proved positive in the renal biopsy, confirming a BKV infection. Oral leflunamide was initiated (loading dose $100 \mathrm{mg}$ id for 3 days and maintenance with $20 \mathrm{mg}$ id). On the 30th day of hospitalisation, it was performed percutaneous dilatation of the graft ureter and it was found a total stenosis. Renal function slowly improved, allowing the suspension of haemodialysis. On follow-up renal function remained stable $(\mathrm{PCr} 2.2 \mathrm{mg} / \mathrm{dL})$ and BKV viremia was undetected. The first step in the treatment of BKV infection is reduction in immunosuppression, but it may not suffice. Recently, leflunamide has emerged as an effective therapy against this agent. It is known to have both an imunossupressive and antiviral effect and could be very useful in an highly sensitized patient with a BK-polyoma disease.

Palavras-chave : Leflunamide, renal transplant, BK-polyoma disease

\section{СВ04-011}

\section{A COMPLEX CASE OF INVASIVE CYTOMEGALOVIRUS DISEASE AND GRAFT REJECTION}

David Fiel'; João Cassis²; Rita Calça ${ }^{3}$; Eunice Cacheira ${ }^{3}$; Sara Querido ${ }^{3}$; Célia Nascimento ${ }^{3}$; Rita Birne ${ }^{3}$; Patrícia Matias ${ }^{3}$; Cristina Jorge ${ }^{3}$; Teresa Adragão $0^{3}$; Margarida Bruges ${ }^{3}$; Paulo Paixão ${ }^{4}$; Domingos Machado ${ }^{3}$; André Weigert ${ }^{3}$

1 - Serviço de Nefrologia do Hospital de Évora; 2 - Serviço de Anatomia Patológica do Hospital de Santa Cruz, CHLO; 3 - Serviço de Nefrologia do Hospital de Santa Cruz, CHLO; 4 - Nova Medical School, CEDOC,

INTRODUCTION. Cytomegalovirus (CMV) infection, defined by detectable CMV antigenemia or CMV DNA in the blood, occurs in up to $90 \%$ of renal transplants, conversely, CMV disease (organ involvement) happens in up to $37 \%$. We present a complex case of invasive CMV disease. CLINICAL CASE. A 38-year-old woman, CKD due to reflux nephropathy, received a cadaveric-donor kidney transplant in 2016: without anti-HLA antibodies, $0 \%$ sensitization, 2 mismatches in A. As CMV IgG was negative in the receptor and positive in the donor, she received prophylaxis with valganciclovir for 6 months. Immunosuppressive therapy included basiliximab, tacrolimus, mycophenolate mofetil (MMF) and Prednisolone. Due to severe neutropenia and raising BK virus copies in urine, MMF was switched to everolimus. One year after transplantation, she developed lumbar Type 2 Herpes simplex (HSV2) and viral meningitis and was treated with aciclovir. Presenting deterioration of renal function ( $\mathrm{pCr} 2,3 \mathrm{mg} / \mathrm{dL}$ ) and mild proteinuria, graft biopsy (15th month) showed acute thrombotic microangiopathy (TMA) and tubulointerstitial nephritis (TIN). Genetic and complement testing for TMA was negative, anti-HLA with maximum MFI 3274, negative C1q activity, not DSAs. Despite methylprednisolone pulses with moderate response, graft function kept worsening and a new biopsy (20th month) showed TIN and new CMV cytoplasmic inclusions in tubular cells, confirmed with CMV DNA testing in the graft and urine (without CMV viremia), for which she received anti-CMV specific immunoglobulin and valganciclovir However, she developed severe pancytopenia and valganciclovir was interrupted. A new biopsy (25th month) showed mixed acute antibody-mediated and cellular rejection, now with negative CMV DNA. CONCLUSION. We present a case of invasive CMV disease in tubular cells (without viremia) followed by graft rejection. Increasing immunosuppressive regimen on the ground of a CMV invasive disease and HSV2 is cumbersome. On the other hand, CMV infection increases the risk of acute graft rejection and chronic graft dysfunction.

Palavras-chave : Cytomegalovirus, rejection
CB04-012

PREVALÊNCIA DE TUBERCULOSE EM UM CENTRO DE TRANSPLANTE RENAL NO RIO DE JANEIRO

Tereza Matuck1; Patricia Finni1; Claudia Fagundes1; Maria Fatima Alvarenga1; Luciano Morgado1; Jadilson Pereira1

\section{1 - Hospital São Francisco na Providência de Deus}

No Brasil, nos dias atuais, a Tuberculose (TB) continua sendo uma infecção freqüente. Nos pacientes transplantados renais a incidência é 14 vezes superior quando comparado com a população em geral, algumas vezes se tornando infecção oportunista de alta mortalidade. No período de fevereiro/2013 a fevereiro/2018 foi realizada uma análise retrospectiva de 1000 transplantes renais, sendo que $96(9,6 \%)$ receberam quimioprofilaxia com Isoniazida, indicada na presença de história prévia de TB, teste de PPD positivo, ou contato com indivíduos em tratamento atual para TB. A prevalência de TB na nossa amostra foi $2 \%$ ( 20 pacientes) sendo que apenas 1 que recebeu Isoniazida desenvolveu a doença, mostrando que a profilaxia resultou em proteção de $99 \%$ dos casos. A localização da doença foi predominantemente pleuropulmonar (13 $/ 65 \%)$, seguida de urinária $(2 / 10 \%)$, intestinal $(2 / 10 \%)$, coluna vertebral $(1 / 5 \%)$ , ganglionar( $1 / 5 \%)$ e ovariana (1/5\%).O diagnóstico de TB foi realizado através de história clinico-epidemiológica com confirmação bacteriológica e/ou histopatológica. O tratamento foi realizado com esquema RIPE(Rifampicina/ Isoniazida/Pirazinamida/Etambutol). O tempo médio de aparecimento da doença foi 21 meses após o transplante e a taxa de mortalidade $20 \%$, não houve correlação com nenhum esquema imunossupressor.TB é uma doença de alta prevalência e mortalidade, sendo assim, é importante identificar os pacientes com risco de desenvolve-lá, já que a quimioprofilaxia resultou em alta proteção. Palavras-chave : Tuberculose

\section{СB08-001}

AVALIAÇÃO DE CINÉTICA DE ANTICORPO DOADOR ESPECÍFICO DURANTE TRATAMENTO DA REJEIÇÃO AGUDA MEDIADA POR ANTICORPO COM PLASMAFERESE, IMUNOGLOBULINA INTRAVENOSA E BORTEZOMIB.

Lúcio Requião-Moura; Gabriela Clarizia; Patrícia Requião-Moura; Maurício Fregonesi Silva; Araci Sakashita; Margareth Afonso Torres; Alvaro PachecoSilva

\section{Hospital Israelita Albert Einstein}

Introdução: O melhor tratamento para a rejeição mediada por anticorpo (RAMA) não está completamente padronizado. Objetivo: avaliar o tratamento da RAMA com ênfase na cinética dos anticorpos doador-específico (DSA). Metodologia: Foram incluídas todas as RAMA diagnosticadas entre 2007-2017. O tratamento deu-se com plasmaferese (PF) e imunoglobulina (IgIV), além de bortezomibe (BZ, após Dez/11), para os casos refratários (redução $<50 \%$ no $\mathrm{mfi}$ após 6PF). A cinética dos DSA anti-HLA (mfi) foi avaliada através do anticorpo mais elevado (Hi-DSA), todos os DSA (All-DSA) e soma dos DSA/paciente (SumDSA). Resultados: A incidência de RAMA foi 5,7\%, ocorrendo em 11[8,5-21,5] dias pós-Tx, sendo $71,1 \%$ já nos primeiros 15 dias (RAMA-Precoce). HLA, ABO e MICA foram responsáveis por $88,9 \%, 6,7 \%$ e $4,4 \%$ dos casos, respectivamente. Os receptores eram previamente sensibilizados: transfusões 3[1-3], reTx-28,9\%, PRA-32\%[0-69]; 26,7\% submetidos à dessensibilização (17,8\%-HLAi; $8,9 \%$-ABOi). A alteração histológica mais comum foi CPT (48,9\%) e $15,5 \%$ tinham C4d-negativo. $O$ tratamento foi realizado com 6 [4-9] PF e 2 [0,5-5] doses de IgIV; 33,3\% receberam BZ. O Hi-DSA reduziu de 8.438 para 1.946, $p<0,0001$, sendo essa resposta eficaz apenas nas RAMA-Precoce ( $p<0,0001$ vs. $p=0,11$ ). Dezenove pacientes tinham mais de um DSA $(\mathrm{N}=81)$, havendo redução no AllDSA de 4.643 para 1.436, $p<0,0001$, sendo essa redução eficaz apenas em classe I ( $p<0,0001$ vs. $p=0,23)$. Sum-DSA reduziu de 10.094 para $2.648, p=0,0003$. Entre os pacientes que receberam $B Z(N=14)$ houve redução significativa em todos os parâmetros: Hi-DSA de 11.785 para 3.276, $\mathrm{p}=0,003$; Sum-DSA de 18.086 para $6.525, p=0,003 ;$ All-DSA ( $N=30)$ de 7.234 para 2.596, $p=0,001$. As sobrevidas do enxerto e do paciente ao final de 2 anos foram $75,5 \%$ e $97,6 \%$, respectivamente. Conclusão: $O$ tratamento da RAMA com PF e IgIV, e BZ em casos refratários, foi considerado eficaz em reduzir DSA, com sobrevida de enxerto e pacientes satisfatórias até dois anos de seguimento.

Palavras-chave : Transplante de rim, Rejeição aguda, Rejeição mediada por anticorpo, Plasmaferese, Bortezomib, Anticorpo doador específico, Cinética 
CB08-002

TAVALIAÇÃO DA UTILIDADE DAS BIÓPSIAS DE VIGILÂNCIA EM RECEPTORES DE RINS DE DOADORES FALECIDOS COM DISFUNÇÃO INICIAL DO ENXERTO

João Batista Saldanha De Castro Filho'; Jeferson De Castro Pompeo²; Andrea Carla Bauer ${ }^{1,2}$; Roberto Ceratti Manfro ${ }^{1,2}$

1 - Serviço de Nefrologia, Unidade de Transplante Renal, Hospital de Clínicas, Porto Alegre, Brasil; 2 - Faculdade de Medicina, Universidade Federal do Rio Grande do Sul, Porto Alegre, Brasil

Introdução: Diretrizes recomendam realização de biópsias de vigilância em pacientes com disfunção inicial do enxerto (DGF). A elevada incidência de DGF observada no Brasil, após transplante com rins de doador falecido (DF) leva ao aumento da necessidade da realização dessas biópsias, devido à maior incidência de complicações nesse durante a DGF. Pacientes e métodos. Estudo retrospectivo em centro único incluindo receptores de rins de DF entre Janeiro/2006 e Dezembro/2017 submetidos à biópsia do enxerto durante o período de DGF. Biópsias interpretadas de acordo com os critérios da classificação de Banff vigente. Resultados: Realizadas 321 biópsias em 303 pacientes, masculinos (61\%), caucasóides (72,6\%) e não hipersensibilizados (59,4\%); tempo de isquemia fria $22,2 \pm 8,5$ h e biópsias executadas no dia $13 \pm 7,3$ de pós-operatório. Os pacientes receberam inibidores da calcineurina ( $84,8 \%$, tacrolimo), um agente antiproliferativo (94,7\%, micofenolato sódico) e corticosteróides. Em 276 pacientes (91\%) foi realizada terapia de indução com Basiliximabe $(47,5 \%)$ ou anticorpos policlonais anti-linfócitos (43,5\%). Cinco (1,65\%) biópsias foram histologicamente normais; $138(45,5 \%)$ necroses tubulares agudas isoladas; 85 (28,0\%) rejeições agudas (RA); 84 (27,7\%) alterações borderline; 8 (2,6\%) necroses de coagulação; 2 (0,61\%) pielonefrites agudas e 1 (0,3\%) microangiopatia trombótica. Apenas 4 RA mediadas por anticorpos, todos recebendo indução com anticorpos policlonais. Correlações entre idade, raça, sensibilização, prova cruzada e doadores limítrofes com a RA não significativas. Deposição de $C 4 d>10 \%$ dos capilares tubulares se correlacionou com RA histológica $(p<0,001)$. A incidência de RA variou conforme a imunossupressão inicial, sendo menor no grupo que recebeu indução com anticorpos policlonais (11,3\%), 15 casos em 132 pacientes; seguida de $37 \%$ em pacientes sem indução com anticorpos e $38,8 \%$ no grupo basiliximabe. Conclusão: Biópsias de vigilância em transplantados com rins de DF permanecem essenciais para o cuidado do receptor e a intensidade do regime imunossupressor está relacionada à incidência de rejeição aguda neste contexto clínico.

Palavras-chave: Biópsia de vigilância, Disfunção inicial do enxerto, Rejeição aguda, Doador falecido

\section{CB08-003}

\section{É ÚTIL A REALIZAÇÃO DE BIÓPSIA NA AVALIAÇÃO DE DADORES MARGINAIS?}

Ana Catarina Teixeira; Emanuel Ferreira; Maria Guedes Marques; Luís Rodrigues; Lídia Santos; Catarina Romãozinho; Nuno Afonso; Vítor Sousa; Carlos Ferreira; Fernando Macário; Rui Alves; Arnaldo Figueiredo

\section{Centro Hospitalar e Universitário de Coimbra}

Introdução: A escassez de órgãos no transplante renal obrigou à aceitação de órgãos de dadores marginais. A importância da avaliação histológica prévia ao transplante destes dadores permanece controversa.

Objetivos: Comparar a sobrevivência do enxerto renal de dadores marginais com e sem avaliação histológica pré-transplante.

Material e Métodos: Foi realizado um estudo coorte retrospetivo e unicêntrico. A coorte incluiu doentes que receberam rins de dadores marginais: $127 \mathrm{com}$ avaliação histológica e 161 sem avaliação no período compreendido entre 2009 e 2016

Resultados: No período analisado, efetuaram-se biópsias em rins de 204 dadores sendo a taxa de aceitação de $37.7 \%$. Verificou-se que score histológico não teve relação com a função do enxerto $(p=0.15)$.

A idade dos recetores e o tempo em diálise apresentaram influencia na sobrevivência do enxerto ( $p=0.049$ e 0.008$)$ nos doentes que receberam rins com biópsia.

Não se identificaram fatores implicados na sobrevivência do enxerto nos rins sem biópsia.

A tabela contém as caraterísticas principais dos grupos avaliados.

O tempo de isquemia fria e a idade dos dadores é significativamente diferente nos dois grupos. A análise comparativa da sobrevida global do enxerto entre os dadores com e sem avaliação histológica não mostrou diferença significativa $(p=0,924)$.

Conclusão: A avaliação histológica de rins marginais não teve influência na sobrevida do enxerto tendo condicionando maior tempo de isquémia fria.

A realização de biópsia de rins marginais é importante para a utilização de órgãos que seriam excluídos só com base em dados clínicos e laboratoriais.

Palavras-chave: Dador Marginal, Biópsia

\begin{tabular}{|l|c|c|c|}
\cline { 2 - 4 } \multicolumn{1}{c|}{} & \multicolumn{1}{c|}{$\begin{array}{c}\text { Avaliação } \\
\text { histológica }\end{array}$} & $\begin{array}{c}\text { Sem avaliação } \\
\text { histológica }\end{array}$ & $\mathbf{p}$ \\
\hline $\begin{array}{l}\text { Idade média dadores } \\
\text { (anos) }\end{array}$ & $64.30 \pm 11.48$ & $63.80 \pm 2.76$ & $<0,001$ \\
\hline $\begin{array}{l}\text { Idade média recetores } \\
\text { (anos) }\end{array}$ & $57.68 \pm 10,29$ & $59.35 \pm 6.92$ & 0,70 \\
\hline $\begin{array}{l}\text { Tempo médio em HD } \\
\text { (meses) }\end{array}$ & $48.93 \pm 26.08$ & $48.19 \pm 28.97$ & 0,67 \\
\hline $\begin{array}{l}\text { Tempo isquémia-fria } \\
\text { (h) }\end{array}$ & $19.39 \pm 4.06$ & $17.93 \pm 4.70$ & 0,03 \\
\hline $\begin{array}{l}\text { Tempo médio de follow-up } \\
\text { (anos) }\end{array}$ & $4.2 \pm 2.3$ & $3.94 \pm 2.52$ & 0,92 \\
\hline $\begin{array}{l}\text { TFG média a um ano (ml/ } \\
\text { min) }\end{array}$ & $47.13 \pm 21.70$ & $46.50 \pm 20.74$ & 0,88 \\
\hline
\end{tabular}

Tabela: Caraterísticas principais dos grupos avaliados

\section{CB08-004}

O GANHO DE PESO E AS COMPLICAÇÕES METABÓLICAS PÓS-TRANSPLANTE RENAL SEGUNDO O USO OU NÃO DE EVEROLIMO

Rosângela Alencar Ribeiro'; Thaisa Maria Silva Sousa²; Thais Maria Frota Silva²; Naiara Lima Fontenele²; Hermano Alexandre Lima Rocha²; Ronaldo Matos Esmeraldo; Claudia Maria Costa De Oliveira ${ }^{3}$

1 - Hospital Geral de Fortaleza-CE; 2 - Centro Universitário UniChristus; 3 Hospital Geral de Fortaleza-CE e Centro Universitário UniChristus

Introdução: O ganho de peso e outras complicações metabólicas (dislipidemia, diabetes mellitus, hipertensão arterial sistêmica) são frequentes após o transplante (TX) renal e podem estar associadas ao esquema imunossupressor. Objetivo: avaliar o ganho de peso e a prevalência de complicações metabólicas pós-TX de acordo com o uso ou não do everolimo. Métodos: Estudo de coorte retrospectivo, com pacientes com idade $>18$ anos e no mínimo 12 meses de seguimento, avaliados em grupos segundo o uso ou não de everolimo (grupos 1 e 2). As diferenças entre os grupos foram pesquisadas, com ênfase no ganho de peso e complicações metabólicas. Foi realizada análise com modelos mistos de ANOVA multivariados de duas vias. Resultados: Foram avaliados 227 pacientes, idade 44 anos, $63,6 \%$ masculino, $94,5 \%$ doador falecido, imunossupressão com tacrolimus $100 \%$ dos casos, everolimus $62,7 \%$, micofenolato $37,3 \%$ e prednisona $33,2 \%$. A prevalência de diabetes mellitus pós-TX foi $37,3 \%$, HAS $74,7 \%$ e dislipidemia $95,9 \%$. Não houve diferença estatística na prevalência de complicações metabólicas entre os grupos. $O$ ganho de peso em 24 meses foi de 4,0 $\mathrm{kg}(-2,2$ a 9,28 $\mathrm{kg})$ para o grupo 1 e $4,29 \mathrm{~kg}(-1,1$ a 10,26) para o grupo $2(p=0,761)$. A classificação segundo o IMC aos 24 meses foi diferente entre os grupos $(p=0,017)$ com $37,4 \%$ de sobrepeso/obesidade no grupo 1 e $51,9 \%$ no grupo 2 . A comparação entre os grupos ao longo de 36 meses revelou diferença significativa no $L D L$ e na PAS, mas não houve diferença na PAD, glicose, colesterol e triglicerídeos.Conclusão: Apesar do ganho de peso pós-TX não ter sido diferente entre os grupos, a classificação por IMC aos 24 meses revelou maior prevalência de sobrepeso/obesidade no grupo sem everolimo. As taxas das demais componentes metabólicos não foram diferentes com e sem os inibidores da mTOR.

Palavras-chave: transplante de rim, ganho de peso, everolimo, complicações metabólicas 
CB08-005

EARLY VERSUS LATE CONVERSION FROM IMMEDIATE RELEASE TO PROLONGED RELEASE TACROLIMUS AFTER KIDNEY TRANSPLANTATION: RENAL AND METABOLIC EFFECTS AND TREATMENT COSTS

Luís Mendonça; Hugo Diniz; José Silvano; Susana Sampaio; Manuel Pestana

\section{1 - Serviço de Nefrologia, Centro Hospitalar São João}

Introduction. Prolonged-release tacrolimus (PR-TAC) has been shown to improve kidney allograft function when compared to the immediate-release formulation (IR-TAC). The aim of this study was to compare clinical outcomes and treatment cost of patients who converted from IR-TAC to PR-TAC during (early-converters $(\mathrm{EC})$ ) or after (late-converters $(\mathrm{LC})$ ) the first-year post-renal transplantation (RT). Methods. We evaluated 79 patients $(E C=39, L C=41)$ who were transplanted between 2007-2010. Data on clinical parameters including serum creatinine, tacrolimus trough levels, fasting glucose, cholesterol were collected $1,3,6,12,36$ and 60 months after RT. Treatment costs were also determined. A mixed-effects approach was used to investigate the differences between groups. Cardiovascular events, allograft rejection, and NODAT were determined at the end of follow-up. Results. The median time from RT to conversion was 3 months in the EC and 25 months in the LC-group. In both groups, a significant increase in eGFR after conversion was observed. One-year post-RT, EC patients presented a higher eGFR $(67,9 \pm 19,4$ vs $59,0 \pm 18,3(p=0,002))$ and inferior tacrolimus trough levels $(6,6 \pm 1,6 \mathrm{ng} / \mathrm{ul}$ vs $8,6 \pm 1,9 \mathrm{ng} / \mathrm{ul}(\mathrm{p}<$ $0,001)$ ), when compared to LC patients. Thereafter, renal function was similar between groups. Additionally, allograft acute rejection was not significantly different $(2,6 \%$ and $2,4 \%)$ as well as NODAT $(15,7 \%$ vs $12,2 \%)$ or cardiovascular events $(5,2 \%$ vs $7,3 \%)$. The mean estimated treatment cost was transiently higher in EC patients after conversion $(2,89 \pm 1,68$ vs $2,01 \pm 1,04 € /$ patient/day, $\mathrm{p}=0.008$ ) but no difference was found between groups since the first year postRT. Conclusion. Our findings demonstrate an acute benefit of conversion from IR-TAC to PR-TAC on renal function. EC patients present better renal function during the first year post-RT, although with higher treatment costs associated. The allograft long-term prognosis, metabolic and cardiovascular outcomes do not seem to be affected by the timing of switching.

Palavras-chave: kidney, tacrolimus, glomerular filtration rate

\section{CB08-006}

\section{RETRANSPLANTE RENAL: INDUÇÃO COM DOSE ÚNICA REDUZIDA DE TIMOGLOBULINA}

Jose Osmar Medina Pestana; Kamilla' Linhares; Marina Cristelli; Henrique Proença; Laila Viana; Renato Marco; Claudia Felipe; Helio Tedesco

\section{Hospital do Rim, UNIFESP}

O retransplante renal é um procedimento de alto risco, sem consenso na literature sobre a melhora estratégia imunossupressora. Poucos estudos avaliaram os desfechos desta crescente proporção de pacientes transplantados, especialmente no Brasil. Avaliar a eficácia da indução com dose única reduzida de timoglobulina no retransplante renal, através da incidência de rejeição aguda comprovada por biopsia. Coorte exploratória, retrospectiva, aberta, de centro único, de retransplantes renais realizados entre 06/16/2014 e 10/31/2016, com 1 ano de seguimento. Todos os pacientes receberam indução $3 \mathrm{mg} / \mathrm{kg}$ de timoglobulina em dose única no pós-operatório imediato. $\mathrm{O} \mathrm{CMV}$ foi tratado preemptivamente.

\begin{tabular}{|l|c|}
\hline Característica do retransplante renal & Total (N = 110) \\
\hline Idade, média \pm DP & $41,1 \pm 11,8$ \\
\hline Masculino & $61 \%$ \\
\hline Doença de base \\
\hline Indeterminada \\
\hline Glomerulopatia & $41,6 \%$ \\
\hline Hipertensão Arterial & $34,5 \%$ \\
\hline PRA $\geq 50 \%$ & $8,2 \%$ \\
\hline Doador falecido & $55 \%$ \\
\hline Critério expandido & $90 \%$ \\
\hline Imunossupressão TAC + MPS & $15,5 \%$ \\
\hline
\end{tabular}

\begin{tabular}{|l|c|}
\hline \multicolumn{1}{|c|}{ Resultados } & Total (N = 110) \\
\hline TIF (horas), média \pm DP & $24,4 \pm 6,7$ \\
\hline DGF & $59 \%$ \\
\hline Readmissão em 30 dias & $28,2 \%$ \\
\hline Infecção/doença por CMV em 12 meses & $35,4 \%$ \\
\hline RACB em 12 meses & $13,6 \%$ \\
\hline Função renal aos 12 meses (CKD-EPI, ml/min) & $49,5 \pm 21,1$ \\
\hline Sobrevida do paciente aos 12 meses & $95,5 \%$ \\
\hline Sobrevida do enxerto aos 12 meses & $87,3 \%$ \\
\hline
\end{tabular}

Os desfechos após 12 meses são semelhantes aos resultados internacionais que utilizaram timoglobulina em doses maiores. As incidências de RACB foram aceitáveis, CMV e DGF afetaram um terço da coorte, provavelmente devido à manutenção do doador e à ausência de profilaxia farmacológica para CMV.

Palavras-chave : transplante renal, r-ATG, re-transplante

\section{CB08-007}

PLASMAFÉRESE PÓS-TRANSPLANTE RENAL: EXPERIÊNCIA DE UM CENTRO DE TRANSPLANTE DO BRASIL

Francisco Daniel Amorim; Denise Menezes Brunetta; Silvia Fernandes Ribeiro; Sônia Leite Da Silva; Paula Cbc Fernandes; Claudia Maria Costa De Oliveira

\section{1 - Hospital Universitário Walter Cantídeo - UFC- Brasil}

Introdução: A plasmaférese (PF) em transplante renal (TR) geralmente ocorre no cenário da dessensibilização pré-TR ou tratamento da rejeição mediada por anticorpos (RMA).

Objetivo: relatar a experiência com PF pós-TR em um centro de transplante do Brasil.

Métodos: Estudo de casos, incluindo pacientes que realizaram PF pós-TR nos anos de 2014 e 2015, sendo pesquisados dados relacionados à indicação, complicações e resposta ao tratamento realizado. Os resultados são expressos em mediana.

Resultados: Foram avaliados 17 pacientes, idade média 34,3 anos (16-67 anos), $41 \%$ masculino, $88,2 \%$ doador falecido. As indicações da PF foram recidiva de GESF em $26,5 \%$ e RMA em $76,5 \%$. No grupo da GESF, o acesso foi a FAV em $100 \%$; tempo pós-TR da PF foi 53 dias; creatinina sérica (CR) pré-PF 1,4 mg/ $\mathrm{dl}$; a proteinuria (PTN24hs) pré-PF de $3365 \mathrm{mg}$ e pós-PF de $326 \mathrm{mg}$. O número de $P F$ realizadas foi 9 em 2 casos, 4 em 1 caso e 20 em 1 caso. A resposta à PF foi completa em $75 \%$ e ausente em $25 \%$. No grupo da RMA, o acesso foi a FAV em 9 casos e cateter em 4; o tempo pós-TR foi 24 dias; CR pré-PF foi 3,5 $\mathrm{mg} / \mathrm{dl}$. A mediana do número de PF foi 7 sessões (2-20), com resposta clínica e/ou histológica em $84,6 \%$ e ausência de resposta em $15,4 \%$. As principais complicações foram parestesias, tremores, náuseas, astenia, hipomagnesemia (7), hipocalcemia (3), plaquetopenia (2). As infecções no primeiro ano pós-PF foram: ITU (3), CMV (3) e zoster (1).

Conclusão: A RMA foi a principal indicação de PF pós-TR. Cateter temporário foi utilizado em $23 \%$ dos pacientes e a mediana do número de sessões foi 7 para RMA e 9 para recidiva de GESF. As complicações associadas à PF foram mínimas O tratamento demonstrou ser seguro e eficaz na população em estudo.

Palavras-chave : plasmaferese, transplante de rim 


\section{CB08-008}

USO DE INDUÇÃO COM DOSE ÚNICA E REDUZIDA DE TIMOGLOBULINA EM RECEPTORES DE TRANSPLANTE DE RIM DE BAIXO RISCO IMUNOLÓGICO TRANSPLANTADO COM DOADOR VIVO.

Lucas Moura; Victor Serrano; Maurício Fregonesi R. Silva; Lúcio RequiãoMoura; Alvaro Pacheco-Silva

\section{Hospital Israelita Albert Einstein}

Introdução: A indução imunológica em transplante de rim de baixo risco imunológico (TxR-BRI) ainda é uma área sob investigação. Objetivo: avaliar o uso de Timoglobulina $2,0 \mathrm{mg} / \mathrm{kg}$ em dose única em uma coorte prospectiva de TxR-BRI. Metodologia: foram incluídos TxR-BRI doador vivo, transplantados entre 2014-2017. A indução foi seguida de tacrolimo (TAC), Prednisona e micofenolato (MPS). A incidência prévia de rejeição aguda (RA) era de 33,342,4\% (dados de banco, até 2014). Resultados: foram incluídos 73 TxR-BRI, idade 39,0+/-12,6 anos, 60,3\% masculino, CMV-D+/R+ 91,8\%. Os doadores tinham $46,1+/-9,2$ anos, mismatches $3,0+/-1,4$. O nível de TAC $(\mathrm{ng} / \mathrm{mL})$ variou de 10,9+/-4,0 a 9,5+/-3,2 no primeiro mês, reduzido para 8,1+/-2,4 a 7,3+/-2,1 entre 2-6 mês $(p<0,0001)$. A dose do MPS ( $g / d i a)$ permaneceu estável nos primeiros dois meses $(1,43+/-0,4)$, havendo redução para 1,32+/-0,3 a 1,1+/-0,4 entre 2-6 meses $(p<0,0001)$. A incidência de RA celular foi de 23,3\%, em 11[4-98] dias pós Tx: limítrofe-8,2\%; IA-6,8\%; IB-1,4\%; IIA-6,8\%. O nível de TAC não variou nos períodos antes, durante e após o episódio RA (7,4 vs. 9,4, p=0,44; 9,4 vs. $8,9, p=0,37)$, entretanto $23,5 \%$ destes tinham o nível abaixo de 5,0 antes e durante a RA. CMV-viremia ocorreu em 54,8\%, com 2,5\% de doença invasiva. Os demais eventos adversos foram: BK-viremia (12,9\%), infecção urinária $(8,2 \%)$ e de ferida operatória (1,4\%), linfocele $(1,4 \%)$ e fístula urinária (2,7\%). A TFG em 1 ano foi $61,4 \mathrm{ml} / \mathrm{min} / 1,73 \mathrm{~m} 2$. Em acompanhamento de $26,2[15,9-33,3]$ meses, todos os pacientes estavam vivos e houve apenas uma perda de enxerto $(1,4 \%)$. Conclusão: a incidência de RA foi inferior aos dados históricos, sendo $2 / 3$ entre BL e IA e $23,5 \%$ associadas a baixa exposição à TAC. CMV-viremia foi o principal evento adverso, mas função renal e sobrevidas de enxerto e paciente foram satisfatórias. Há necessidade de grupo controle histórico comparativo para prosseguir a avaliação desta estratégia de indução.

Palavras-chave: Transplante de rim, Indução imunológica, Timoglobulina, Rejeição aguda

\section{CB08-009}

\section{CORIOCARCINOMA TRANSMITIDO PELO ENXERTO RENAL: À PROPÓSITO DE} UM CASO

José Celio Costa Lima Filho; Daniela Queiroz Moura; Sonia Leite Da Silva; Thiago Luiz Da Paz Santos; Duilio Reis Rocha Filho; Ulisses Medeiros De Albuquerque; Paula Cbc Fernandes1; João Batista Cerqueira; Claudia Maria Costa De Oliveira

\section{Hospital Universitário Walter Cantideo-UFC-Brasil}

Introdução: O transplante de órgãos tem risco de transmissão de doenças infecciosas e neoplásicas. As neoplasias mais transmitidas são câncer renal, melanoma, linfoma e pulmonar. O coriocarcinoma tem representado $5,5 \%$ das neoplasias transmitidas pelo enxerto, usualmente com um tempo inferior a dois meses entre o transplante e o diagnóstico da neoplasia. Relato de caso: Paciente masculino, 65 anos, doença renal por nefrite tubulointersticial, foi submetido a transplante renal preemptivo com doador falecido. Imunossupressão com timoglobulina, tacrolimus e micofenolato sódico. Doador feminino, 17 anos, causa mortis AVC hemorrágico, creatinina de $1,0 \mathrm{mg} / \mathrm{dl}$. Evoluiu com boa diurese, tendo alta hospitalar após 9 dias com creatinina 2,6 mg/dl. Aos 30 dias, apresentou infecção urinaria por bactéria ESBL positivo, tratada com ertapenem e infecção por CMV, tratada com ganciclovir endovenoso. Aos 60 dias, um novo episódio de ITU foi tratado com ertapenem e um ultrassom renal revelou nódulo sólido hipoecoico com vascularização no 1/3 médio do enxerto medindo 3,0 × 2,8 cm. A biópsia do nódulo revelou neoplasia pouco diferenciada, sendo submetido à nefrectomia do enxerto e suspensão da imunosupressão. A imunohistoquímica evidenciou coriocarcinoma e betaHCG de $225.000 \mathrm{mUI} /$ $\mathrm{ml}$. Encaminhado à oncologia para tratamento, mas foi reinternado com anemia sintomática, piora da função renal, dispneia aos esforços, radiografia e tomografia de tórax mostrando implantes neoplásicos. Iniciou hemodiálise e quimioterapia com cisplatina e etoposídeo, mas no terceiro dia de tratamento evoluiu com insuficiência respiratória e óbito. O doador não tinha história conhecida de coriocarcinoma, mas tratava-se de paciente de 17 anos, com história de gravidez no último ano e que faleceu de um $\mathrm{AVCH}$, podendo representar sangramento por metástase cerebral, comum neste tipo de tumor. Conclusão: Apesar do diagnóstico e conduta precoces, os autores relatam um caso raro de coriocarcinoma transmitido pelo doador, com metástase precoce, ausência de resposta à quimioterapia e evolução fatal.

Palavras-chave: transplante de rim, neoplasia, coriocarcinoma
CB08-010

HEPATOCELLULAR CARCINOMA AFTER HCV ERRADICATION IN RENAL ALLOGRAFT RECIPENTS - TWO CASE REPORTS

Rita Calça; David Fiel; Eunice Cacheira; Cristina Jorge; Célia Nascimento; Sara Querido; Rita Birne; Patrícia Matias; Teresa Adragão; André Weigert; Margarida Bruges; Luís Lebre; Domingos Machado

1 - Serviço de Nefrologia do Hospital de Santa Cruz, CHLO; 2 - Serviço de Nefrologia do Hospital do Espírito Santo de Évora; 3 - Serviço de Gastrenterologia do Hospital Egas Moniz, CHLO

Introduction: Direct-acting antiviral agents (DAA) are an effective therapy for chronic hepatitis $\mathrm{C}$ virus (HCV) infection after renal transplantation. The induction of sustained virological response (SVR) has reduced HCV-associated morbidity and mortality. Nevertheless, hepatocellular carcinoma (HCC) has been reported after SVR, particularly in patients with liver fibrosis or cirrhosis. Clinical case 1: A 71-year-old male with IgA nephropathy and stage 5 chronic kidney disease (CKD) with prior HCV infection, underwent renal transplantation in 1991. He had documented hepatic fibrosis (fibroscan F3 score) and received HCV treatment with ledipasvir/sofosbuvir (March 2016) reaching SVR at 12 weeks. One year after DAA treatment, elevation of alpha-fetoprotein (2.9 to $10.9 \mathrm{ng} / \mathrm{mL}$ ) was detected, despite undetectable HCV viral load. Hepatic ultrasound found no abnormalities but computed tomography (CT) showed extensive nodular involvement suggestive of HCC. The diagnosis was confirmed by magnetic resonance imaging (MRI). The patient died in 4 months after the diagnosis. Clinical case 2: A 72-year-old female with stage 5 CKD due to focal and secondary segmental glomerulosclerosis underwent renal transplantation in January 2003. She had prior chronic HCV infection and had documented hepatic cirrhosis (F4 score) prior to treatment with sofosbuvir/ledipasvir/ribavirin in October 2015 reaching SVR at 24 weeks. In May 2018, alpha-fetoprotein increased (17.2 to $2864 \mathrm{ng} / \mathrm{mL}$ ) and hepatic ultrasound showed no 'de novo' lesions. MRI showed a nodular lesion compatible with $\mathrm{CHC}$; HCV viral load was always undetectable at follow-up. Conclusion: Even when HCV is eradicated by DAA the risk of progression from liver fibrosis to HCC remains a threat, as illustrated in these two cases, suspected by an increased alpha-fetoprotein. A continued follow up is necessary, but ultrasound was unsuccessful to unveil HCC.

Palavras-chave : Hepatocellular carcinoma, HCV, kidney, transplant

\section{CB08-011}

DIAGNÓSTICO PRECOCE E TRATAMENTO CIRÚRgICO DE LESÕES RENAIS SUSPEITAS DE NEOPLASIA EM PACIENTES RENAIS CRÔNICOS E TRANSPLANTADOS

Brunno Raphael lamashita Voris1; Daniel De Almeida Braga1; Marilda Mazzali1; Marcelo Lopes De Lima1

\section{1 - UNICAMP}

A imunossupressão crônica devido a longos períodos de manutenção do enxerto renal e a maior sobrevida dos pacientes em hemodiálise, fez aumentar o diagnóstico de neoplasias renais nos rins nativos desses pacientes. Foram incluídos 12 pacientes transplantados renais com diagnóstico a posteriori de lesão renal focal em rim nativo. A tomografia foi o método de eleição para diagnóstico e planejamento terapêutico. A média de tempo do transplante renal até diagnóstico da neoplasia foi de 15 anos. Todos os pacientes foram submetidos à cirurgia, com tempo médio de internação de 3,45dias. O resultado do anátomo-patológico confirmou se tratar de neoplasia em $60 \%$ dos casos: 4 (quatro) carcinomas renais de células claras, três pacientes com mais de um tipo histológico de carcinoma renal sendo dois Carcinoma Células Claras + Carcionoma papilífero e 1 caso de CA papilífero + múltiplos adenomas túbulo-papilares, um carcinoma papilífero e um carcinoma cromófobo. Os casos benignos foram: dois oncocitomas, um adenoma túbulo-papilar, dois rins policísticos e uma pielonefrite xantogranulomatosa. 0 diagnóstico de tumoração renal suspeita de neoplasia foi realizado principalmente por alterações identificadas no US de trato urinário anual de rotina onde são avaliados os rins nativos e o rim transplantado. Os pacientes não tinham sinais ou sintomas sugestivos de neoplasias do trato urinário, como hematúria ou tumorações palpáveis. Acreditamos que o diagnóstico, nos exames de rotina, de tumorações renais relativamente pequenas, permitiu cirurgias precoces, com maior possibilidade de neoplasias restritas aos rins. $60 \%$ dos casos operados foram de carcinoma, sendo o carcinoma renal de células claras o tipo mais comum encontrado, o que difere de alguns trabalhos da literatura que mostravam o carcinoma papilífero como a neoplasia renal mais comum nos rins nativos de pacientes transplantados. O acompanhamento, com exames de imagem, de pacientes com imunossupressão crônica é fundamental para diagnóstico precoce de neoplasias nos rins nativos. O tratamento cirúrgico com a nefrectomia radical videolaparoscópica foi eficaz e com baixo índice de complicações. No interim de maior duração do enxerto associado a melhora na sobrevida dos pacientes transplantados, pode-se sugerir uma mudança no esquema de imunossupressão no seguimento destes pacientes com inibidores de mTor. 
CB08-012

ANÁLISE DAS CAUSAS DE DESCARTE DO PÂNCREAS DE DOADORES FALECIDOS NUM CENTRO ÚNICO DE TRANSPLANTE

Laura Garcia Barufatti'; João Luis Erbs Pessoa'; Bartira De Aguiar Roza'; Janine Schirmer'; Marcelo Moura Linhares ${ }^{2}$; Alcides Salzedas-Neto ${ }^{2}$; Adriano Miziara Gonzalez $^{2}$; José Osmar Medina-Pestana ${ }^{3}$; Erika Bevilaqua Rangel ${ }^{3}$

1 - Departamento de Enfermagem Clínica e Cirúrgica da UNIFESP-EPM; 2 - Departamento de Gastrocirurgia da UNIFESP-EPM; 3 - Departamento de Nefrologia da UNIFESP-EPM/Hospital do Rim e Hipertensão

Introdução: O número de transplante de pâncreas reduziu mundialmente devido à redução do encaminhamento dos pacientes devido as terapias disponíveis para tratar o diabetes mellitus (DM) , além de uma seleção mais rigorosa quanto aos doadores e receptores. Este estudo tem então o objetivo de analisar as causas de descarte de pâncreas em um centro único no período de 2000-2016.

Métodos: Trata-se de uma pesquisa descritiva retrospectiva observacional, em que foram realizadas análises de 51 relatórios do banco de dados da Secretaria de Saúde do Estado de São Paulo (SP) referentes a um centro único quanto à alocação do pâncreas

Resultados e conclusão: Neste centro único, de 1843 pâncreas disponibilizados para o transplante de pâncreas no nosso centro, 408 (22\%) foram retirados e $347(18,8 \% \%)$ foram transplantados. As principais causas de descarte do pâncreas foram relacionadas ao doador $(75,4 \%)$, destacando-se a idade $(43,7 \%)$ e morte por causa cardiovascular (56\%), e ao doador ter se transformado em doador exclusivo de rim (11,6\%). Tal fato se deve à ocorrência crescente de instabilidade hemodinâmica do doador, o que tem contribuído para a perda de potenciais doadores de pâncreas nos últimos anos. No banco de dados europeu, Eurotransplant, as principais causas de descarte do pâncreas também foram relacionadas ao doador $(75,2 \%)$, seguido de características relacionadas ao receptor(16,2\%). Conclui-se então que nossos achados estão de acordo com a Eurotransplant. Entretanto, são necessárias políticas institucionais que propiciem melhor manutenção dos doadores para manter o pool, uma vez que há tendência de aumento da idade e frequência de óbito de causa cardiovascular, o que diminui a qualidade dos órgãos disponibilizados.

Palavras-chave : transplante de pâncreas, doação, causas de óbito, motivos de descarte

\section{CB09-001}

TRANSPLANTE RENAL ORTOTÓPICO EM TROMBOSE DE CAVA. RELATO DE CASO

Paulo Medeiros; José Hipólito Dantas Júnior; José Máximo Costa Pinto; Nadson Frederico Siqueira Medeiros; Rafael Cruz Rios Sampaio; Pedro Sales Lima Carvalho; Gabriela Ayumi Owada Borges; Fellipe Rodrigo Gomes Figueiredo

1 - Hospital Universitário Onofre Lopes Universidade Federal do Rio Grande do Norte

Introdução: O transplante renal é o tratamento de escolha para doentes com doença renal em estágio terminal, sendo realizado, geralmente, em posição heterotópica, nas fossas ilíacas, devido a facilidade da técnica. Entretanto, em situações especiais, como nos retransplantes, doença aterosclerótica grave ilíaca e trombose de cava e veias ilíacas, ele não é possível. Nestes casos, o transplante é realizado em posição mais cranial, e raramente na posição ortotópica.

Métodos: Apresentamos um caso de uma paciente do sexo masculino que se apresentou para transplante renal com doador falecido, com histórico de perda de acesso venoso para hemodiálise em fístulas arterio-venosas nos membros superiores, obstrução e perda de cateteres nas jugulares, subclávias e femorais. No momento, realizava diálise por cateter trans-hepático. A angiotomografia computadorizada previamente demonstrou trombose de veia cava. A veia esplênica apresentava bom calibre. Portanto, foi decidido por transplante ortotópico.

Resultado: Realizado transplante ortotópico na loja renal esquerda, por incisão subcostal estendida, com nefrectomia esquerda concomitante. A veia foi anastomosada na veia esplênica, a artéria na artéria renal e o ureter no ureter superior, com colocação de cateter duplo J. A perfusão imediata foi satisfatória e o paciente segue em fase de disfunção precoce do enxerto.

Conclusão: O transplante renal ortótopico deve ser considerado nos casos de trombose de veia cava, representando uma alternativa viável nestes casos.

Palavras-chave : Ortotópico. Transplante renal. Trombose cava
CB09-002

POST KIDNEY TRANSPLANT NEPHRECTOMY PSEUDOANEURYSM: A RARE LATE COMPLICATION AFTER KIDNEY TRANSPLANT NEPHRECTOMY

Joana Monteiro Dias; Noélia Lopez; Hugo Silva; João Gonçalves; Marta Neves; Sofia Jorge; Alice Santana; José Guerra

\section{Hospital de Santa Maria - Centro Hospitalar Lisboa Norte}

Surgical complications after kidney transplant nephrectomy (KTN), are mostly evident in the early post operatory period. Permanence of small segments of allograft artery or vein is usually unremarkable, except in the rare case of infection. Pseudoaneurysm formation after KTN is an extremely rare complication, but can result in life-threatening events, namely aneurysm rupture. In the scarce previously reported cases, these were found after becoming clinically symptomatic through rupture or hemodynamic significant fistulas.

The authors present a case of a 60-year-old man submitted to a deceased donor kidney transplant (KT) 20 years ago for end stage kidney disease secondary to chronic glomerulonephritis, complicated with chronic rejection which led to his return to hemodialysis 2 years later. After 12 months in hemodialysis he had KTN for acute toxic kidney syndrome. He was submitted to a second deceased donor KT 10 years later, maintaining a stable renal function with a serum creatinine $1.2 \mathrm{mg} / \mathrm{dL}$ until now, when he developed acute kidney disfunction (AKD) because of acute humoral rejection related to therapeutic non-compliance. The doppler study done in the context of AKD revealed a $5 \mathrm{~cm}$ pseudoaneurysm in the left external iliac artery in relation to the previous KTN, later confirmed by AngioTC. He was submitted to an endovascular stent exclusion of pseudoaneurysm, remaining asymptomatic in the post-operatory period.

Endovascular treatment of pseudoaneurysms in non-function KT has become the treatment of choice. Nevertheless, this may reveal problematic in the patient with another functioning kidney graft. Our patient case is unique in reflecting both a rare case of post KTN pseudoaneurysm and the diagnosis of a clinically silent pseudoaneurysm. It reflects the need for long term follow up and careful observation even in asymptomatic post KTN and enlightens the need for an experienced multidisciplinary team when exploring therapeutic options in these rare cases.

Palavras-chave : kidney transplant nephrectomy, Pseudoaneurysm

\section{CB09-003}

SURGICAL COMPLICATIONS IN KIDNEY TRANSPLANTATION: OVERVIEW OF A PORTUGUESE REFERENCE CENTER

João Carvalho; Pedro Nunes; Hugo Antunes; Belmiro Parada; Edgar TavaresDa-Silva; António Roseiro; Carlos Bastos; Arnaldo Figueiredo

\section{1 - Centro Hospitalar e Universitário de Coimbra}

Introduction: Kidney transplantation is a surgery performed worldwide with an incidence of $20 \%$ of graft loss between 1960 and 1980 . With growing experience and expertise, this rate has dropped but surgical complications remain an important issue. Objectives:The objective of this study is to evaluate our surgical complications and compare the outcomes of complicated transplants with those without surgical complications Patients and Methods:Observational retrospective study of all surgical complications among 3102 kidney transplants performed between June 1980 and April 2018.Results:Of 3102, 557 (18\%) kidney transplantations had surgical complications: vascular $(10.7 \%)$, urologic $(6.2 \%)$, wound problems $(2.4 \%)$ and others $(1.3 \%)$. The most common complications were arterial and venous thrombosis (2.6\%), Iymphocele $(1.7 \%)$, ureteral obstruction (2.7\%) and urinary fistula (2.2\%). The immunosuppression regimen did not influence the surgical complications. In every 1000 transplants, it was realized a stabilized number of surgical complications.Surgical complications mostly occurred in male $(71.5 \%$ versus $28.5 \%)$, heavier $(67.28 \pm$ 13.8 vs $65.93 \pm 13.5 \mathrm{~kg}$ ) and older donor grafts ( $43.65 \pm 17.0$ vs $42.04 \pm 17.3$ years), $\mathrm{p}<0.05$. Lich Gregoir with double J stent was the urinary anastomosis type with fewer complications $(3.9 \%, \mathrm{p}<0.05)$. The hospitalization time was higher when surgical complications occurred $(25.5 \pm 29.2$ vs $14.9 \pm 39.3$ days, $p<0.05)$. Serum creatinine values were higher until the second year in complicated transplants. After that, the renal function was nearly the same. Nearly $17.2 \%$ of complicated kidney transplants were immediate non-functioning kidneys (vs $1.6 \%, p<0.05$ ) and $25.9 \%$ had delayed graft function (vs $14.6 \%, p<0.05$ ). Only $22.8 \%$ of complicated kidney transplants needed transplant nephrectomy (vs $6 \%$ on the non-complicated group, $\mathrm{p}<0.05)$. Graft survival of transplants with surgical complications was lower ( $63.3 \pm 74.7$ vs $95.1 \pm 84.4$ months, $p<0.05)$. Discussion/ Conclusion:Kidney transplant surgical complications, especially urologic and vascular, remain a problem leading to prolonged hospitalization and decreased graft survival. Our rates are comparable to those reported by other large series from experienced centers.

Palavras-chave : Kidney Transplantation, Surgical Complications 
СВ09-004

WHICH ONE IS THE BEST FOR LIVING DONATION: A MULTIPLE ARTERY LEFT KIDNEY OR A RIGHT ONE?

Diogo Nunes-Carneiro; André Marques-Pinto; Carlos Veiga; João Cabral; Isaac Braga; Manuela Almeida; Vítor Cavadas; António Castro Henriques; Rui Almeida; Avelino Fraga; Miguel Ramos

\section{1 - Centro Hospitalar do Porto}

Introduction: In living donor nephrectomies the current approach is to preserve the best kidney for the donor, harvesting the contralateral one. Due to a shorter renal vein and a greater incidence of venous thrombosis in some series of right living donor nephrectomies, left kidneys are more frequently elected if no significant difference in kidney function is encountered. On the other hand, arterial anatomy may be complex and thus render the transplantation procedure more difficult and prone to complications. Objectives: Compare outcomes after multiple-artery left kidney nephrectomies (MALKN) and right kidney nephrectomy (RKN) and respective transplants performed in our institution from 1999 to 2017. Results: Seventy-three cases with MALKN and RKN were performed: 34 and 39 respectively. The mean operative time was significantly longer in MALKN (122.18 vs. $107.77 \mathrm{~min}, p=0,038)$. Warm ischemia time ( $267 \pm 179$ vs. $236 \pm 72 \mathrm{sec})$, cold ischemia time (168 \pm 49 vs. $159 \pm 24 \mathrm{~min})$, donor ( $4.9 \pm 2.5$ vs. $4.5 \pm 1.1$ days) and receptor hospital stay ( $12.6 \pm 9.6$ vs. $12.9 \pm 6.9$ days) and post-operative complications did not differ between groups. There was a positive correlation between renal arteries ostia distance in MALKN and the warm ischemia time. There was no significant difference between groups in the incidence of Acute Tubular Necrosis, first year variations in serum creatinine and Glomerular Filtration Rate. Long-term graft survival did not significantly differ between groups too. There were reported three cases of vein thrombosis after RKN transplant with graft loss and no reports of vascular incidents in MALKN. Conclusion: Herein we conclude that the safety and efficacy of MALKN does not differ from RKN although there appears to be a higher incidence of vein thrombosis after right kidney transplantation. So despite being technically demanding, particularly in cases with distant artery ostia, MALKN could be a better option comparing with RKN for living donation, although more studies are needed to support this.

Palavras-chave : renal transplant, living donor, nefrectomy

\section{CB09-005}

PERFIL DAS INTERVENÇOES FARMACÊUTICAS REALIZADAS EM UMA UNIDADE DE TRANSPLANTE DE UM HOSPITAL UNIVERSITÁRIO

Luana Cristina Lins De Medeiros Oliveira; Thayanny De Souza Silva; José Roberto Freire De Oliveira; Raquel Martins E Quinino; Kellen Micheline Alves Henrique Costa

\section{1 - Hospital Universitário Onofre Lopes.}

A abordagem multidisciplinar é essencial para garantir um atendimento adequado à realidade do paciente transplantado, tendo em vista a complexidade terapêutica envolvida. Neste contexto, o farmacêutico clínico tornou-se um profissional necessário na equipe de transplante, podendo contribuir significativamente na otimização da farmacoterapia. Dessa forma, o objetivo deste trabalho foi descrever e analisar as intervenções farmacêuticas realizadas em uma unidade de transplante renal do Hospital Universitário Onofre Lopes (HUOL), localizado em Natal/RN. O estudo caracteriza-se como descritivo e transversal, o qual utilizou como fonte secundária, os registros das intervenções farmacêuticas dos pacientes internados e acompanhados pelo farmacêutico clínico na unidade de transplante renal do HUOL entre maio à novembro de 2017. Foram registradas 368 intervenções farmacêuticas, das quais 235 (63,86\%) foi do tipo orientação farmacêutica, $93(25,27 \%)$ ao acesso ao medicamento e 40 (10,87\%) relacionaramse ao erro de prescrição. Dentre as intervenções acerca de orientação farmacêutica, observa-se as mais frequentes, respectivamente, interações medicamento/medicamento (31,06\%); interações medicamento/alimento e incompatibilidade $(20,43 \%)$. No tocante ao acesso ao medicamento, nota-se com maior frequência a viabilização de medicamento na Unidade Central de Agentes Terapêuticos $(45,16 \%)$, seguida da viabilização de medicamentos em falta no hospital $(25,88 \%)$ e resolução da falta/inadequação do controle de solicitação antimicrobianos $(18,28 \%)$. As principais intervenções farmacêuticas do tipo erro de prescrição referem-se à necessidade da prescrição do medicamento (27,50 \%), a dose $(22,50 \%)$ e a diluição (20\%). Portanto, conclui-se que o farmacêutico clínico junto a equipe multiprofissional em uma unidade de pacientes transplantados foi capaz de realizar intervenções sobre a farmacoterapia instituída, sendo estas relevantes por otimizar a farmacoterapia e, consequentemente, aumentar a qualidade do atendimento realizado ao paciente transplantado renal. Além disso, pode-se inferir que as intervenções farmacêuticas realizadas também contribuíram para diminuir os riscos de ocorrência de resultados negativos relacionados aos medicamentos.

Palavras-chave: Intervençao Farmaceutica; Transplante Renal, Equipe Multiprofissional.

\section{CB09-006}

IMPACTO DA REINTERNAÇÃO HOSPITALAR PRECOCE NA COMPOSIÇÃO CORPORAL DE PACIENTES TRANSPLANTADOS RENAIS

Milena Dos Santos Mantovani; Nyara Coelho De Carvalho; Thomáz Eduardo Archangelo; Luis Gustavo Modelli De Andrade; Sebastião Pires Ferreira Filho; Silvia Justina Papini; Ricardo De Souza Cavalcante; Ricardo Augusto Monteiro De Barros Almeida

Faculdade de Medicina de Botucatu-UNESP, Botucatu, SP, Brasil;

O transplante renal (TxR) é uma alternativa terapêutica essencial para a doença renal crônica (DRC). A avaliação nutricional tem fundamental importância no período pré e pós-TxR, podendo interferir nos seus desfechos. Apesar da redução de morbimortalidade a longo prazo, pode haver complicações relevantes no período pós-TxR precoce, as quais frequentemente resultam em reinternação hospitalar (RH). Não foram identificados estudos que descrevessem as consequências nutricionais relacionadas a estas reinternações. Realizou-se a avaliação da composição corporal de 39 transplantados renais, imediatamente antes e após três meses do TxR, utilizando-se bioimpedância multifrequencial. Foram coletados dados demográficos, clínicos, referentes à composição corporal e à RH. Para a análise estatística, foi utilizado o teste T pareado com as variáveis de interesse, divididos em dois grupos de indivíduos, os que sofreram $\mathrm{RH}$ e os que não necessitaram RH no período de três meses após o TxR. Foi considerado significante $p<0,05$. Predominaram pacientes do sexo masculino (59\%). A idade média foi de 43,2 anos. Prevaleceram os doadores falecidos (69,2\%). A etiologia da DRC foi indeterminada em $48,7 \%$ dos pacientes, hipertensão arterial sistêmica em $17,9 \%$ e, em $33,4 \%$, outras etiologias. A hemodiálise foi a terapia renal substitutiva mais prevalente $(84,6 \%)$. Dezesseis $(41,0 \%)$ pacientes necessitaram $\mathrm{RH}$ precoce. Dentre estes, constatou-se diminuição significante de massa magra $(1,28 \pm 2,07 \mathrm{~kg} ; p=0,025)$ e da circunferência da cintura $(1,93 \pm 3,33 \mathrm{~cm} ; p=0,035)$. Para os 23 indivíduos sem necessidade de $\mathrm{RH}$, observou-se aumento da gordura corporal $(3,12 \pm 2,4 \mathrm{~kg} ; \mathrm{p}<0,0001)$, da porcentagem de gordura $(3,19 \pm 2,92 \%$; $<0,0001)$ e do IMC $\left(1,00 \pm 1,62 \mathrm{~kg} / \mathrm{m}^{2} ; \mathrm{p}=0,008\right)$. Não houve diferença significante entre a avaliação nutricional pré-TxR de ambos os grupos, sugerindo que a $\mathrm{RH}$ seja um fator relevante na evolução nutricional após o TxR. Os resultados apontam a necessidade de acompanhamento nutricional desta população. Apoio: processo no 2016/24745-3, Fundação de Amparo à Pesquisa do Estado de São Paulo (FAPESP).

Palavras-chave: Composição corporal, Transplante renal, Reinternação hospitalar

\section{CB09-007}

AVALIAÇÃO BIOPSICOSSOCIAL DE PACIENTES CANDIDATOS A UM TRANSPLANTE RENAL NO BRASIL ATRAVÉS DO MÉTODO INTERMED

Carolline Rangel; Lara Tiglia; Elen Almeida Romão; Ricardo Gorayeb

Hospital das Clínicas da Faculdade de Medicina de Ribeirao Preto da Universidade de São Paulo

Dentre as formas de tratamento para a doença renal crônica, destaca-se o transplante renal, por oferecer aos pacientes transplantados possibilidade de maior sobrevida e melhor qualidade de vida. A avaliação psicossocial prétransplante busca identificar motivações e expectativas do candidato em relação ao transplante. O presente estudo foi realizado nos ambulatórios do Hospital das Clínicas da Faculdade de Medicina de Ribeirão Preto da Universidade de São Paulo a partir de entrevista feita por psicólogo e aplicação do instrumento INTERMED. Trata-se de método europeu validado no Brasil que se propõe a analisar o indivíduo em modelo ampliado, considerando os aspectos biológico, psicológico e social. O objetivo foi analisar o conteúdo obtido através das respostas dos candidatos pré-transplante renal após a aplicação do instrumento INTERMED, no intuito de verificar as necessidades de cuidado do paciente. Nos resultados, observou-se que a complexidade biológica de saúde dos candidatos se destaca, acarretando em prejuízos na qualidade de vida do indivíduo, podendo o mesmo desenvolver comorbidades psicológicas e psiquiátricas. Em seguida, verifica-se alta pontuação no domínio psicológico. Destacou-se ainda o domínio chamado Estado Atual, localizando a doença crônica com repercussões importantes na vida do paciente em um momento pré-transplante. Tal resultado encontrado pode estar relacionado à própria doença crônica que traz um risco de limitações permanentes e/ ou significativas na rotina e funcionalidade do paciente. $O$ instrumento possibilitou compreender o paciente candidato a transplante renal como um todo, investigando desde os aspectos emocionais, expectativas dos pacientes, estilo de enfrentamento, manejo de estresse, padrões de defesa, deficiência de adesão ao tratamento, dificuldades de lidar com o medo da hospitalização e da dor, preocupações com o insucesso da cirurgia. Além disso, permitiu localizar a complexidade biológica enquanto um principal fator gerador de sofrimento em diversos aspectos da vida do sujeito, orientando intervenções e melhor oferta do cuidado pela equipe.

Palavras-chave : transplante rim, avaliação pré-transplante, multiprofissional, avaliação biopsicossocial 


\section{CB09-009}

INDICADORES DE EXCELÊNCIA DE UM HOSPITAL NO ESTADO COM MAIOR DOAÇÃO DE ÓRGÃOS DO BRASIL

Ivonei Bittencourt; Robson Duarte; Maria Caroline Siqueira Rosa; Aline Rosana Lopes; Liliani Cristina Gonçalves De Azevedo

\section{Hospital Municipal São José}

O presente estudo traz o resultado do trabalho de uma Comissão Hospitalar de Transplantes (CHT) em um hospital público de Santa Catarina, estado com maior índice de doação de órgãos do Brasil por mais de 10 anos consecutivos. A comissão composta por 5 enfermeiros e 1 medico notificou em 2017, 45 protocolos para diagnóstico de morte encefálica. 28 (62\%) deles tiveram consentimento familiar e se converteram em doação efetiva de múltiplos órgãos. Dos motivos da não efetivação, houve $13(29 \%)$ recusas familiares para doação, número bem abaixo da média nacional (42\%), refletindo o ótimo acolhimento familiar e a profissionalização dos envolvidos. Houve apenas 2 (4\%) casos de Parada Cardiorrespiratória, o que mostra a eficaz manutenção do potencial doador guiado por protocolos nacionais e 2 (4\%) contra-indicação clínica para doação devido ao hospital ser referência em oncologia.

Além da assistência aos pacientes críticos, a CHT também realiza educação em saúde e em 2017 capacitou mais de 1.000 estudantes da área da saúde sobre o processo de doação e transplante de órgãos, preparando multiplicadores que atuarão em diversos hospitais do país. Através de campanhas públicas e da mídia, a comissão levou à população a importância de ser e como ser um doador. Na área da pesquisa, foi apresentado 8 trabalhos científicos em 2 congressos internacionais de transplantes.

Das estratégias adotadas para obter esses ótimos indicadores, destacamos o acolhimento familiar humanizado, a busca ativa realizada nas unidades de pacientes críticos e a parceria com os profissionais da sala de emergência e UTI. E o resultado de tudo isso foi mais de 140 pacientes retirados da lista de espera e beneficiados pelo transplante, trazendo esperança para suas famílias. A meta para 2018 é elevar em 10\% os indicadores.

Palavras-chave: Doação de órgãos, Gestão em transplantes, Programa de garantia de qualidade

CB09-010

PANORAMA DE 1000 TRANSPLANTES RENAIS EM UM CENTRO DE TRANSPLANTE DO RIO DE JANEIRO

Claudia Fagundes; Patricia Fagundes; Ana Claudia Pires; Onofre Barros; Thalita Uchoa; Tereza Matuck; Deise Carvalho

Hospital São Francisco na Providência de Deus

Os resultados dos transplantes têm sido progressivamente melhores no decorrer dos anos. O serviço de transplante renal foi inaugurado em fevereiro de 2013 e desde então já realizou mais de mil transplantes renais.Durante o período de fevereiro/2013 a fevereiro/2018 foram realizados 1000 transplantes renais em um centro único no Rio de Janeiro, sendo $87 \% \mathrm{com}$ doadores falecidos. As principais características dos receptores: média de idade $46 \pm$ 13 anos, $63 \%$ do sexo masculino, tempo em diálise $51 \pm 44$ meses e $33 \%$ com diagnóstico de hipertensão arterial sistêmica como doença de base. Em relação aos doadores, as principais características: média de idade $44 \pm 16$ anos (mínimo de 3 e máximo de 75 anos), $57 \%$ do sexo masculino e principal causa de morte encefálica foi acidente vascular cerebral hemorrágico em $43 \%$. A média do tempo de isquemia fria foi $17 \pm 6$ horas. Os resultados foram: sobrevida do paciente e do enxerto ao final de dois anos foi $89 \%$ e $82 \%$ respectivamente.

Palavras-chave: 1000 transplantes
CB09-011

CONSULTA FARMACÊUTICA EM DOENTES TRANSPLANTADOS RENAIS: 8 MESES DE IMPLEMENTAÇÃO.

Vanessa Pina; Ana Mirco; Alexandra Atalaia; Domingos Machado; Fátima Falcão

\section{CHLO - Hospital Santa Cruz, EPE}

A consulta farmacêutica (CF) permite o acompanhamento do doente no que diz respeito à sua patologia e terapêutica instituída. Promove a implementação da reconciliação da terapêutica (RT), melhora a adesão e o conhecimento do doente ou cuidador no que diz respeito à importância do cumprimento da posologia instituída, em especial em doentes crónicos com várias comorbilidades.

O estudo foi realizado entre Julho de 2017 a Março de 2018, tendo sido incluídos todos os doentes seguidos na consulta pós-transplante renal (TxR) realizada previamente à CF. A CF realizou-se no serviço de TxR, em gabinete próprio. Os dados foram recolhidos por consulta do processo clínico do doente, contacto com o médico assistente e durante a entrevista realizada na CF.

No período de estudo, foram realizadas 441 CF a 306 doentes. Dos doentes incluídos, 62,4\% eram do sexo masculino, com uma média de idades de 52,1 anos (entre 19 a 83 anos). A média de tempo pós-TxR foi de 7,7 anos (variação entre 1 mês a 30 anos). A principal intervenção farmacêutica efectuada foi a adequação dos horários de administração dos medicamentos imunossupressores e antihipertensores (recomendar administrar sem alimentos, 64,7\%). De todas as intervenções efectuadas ( $n=101), 23,8 \%(n=24)$ foram encaminhadas para o médico e aceites pelos clínicos. Foram ainda identificadas 884 interacções medicamentosas: categoria C (87.1\%), categoria D $(11.4 \%)$ e categoria X $(1.5 \%)$ (Lexicomp ${ }^{\circledR}$ Drug Interactions). Os doentes TxR demonstraram ter uma boa adesão ao tratamento.

A CF permite ao farmacêutico, integrado na equipa multidisciplinar da consulta de pós-TxR, contribuir para a optimização da terapêutica, diminuindo a morbi-mortalidade associada ao uso do medicamento. A RT permite detectar discrepâncias na terapêutica, sendo relevante a intervenção do farmacêutico, com benefícios claros para o doente e para o sistema de saúde. A CF tem como objectivo futuro incluir todos os doentes seguidos na consulta pós-TxR.

Palavras-chave: Consulta Farmacêutica, Transplante Renal, Reconciliação Terapêutica 